\title{
Contract and Collaboration
}

\author{
Daniel Markovits ${ }^{\dagger}$
}

CONTENTS

INTRODUCTION.

I. INTRODUCING THE PRomise RELATION

A. Truth-Telling and Community

B. From Truth-Telling to Promising ........................................... 1428

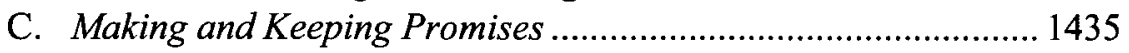

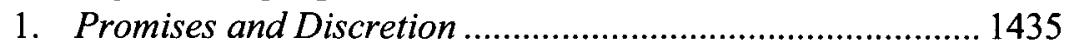

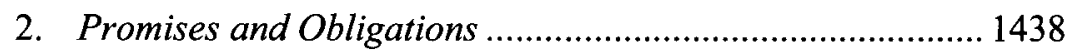

3. The Grounds of Promise-Keeping ................................... 1442

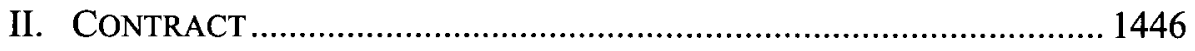

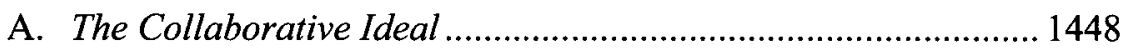

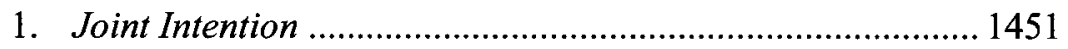

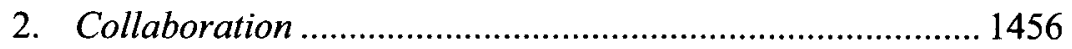

B. Who Can Collaborate ............................................................. 1464

III. ILLUSTRATIONS AND ELABORATIONS ........................................... 1474

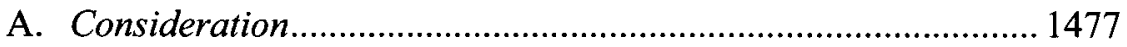

1. The Conventional Wisdom............................................... 1477

2. The Collaborative View.................................................. 1481

$\dagger$ Associate Professor of Law, Yale Law School. This Article has benefited substantially from responses received at the Second Annual May Meeting of Young Law Professors and at faculty workshops at Yale, the University of Michigan, and the University of Texas Law Schools. I would like to thank the participants in all these discussions. I would also like to thank Bruce Ackerman, Omri Ben-Shahar, Sarah Bilston, Michael Bratman, Sherman Clark, Jules Coleman, Richard Craswell, Hanoch Dagan, Owen Fiss, Robert Gordon, Rachel Harmon, David Hasen, Dan Kahan, Alvin Klevorick, Harold Koh, Anthony Kronman, Christopher Kutz, Richard Markovits, Carol Rose, Susan Rose-Ackerman, Jed Rubenfeld, Alan Schwartz, Scott Shapiro, Henry Smith, Kevin Stack, and James Whitman. Finally, I would like to thank Jonathan Kravis and the staff of The Yale Law Journal for their outstanding editorial support. 
B. Expectation Damages 1491

1. The Conventional Wisdom................................................ 1492

2. The Collaborative View..................................................... 1497

CONCLUSION 1514 


\section{INTRODUCTION}

Promises lie at the center of persons' moral experience of one another, and contracts lie at the center of their legal experience of one another. Many of the most important relationships in our moral and legal culture characteristically arise in connection with promises and contracts of some form or other: Persons' families are connected to marriage promises, their work is connected to employment contracts, and even their citizenship is connected (albeit metaphorically) to the social contract. In all these cases, and in myriad others, promises and contracts establish relations among the persons who engage them.

But in spite of the obviously communal character of promise and contract, the most prominent accounts of these practices remain firmly individualistic, seeking to explain the obligations they involve in terms of one or another service that these practices render to the several parties who engage them. Some theories emphasize that promissory and contractual obligations increase the freedom of promisors, by enabling them to project their intentions into the future and rendering plans of action that require such precommitments available to them. ${ }^{1}$ Other theories emphasize that promissory and contractual obligations reflect concern for the reasonable expectations of promisees and the harms that promisees suffer when these expectations are disappointed. ${ }^{2}$ And, most prominently, yet other theories emphasize that promissory and contractual obligations promote the well-being of both promisees and promisors, by increasing the reliability of social coordination and promoting the efficient allocation of resources. ${ }^{3}$ These theories differ from one another in many ways, to be sure, and they often cast themselves as competitors. But they are of a piece insofar as they all seek the roots of the morality of promise and contract in properties of the several individual participants in such agreements.

I do not doubt that the individualistic values from which these theories begin can give rise to reasons for action and indeed to moral obligations. I insist, however, that individualistic theories do not capture or reflect the distinctive moral center of promise and contract, which cannot be found in

1. See, e.g., Charles Fried, Contract as Promise (1981). Relatedly, see Randy E. Barnett, A Consent Theory of Contract, 86 CoLuM. L. REV. 269 (1986); and Peter Benson, The Unity of Contract Law, in THE THEORY OF CONTRACT LAW 118 (Peter Benson ed., 2001).

2. See, e.g., P.S. ATIYAH, ESSAYS ON CONTRACT (1986); P.S. ATIYAH, THE RISE AND FALL OF Freedom of CONTRACT (1979); Thomas Scanlon, Promises and Contracts [hereinafter Scanlon, Promises and Contracts], in THE THEORY OF CONTRACT LAW, supra note 1, at 86; Thomas Scanlon, Promises and Practices, 19 PHIL. \& PUB. AFF. 199 (1990) [hereinafter Scanlon, Promises and Practices].

3. See, e.g., Richard Craswell, Contract Law, Default Rules, and the Philosophy of Promising, 88 MICH. L. REV. 489 (1989); Charles J. Goetz \& Robert E. Scott, Enforcing Promises: An Examination of the Basis of Contract, 89 YALE L.J. 1261 (1980); Alan Schwartz \& Robert E. Scott, Contract Theory and the Limits of Contract Law, 113 YALE L.J. 541 (2003). 
any properties of the parties taken severally but appears instead in the relations among persons that promises and contracts create. I develop the insight that promise and contract establish relations among the persons who engage them into a mature theory of promise and especially of contract, in which I describe the relations among persons that promises and especially contracts establish, and I characterize these relations in terms of familiar and attractive moral and political values. I claim that promises generally, and contracts in particular, establish a relation of recognition and respectand indeed a kind of community-among those who participate in them, and I explain the reasons that exist for making and for keeping promises and contracts in terms of the value of this relation. ${ }^{4}$

Moreover, I argue that contract participates in this ideal of respectful community even though contracts typically arise among self-interested parties who aim to appropriate as much of the value that contracts create as they can. Respectful community, as I understand it, is a capacious ideal, which encompasses many forms of joint endeavor, including contract. The centerpiece of my approach to the morality of contract is an argument that finds the value of community directly in the form of the contract relation rather than in any substantive ends that the parties to contracts pursue. I present a detailed account of the characteristic relations that this form of community, which I call collaboration, involves.

Finally, because my ultimate purpose is to develop a theory of contract law, I show that the contract relation as I characterize it is no mere academic conceit but is instead immanent in our legal practice. In particular, I consider two familiar doctrinal puzzles presented by the law of contracts-involving the consideration doctrine and the expectation remedy - in light of the values that I claim lie beneath the contract relation.

4. My proposal that a moral analysis of promise and contract should turn to the value of the relations that these practices involve, although out of the mainstream, is not unprecedented. Individualistic theories of contract sometimes mention the contract relation in passing: Charles Fried, for example, asserts that contracts can involve trust, and that persons may pursue trust for its own sake. See FRIED, supra note 1 , at 8 . But Fried does not make this a substantial component of his view. He never explains what trust is or how contracts (especially contracts among self-interested parties whose functioning depends on state enforcement) involve trust, and his substantive arguments about contract all return inexorably to ideas about freedom.

More auspiciously, Joseph Raz has suggested that promises create a "special bond" between promisor and promisee and that the value of this bond might "explain[] not only why one ought to keep promises one has made, but also why it is good to make promises." Joseph Raz, Promises and Obligations, in LAW, MORALITY, AND SOCIETY: ESSAYS IN HONOUR OF H.L.A. HART 210 , 227-28 (P.M.S. Hacker \& Joseph Raz eds., 1977). Raz's approach to promise and contract, which I take up in some detail in Subsection I.C.2, remains purely formal, however. He is concerned with explaining how promissory and contractual obligations might function in our practical reasoning more generally and expressly makes no effort to identify the substantive features of promissory and contractual relations that give them their value.

These pages, by contrast, present a sustained, substantive account of the moral value of promise and contract relations and propose, in this way, to construct a genuine competitor to the dominant views. 
I argue that the general theory of contractual obligation I am proposing underwrites a more satisfactory account of these doctrines than has so far been possible.

I seek, then, to reclaim for practical philosophy the communal character that is the essence of both the obligations and the lived experience of promise and contract, and that the dominant, individualistic accounts obscure. Furthermore, instead of deriving the morality of promise and contract from more general and more fundamental moral principles (of freedom, harm, or welfare), I understand promise and contract as presenting distinctive and freestanding moral ideals. These ideals, moreover, radiate outwards from promise and contract, to illuminate aspects of practical life that lie beyond the narrow confines of these practices. I propose, at the end of the argument, that the collaborative ideal I find in the contract relation represents a crucial foundation stone for the authority of modern, pluralist economic and political institutions. In addition to developing a legal theory of contract, these pages therefore also contribute to the political theory of the market, and indeed of liberalism.

At the same time, the theory that I develop remains humble in other important ways, and it pays to identify these before commencing with the argument, in order to avoid appearing to claim more than I do. I do not deny that a wide array of moral obligations arise in and around promise and contract or that many of these obligations may be illuminated by reference to the ideas of freedom, harm, and welfare that figure so prominently in the familiar theories of contract that I seek to supplant. ${ }^{5}$ I deny only that these obligations are of a piece with promise and contract, and that these familiar explanations capture the characteristic moral and legal core of promise and contract. Moreover, I focus my attention on contracts among individual, natural persons. I take these cases to represent the core of contract and content myself to address contracts that involve organizations in a derivative fashion only. ${ }^{6}$ Each of these restrictions is intimately connected to my broader ambitions. A theory that understands contract as a distinctive and freestanding fount of moral obligation will naturally distinguish between contract proper and various associated forms of obligation; and a theory that seeks to connect contract to the basic structure of liberal political authority will naturally emphasize the individual persons to whom political justifications must be addressed.

5. Fried has similarly observed that many obligations that are not strictly speaking contractual can arise in and especially around circumstances that generate contractual obligations, and he has suggested that it was one of the weaknesses of the classical account of contract law dogmatically to deny this. See FRIED, supra note 1 , at 6.

6. See infra Section II.B. 


\section{INTRODUCING THE PROMISE RELATION}

I have proposed to develop the morality of promises and contractsincluding both the reasons for making and for keeping promises and contracts-in terms of the relations that promises and contracts engender. In this Part, I develop the basic ideas that figure in the morality of promises quite generally. I delay any more specific discussion of special cases of promise-including, in particular, contract—until later Parts. The larger argument therefore proceeds through several increasingly specific stages. In this first stage, I introduce the promise relation, and the values that it involves, in generic terms. In the next stage, I develop a more precise account of the particular form that the promise relation takes on through the legal institution of contract. (One of the main challenges of the argument, once again, is to show that even a form of promise so impersonal and instrumental as contract-a practice in which the parties each try to take advantage of the other-produces a relation of community that can sustain substantial reasons for making and keeping contracts.) Then, in the argument's final stage, I connect this philosophical characterization of the contract relation to certain central components of that relation's legal, and indeed doctrinal, expression.

\section{A. Truth-Telling and Community}

I begin at some distance from contract and indeed even from promise by considering the reasons that support truth-telling and oppose lying. I explain these reasons by reference to the relation of community that truthtelling creates between a speaker and her listeners, and that lying destroys. The account of truthfulness that I develop provides the material out of which I construct the theories of promise and eventually of contract that remain my ultimate goal. ${ }^{7}$

When a person tells the truth, she promotes a kind of community between herself and her listeners. By telling the truth, a person gives her listeners access to what she knows, to her point of view of the world, or at least of her subject, and in this way she enables them to share it: The truth-teller and her listeners can approach the subject matter of her truth-telling together, and on equal terms. Lying, by contrast, places a speaker actively out of community with her listeners. At least insofar as a lie succeeds-insofar as the listeners are deceived-the liar and the listeners cannot share a point of view with respect to the lie's subject

7. This account of truth-telling has grown out of a conversation that I had with Kevin Stack while walking through the Covered Market in Oxford, where we were both graduate students, in the early 1990s. I can no longer remember who said what, but I am certain that Kevin's contributions were substantial. 
matter: The liar knows something that the listeners do not-this is precisely the nature of a lie-and this combination of knowledge and ignorance opens up a gulf between them. ${ }^{8}$ And even when a lie fails, so that the listener discovers the truth, the liar and the listener approach their knowledge separately rather than together. One might say that prior to communication persons are strangers with distinct points of view. Truthtelling brings persons together, engendering a community by creating a shared point of view. And lying forces persons apart, estranging them from each other by making their points of view incompatible.

Truth-telling and lying, on this account and also in most people's naive imaginings, involve questions of what to believe-that is, questions of theoretical reason. But truth-telling and lying are not exclusively theoretical activities, and a person might tell the truth or might lie not only in order to get another to believe something, but also in order to get another to do something. And these practical cases of truth-telling and lying produce effects that display close analogies to the forms of community and estrangement described in the discussion of purely theoretical lies. A doctor, for example, might truthfully report her diagnosis in order to encourage a person to choose an appropriate treatment; and a propagandist might lie about a political matter in order to encourage a person to support a political adventure that he would oppose if he understood the truth. It seems natural, in the first case, to say that the truthful doctor respects her patient and supports his effort to return to good health, and indeed that the two pursue this effort together; just as it seems natural, in the second case, to say that the propagandist disrespects her victim and frustrates his effort at political participation, and indeed that she undertakes the adventure without him, or at least that his participation in the adventure is in some way alienated. Accordingly, one might say, in these practical cases also, that prior to communication persons are strangers who act separately; that truthtelling enables them to act together; and that lying sets them apart from each other.

These remarks about truth-telling and lying render intuitive that such behaviors may be understood not just in terms of the benefits and harms that they confer on the persons involved in them taken severally, but also in terms of the relations that they establish among these persons taken together. Of course, these are rough characterizations only, and an adequate explanation of the morality of truthfulness must replace the intuitive suggestion that truth-telling engenders community and that lying causes

8. The liar will of course be aware of this gulf, at least insofar as knowing misrepresentation is an element of lying. (This certainly seems a natural suggestion, although nothing will turn on the point here.) Moreover, because a listener may know that he has been lied to even as he remains ignorant of the truth that the lie conceals, the listener may also be aware of the gulf opened up by the lie. 
estrangement with a more precise and more articulate account of the forms of community and estrangement at play.

I begin this project of elaboration by taking up certain of Kant's ideas about lying. This is a natural starting point because the intuitive ideals of respect and community that I have invoked are themselves Kantian in their inspiration. Returning to Kant enables me to develop these ideals in greater detail and in this way to describe the precise moral relations that truth-telling and lying create. At the same time, my interest in Kant is shamelessly instrumental rather than exegetical: I seek to borrow some of Kant's ideas in the service of developing my own account of the moral relations involved in truth-telling and lying, and I do not worry or indeed explain when my views depart from Kant, or from more orthodox interpretations of Kant, as they certainly do. Moreover, because this exercise in the morality of truthfulness comprises only the first step toward the theories of promise and contract that remain my ultimate goal, its purpose departs from its nominal subject, and I do not worry or explain when the account falls short of presenting a complete view of the subject.

Kant develops his moral ideas, including even the basic moral principle he calls the Categorical Imperative, in several ways, by means of several formulations. ${ }^{9}$ Kant considers truth-telling and lying several times, under more than one of these formulations, but his views receive their most persuasive development through one approach in particular, under the version of the Categorical Imperative that Kant calls the Formula of the End in Itself. ${ }^{10}$ This principle, which is also sometimes called the Formula of Humanity, "instructs: "Act in such a way that you always treat humanity, whether in your own person or in the person of any other, never simply as a means, but always at the same time as an end." 12 The Formula of the End in Itself expresses ideals of respect and community closely allied to those that I have been invoking. It contains, as is often observed, two distinct commands concerning how to treat humanity, in the form of the persons with whom one interacts: ${ }^{13}$ first, that one should never use persons merely as means; and second, that one should always treat them as ends in themselves. ${ }^{14}$ Moreover, these two commands describe, on Kant's view,

9. Kant suggests that the several formulations of the Categorical Imperative that he presents are equivalent. IMMANUEL KANT, GROUNDWORK OF THE METAPHYSIC OF MORALS 437-38 (H.J. Paton trans., Harper \& Row 1964) (1785). I believe that he was mistaken to think so.

10. Id. at $427-30$.

11. See, e.g., Christine M. KorsgaARD, CREATING THE Kingdom OF ENDS 137 (1996).

12. KANT, supra note 9 , at 429 (emphasis omitted).

13. "Humanity," as Christine Korsgaard points out, is used by Kant to refer to the "capacity to determine ends through rational choice." KORSGAARD, supra note 11, at 137; see also id. at 346. Kant observes that although this capacity may arise in any rational being, we experience it only in human persons. KANT, supra note 9, at 428-29.

14. This distinction is emphasized, for example, in ONORA O'NEILL, CONSTRUCTIONS OF REASON: EXPLORATIONS OF KANT'S PRACTICAL PHILOSOPHY 112-13 (1989). 
distinct rules of conduct governing participation in the respectful community of free and rational persons. The principle that one should never use persons merely as means prohibits actions that follow principles or rules (Kant calls them maxims) that could not possibly be accepted by the persons whom the actions affect. The principle that one should always treat other persons as ends in themselves prohibits actions in pursuit of ends that the persons whom they affect cannot share. ${ }^{15}$

These two distinct although sometimes overlapping commands express two parts of an intuitively powerful conception of moral life - two rules of conduct that persons must adopt in order for a moral community to arise among them. The first command-about not using persons merely as means-captures the idea that persons are not simply available to one another. Unlike things, persons have independent intellects and wills-independent points of view-concerning the world and their places in it. A person who acts against others based on a maxim that they cannot accept in effect denies this: She bypasses their points of view (their intellects and their wills) altogether and so treats them not as persons but merely as things.

The second command-about treating persons as ends in themselvescaptures the idea that even though persons are not simply available to one another, they must nevertheless be open to one another. Persons must be open to one another both for the instrumental reason that there are some ends that they can achieve only by acting together and for the intrinsic reason that they have an inner need to act together or, to put it the other way around, because they can be lonely and generally dislike it. ${ }^{16} \mathrm{~A}$ person who acts against others in pursuit of ends that they cannot share, even if she responds to their wills in one way, does so on terms that necessarily set her

15. This development of the two components of the Formula of the End in Itself follows the work of Korsgaard and Onora O'Neill. See KORSGAARD, supra note 11, at 137-38; O'NEILL, supra note 14, at 112-13. O'Neill's discussion emphasizes more clearly than Korsgaard's that the two components of the formula are distinct and complementary - that they identify "two separate aspects to treating others as persons." O'NEILL, supra note 14, at 113.

My development of these ideas lies somewhat beyond the mainstream, both in the emphasis that I give the distinction between the two components of the Formula of the End in Itself and, relatedly, in the construction that I give the second component, in particular in my focus on the idea of sharing ends with others and thereby entering into community with them. The more common approach to these matters is perhaps represented by Paul Guyer, who dispenses with my particular emphasis on sharing and community and instead views the imperative to treat other persons as ends in themselves as a command generically "to enhance their prospects for the successful exercise of their agency," including "by directly assisting [them] in their pursuit of [their] ends." PAUL GUYER, KANT ON FREEDOM, LAW, AND HAPPINESS 148 (2000). Although I insist that my approach captures something essential to our moral experience of other persons, I do not (as I have said) vouch for it as an account specifically of Kant's ideas.

16. These two reasons come together in the human attraction to games, whose charm lies not just in the individual tasks that they involve but also (as the unsatisfactory character of the many forms of solitaire attests) in the fact that they constitute forms of interpersonal solidarity. 
apart from them and therefore that rule out joint participation in the acts in question.

Someone who violates these two commands refuses to engage others as persons, in the first case by declining to address them at all and in the second case by addressing them on terms that they cannot accept. And in refusing to engage them, she estranges herself from them and renders shared participation in a respectful relation-at least in connection with the actions in question-quite literally impossible.

This elaboration of the forms of estrangement may be applied to the case of lying in order to develop a more complete and precise characterization of my earlier intuitive suggestion that a lie separates liar from listener. Indeed, Kant himself pursues this possibility and illustrates the Formula of the End in Itself by discussing, among other examples, the wrongness of lying. ${ }^{17}$ As it happens, the particular lie by reference to which Kant illustrates his views involves a lying promise: Kant imagines that a person borrows money that he knows he will be unable to repay, and that he intends not to repay, but nevertheless (in order to procure the loan) gives a firm promise to repay the money within a fixed time. ${ }^{18}$ In what, Kant asks, does the wrong committed by the lying promisor consist-how does he fail to treat the victim of his lie with the respect that morality demands? The Formula of the End in Itself generates the answer-really the two answers-to Kant's question. As Kant says, "[T]he man whom I seek to use for my own purpose by such a [false] promise cannot possibly agree with my way of behaving to him, and so cannot himself share the end of the action." 19

17. As Korsgaard observes, lying is, for Kant, one of the two "most fundamental forms of wrongdoing to others." KORSGAARD, supra note 11 , at 140 . The other form is coercion. Id. The reason for this, according to Korsgaard, is that lying and coercion quintessentially undermine the assent of their victims-lying by manipulating the victim's will and coercion by bypassing the victim's will altogether. $I d$.

I cast the wrong of lying slightly differently from Korsgaard, not only as assaulting the will of the listener but also, through this assault, as estranging the liar from the listener and rendering a community between them impossible. I do not have anything explicit to say about coercion, although I believe that an account analogous to the argument that I make about lying is possible in that case also.

18. KANT, supra note 9, at 422 . Kant does not expressly say why this lying promise is a lie in the ordinary sense at all. He presumably treats it as a lie about the promisor's capacity or intention to repay the loan. This view of the lying promise is persuasively defended by Páll Árdal. Árdal begins by observing that "[p]romises are statements, whatever else they may involve," and specifically, that "[o]rdinary promises ... both state an intention of the speaker, and make an assertion about his future action." Páll S. Árdal, And That's a Promise, 18 PHIL. Q. 225, 225-26 (1968). This enables Árdal to say (as I have done) that "a false promise is deceitful, because it states something which is not the case, i.e., the promisor's intention to do what he promises to do. On my view, a lying promise is a lie." Id. at 228 . For a detailed account of the propositional content specifically of contractual promises that includes economic and doctrinal illustrations, see IAN AYRES \& GREGORY KLASS, INSINCERE PROMISES: THE LAW OF MISREPRESENTED INTENT (forthcoming 2005).

19. KANT, supra note 9, at 429. 
The two parts of this compact indictment of the lying promise should be distinguished and separately emphasized, because they recapitulate the two distinct principles contained in the Formula of the End in Itself. First, the victim of the false promise cannot possibly agree to the plan in which the promisor involves her. Insofar as the lie at the heart of the false promise succeeds, the false promisor's victim lacks the information necessary to agree to the plan, so that rather than being a participant in the plan, she becomes its object. This remains true even if the false promisor's victim would be willing to give him the money outright. She cannot agree to give a gift as long as she believes that she is making a loan. ${ }^{20}$ The false promisor uses his victim, as Kant would say, merely as a means. ${ }^{21}$

And second, the victim of the false promise cannot share in the lying promisor's ends. In the case of the successful lying promise (the case in which the victim is in fact deceived), she cannot share in the promisor's ends because he has not invited her to but has, instead, kept her in the dark about them. And even when the lie in a lying promise fails, so that the victim knows (in the case at hand) that the promisor has no intent to repay the money and therefore resists being used as a mere means, she still cannot share in his ends. Moreover, she cannot share in his ends even if, for some reason or other, she does not object to giving him the money outright and even if she does not object to being deceived into doing so. Even if the lying promisor's victim does not object to his plans, she cannot join in them: Her ends and his might coincide, but they cannot be shared. This is what Kant must mean when he says, separately from his claims about treating persons merely as means, that the liar fails to treat his victim as an end. ${ }^{22}$ Even when the victim of a lying promise is not as it happens manipulated, even when she is not treated merely as a means, she is

20. For further discussion of this point, see KORSGAARD, supra note 11, at 138-39, 346-47.

21. This explains, incidentally, why lying is such a dangerous practice for Kant, and why it is so difficult to justify even well-motivated lies (for example, white lies or lies told to thwart evil intentions in those whom they deceive). It is dangerous to make a means of a person, for her freedom makes her an unpredictable means. As Arthur Ripstein observes, Kant suggests that to lie to persons is to "convert them into a mere thing, through which responsibility flows back to you." Arthur Ripstein, Equality, Luck, and Responsibility, 23 PHIL. \& PUB. AFF. 3, 9 n.12 (1994). Ripstein concludes that to lie, for Kant, is "to play a game of chance with another's agency." Id. (discussing IMMANUEL KANT, On a Supposed Right To Lie from Altruistic Motives, in CRITIQUE OF PRACTICAL REASON 346 (Lewis White Beck trans., Univ. of Chi. Press 1949) (1788)).

22. This important but tricky point is easily missed. Korsgaard, for example, devotes several pages to explaining why the lying promisor treats his listener merely as a means, but only one paragraph to discussing why he fails to treat her as an end. And even in this paragraph, Korsgaard merely repeats the argument concerning the impossibility of assenting to lying promises that drove the former analysis, saying that "[w]hat matters" under the "failure to treat as an end" prong of the Formula of the End in Itself is that the victim of a lying promise "never gets a chance to choose the [promisor's] end, not knowing that it is to be the consequence of her action." KORSGAARD, supra note 11, at 140. This formulation obscures the fact that the second prong of the Formula of the End in Itself is distinct from the first and envisions an ideal of community that involves not just the absence of manipulation but also a respectful sharing of ends. This feature of community is essential to my eventual analysis of promise and contract. 
nevertheless not invited to share in the liar's ends as part of a respectful community; and even if her ends and his coincide, the lie renders impossible the shared ends that such a community involves. ${ }^{23}$

This application of the second element of the Formula of the End in Itself may seem odd-it may seem an unnatural understatement to express the wrongness of lying by saying that the liar pursues ends that her victim cannot share. But it illustrates something extremely important, namely that the two commands of the Formula of the End in Itself pick out distinct moral ideas, each of which contributes to the conception of respectful community that stands behind the larger argument. The possibility of community is undermined both when a person uses another as a means to her ends, by manipulating him in ways that he cannot accept, and when a person excludes another from the ends of actions that apply to him, by pursuing (in such contexts) ends in which he cannot possibly share. The Formula of the End in Itself therefore identifies two distinct ways in which persons may become estranged from each other in connection with lying. Successful lies, including Kant's example of the successful lying promise, illustrate the first but obscure the second of these failures of community. But unsuccessful lies emphasize the separate importance of the second form of estrangement. This form, in which a person estranges herself from another by adopting ends that he cannot possibly share, will be essential to the account of honest promises that follows.

\section{B. From Truth-Telling to Promising}

Kant's account of the lying promise treats the lie that this case involves as more fundamental morally than the broken promise. As the analysis in the preceding pages reveals, the wrongness of the lying promise turns, for Kant, on the fact that the listener is deceived and not on the fact that she is in any separate sense disappointed. (The same argument would apply, mutatis mutandis, to the case of an ordinary lie not couched in promissory form-say, a lie committed by a wrongdoer who denies responsibility for a harm in order to avoid her victim's claim to compensation.) Kant's analysis of the obligation of truthfulness and the wrongness of lying therefore does not extend in any mechanical way to the core cases of the morality of

23. The earlier discussion of purely theoretical lies did not consider the case in which a purely theoretical lie fails-in which the listener remains undeceived. Accordingly, that discussion did not inquire into whether the breakdown of community into separate points of view that the successful theoretical lie causes also follows from the unsuccessful lie. In the practical case, a respectful community requires not just a coincidence but also a sharing of ends-that is, a certain intentional stance toward the ends of others. This is why even an unsuccessful practical lie violates community. I do not speculate about whether a mere coincidence of points of view is sufficient for a respectful theoretical community or whether some analogous intentional stance is also required there. 
promises, including most familiarly the case of the subsequent breach of a promise that was honestly made. ${ }^{24} \mathrm{~A}$ lying promise may indeed be wrong in the same way in which a lie is wrong (one would be surprised if it were not), but the breach of an honest promise need not involve a lie. A promise, after all, may be made in good faith and broken only afterwards, so that any statements of fact that it involves, for example about the intentions of the promisor, are truthful and support (at least at the time of the promise and at least with respect to the parties' beliefs) a point of view that the promisor and her promisee can share. An argument that is based upon the wrongness of lying would therefore seem to cast little light upon the morality of more honest, and more ordinary, promises.

This appearance, although commonly observed, is deceptive. The view that Kant's account of the wrongness of a lying promise has little to say about the morality of the honest promise crucially mischaracterizes the center of gravity of the moral objection to the lying promise. Kant approaches the lying promise as a species of lie rather than as a species of promise, to be sure, and no account of the morality of honest promises can ignore this feature of the argument. But the foundations of the morality of lying are themselves much broader than the application Kant gives them through the case of the lying promise and are in fact quite broad enough to explain the morality not just of lying but also of promising. The lying promise may be a special kind of lie rather than a special kind of promise, but lies in general and broken promises in general are both themselves a special kind of breach of community, and they therefore share much more in common than is usually emphasized.

One can see this by attending carefully to the two distinct components of the conception of respectful community that I have developed by reference to Kant's Formula of the End in Itself. First, the basis of respectful community must be free: Persons must join the community willingly, and one of the basic forms of estrangement arises when one person manipulates another through deception (or coercion). Second, the basis of respectful community must be shared: Persons must enter into community with each other through the pursuit of ends that they adopt together (in a sense to be refined in a moment), and a second form of estrangement arises when one person adopts pursuits in which another, who is implicated in them, cannot participate.

Now a violation of the first command entails a violation of the second: A person who is deceived (or coerced) and therefore treated merely as a

24. Kant is sometimes taken to task for this, but such criticisms are not entirely fair. For one thing, they chastise Kant for failing at a task-the task of explaining promissory obligation-that he did not, at least in this discussion, set for himself. And for another, as my arguments reveal, Kant's account of lying in fact contains the resources needed for constructing a successful account of promising. 
means cannot possibly share in the ends in pursuit of which she has been so used, and in light of this relation, the moral analysis of the successful lie (which violates the first command) did not need to distinguish between them. But the two commands are nevertheless extentionally distinct, and it is possible for an action to violate the second command without violating the first-to fail to treat a person as an end in himself by pursuing an end that he cannot share without treating him as a means by deceiving or coercing him. This is precisely what occurs, I have suggested, when a person disbelieves a lie but nevertheless freely goes along with it (for whatever reason). A liar in such a case does not successfully bypass her victim's will and therefore does not use him merely as a means. But she nevertheless fails to treat him as an end in himself, and therefore estranges herself from him, by insistently pursuing an end that her lie renders him unable to share.

Moreover, a person may fail to treat another as an end in himself even though she never even attempts to use him merely as a means, and the second element of the conception of respectful community is therefore no mere afterthought that follows ineffective efforts to violate the first but instead presents an independent, freestanding moral ideal. Cases in which the second element of the conception of respectful community figures independently of the first arise when a person accepts that she must not simply bypass the will of another but nevertheless pursues ends in which the other cannot share. Persons who forswear using force or fraud against each other may nevertheless pursue irreconcilable and fundamentally opposed purposes, and even as they accept Kant's first command, they remain, intractably, enemies. And although (having forsworn force and fraud) they do not render respectful community impossible by undermining each other's wills, they do (at least within the sphere of their enmity) render respectful community impossible by each pursuing ends in which the other cannot join. The rejection of force and fraud only constrains the expression of their opposition; it does not eliminate the opposition.

"Means" and "ends," as these observations reveal, are not exhaustive ways of treating persons: It is possible for someone to treat another person neither merely as a means nor yet as an end in himself, and not just in the trivial sense that the two persons may simply remain strangers, who do not treat each other in any way at all. Accordingly, someone who forswears using others merely as means does not thereby secure a respectful community with them. The forms of estrangement are not exhausted by the disruption of the will that occurs when one person, employing force or fraud, treats another merely as a means. Instead, persons may abjure force 
and fraud and yet still estrange themselves from others by pursuing ends that engender separation rather than community. ${ }^{25}$

It is now possible, against this backdrop, to approach the morality of the ordinary breach of an honest promise - the breach of a promise made by a promisor who intended to keep it. The lying promisor drafts her promisee into her service through deception, and in this way undermines his will. This is the root both of Kant's suggestion that the lying promisor uses her promisee merely as a means and of my claim that the lying promisor estranges herself from her promisee by refusing to engage him as a person. The ordinary promise-breaker, by contrast, does no such thing. She does not convert her promisee into her instrument or draft him into her service, and, accordingly, she does not use him as a means at all. ${ }^{26}$ This difference underwrites the familiar skepticism of efforts to connect the morality of promising to the morality of truth-telling. But, as the two-pronged development of Kant's Formula of the End in Itself reveals, the ideal of community to which the morality of promising must answer involves more than the principle that persons ought not to use one another merely as means; it also incorporates the separate and distinct principle that persons should treat one another as ends in themselves. And a promisor who breaches an honest promise, even though she does not violate the first of these principles, may yet (just as did the unsuccessful liar) violate the second. The promisor who breaches an honest promise does not use her promisee merely as a means, to be sure. But she nevertheless estranges herself from him, and violates the command that she treat him as an end, because she pursues (through her breach) an end in which he cannot possibly share.

When a person makes a promise, she adopts certain ends-the ends associated with the promised performance - that are also available to her promisee and indeed, in the ordinary case, that are in fact also adopted by her promisee. ${ }^{27}$ The ends of a promisor therefore coincide with those of her

25. The first form of estrangement, involving force or fraud, undermines community by depriving persons of the capacity freely to act at all; the second form of estrangement, involving incompatible ends, undermines community by depriving persons of the capacity freely to act together.

26. This claim must be approached cautiously, because the distinction between making a lying promise and breaking an honest promise cannot be drawn formally. A promise that was honestly made may become a lying promise when a promisor develops a secret intent to breach that she does not disclose in order that the promise might continue to encourage her promisee to complete his own agreed-upon performance. (An installment buyer, for example, might form an intention not to pay for goods that she had intended to pay for when she bought them but keep this intention secret from her sellers in order that they deliver the goods.) A once-honest promisor who forms such a secret intention to deceive her promisee becomes a lying promisor, and uses him merely as a means, just as surely as a promisor who lies from the start.

27. I say "in the ordinary case" because I do not want to rule out that a promisee might hope that the promised performance never occurs-that the promise is broken-and therefore might not adopt the ends associated with the performance. Raz imagines the case of "a man who solicits a 
promisee, at least in respect of the promised performance. Moreover, the connection between the promisor's and promisee's ends is no mere coincidence, and the overlap in their ends is not just incidental. Instead, the promisor, through her promise, intends to entrench her pursuit of the ends announced by the promise and to refuse to defect from these ends unless the promisee releases her. She intends, in effect, to give the promisee authority over her ends - to pursue, within the sphere of the promise, only ends that the promisee also affirms. She intends, one might even say, to become obligated to the promisee to render the promised performance. ${ }^{28}$ And finally, insofar as the promisor performs the promise-insofar as she refuses to deviate from the promised performance without obtaining a release from the promisee-she carries out the intention not to defect and actually confers this authority over her ends to the promisee.

A promisor therefore intends, within the sphere of the promise, to defer to her promisee and indeed to subordinate her ends to her promisee's will. And through this subordination-through placing her ends in his handsthe promisor comes to take the promisee's ends as her own and, moreover, to treat him-his will-as an end. ${ }^{29}$ In this way, the promise underwrites a respectful community between the promisor and the promisee.

Moreover, the community that a promise establishes is not empty or formless, and a promisor does not engage with her promisee on just any terms, or treat him as an end in himself in a contentless or generic fashion. A promise, through the performance that it describes, specifies the precise ends that the promisor shares with her promisee and in this way fixes the terms upon which she engages him and treats him as an end in himself. A

promise, hoping and believing that it will be broken, in order to prove to a certain lady how unreliable the promisor is." Raz, supra note 4, at 213. It is not clear to me that the promisor and promisee in this unusual case in fact do treat each other as ends in themselves in the manner described in the main text, although I see no need to decide the question here.

One further related point is also worth making. I refer in the main text to "ends that are also available to the promisee." I mean, by this, to eliminate cases in which the promised performance could not be assented to by the promisee, for example because it involves the use of force against the promisee (as in, "If you don't hand over that jewel, I promise I'll kill you"). Such cases involve, as is commonly said, threats rather than promises. One possible implication of my account of promising is that the familiarly tricky distinction between the two turns on whether promisees might possibly share in the ends associated with the promised performance (in which case there is a promise) or instead cannot adopt these ends (in which case there is a threat). This is a suggestion only, and I do not defend it or even elaborate upon it.

28. The last two ways of characterizing promissory intentions, which build the idea of obligation (or its cognates) into these intentions, turn out significantly to complicate the theory of promising. I take up the complications below. See infra Subsection I.C.3.

29. It is worth pointing out, in light of the complication mentioned in the previous footnote, that this account of the promissory relation does not depend upon characterizing the promisor's intentions in terms of obligation or any of its cognates. All the elements of the promissory relation appear even if promising is characterized, as I have also done, simply in terms of a promisor's intentions not to defect from the promised performance unless she is released from the promise. 
subsequent breach of the promise (when it is truly a breach ${ }^{30}$ ) abandons these shared ends in favor of others that cannot be shared with the promisee because they are inconsistent with the ends that the promisee has in fact adopted in conjunction with the promise.

The breach therefore does more than merely return the promisor and promisee to the status quo ante, in which they were strangers. Strangers do not share ends and do not treat each other as ends in themselves, but they may at any moment come to do so. The breach of the promise, however, presents an obstacle to such sharing between the promisor and promisee. The breach entails that, at least in respect of the promised performance, the two adopt inconsistent ends. The breaching promisor in such a case does not treat her promisee merely as a means, to be sure. ${ }^{31}$ But this does not exhaust the moral significance of the breach, because the forms of estrangement are not exhausted by the disruption of the will that occurs when one person, employing force or fraud, treats another merely as a means.

Although a promisor who breaches an honest promise need not employ force or fraud, and may even abjure using her promisee merely as a means, she will nevertheless forfeit the possibility of treating him as an end and in this respect become estranged from him. The breaching promisor does not just unmake but instead actively betrays the community established by the promise. She pursues ends, through her breach, that do not just depart from but instead contradict her promisee's ends. The breaching promisor therefore becomes, within the sphere of the promise, an enemy of her promisee: Her breach forecloses possibilities for sharing ends that previously existed and imposes conflict in their place. The parties to a broken promise, even one with an honest beginning, therefore become more distant than strangers-they become, as I have been saying, actively estranged. ${ }^{32}$ And this estrangement explains why not only making lying promises but also breaking honest promises is morally wrong.

30. That is, when the circumstances do not excuse the promisor from performance under either the express or implied terms of the promise.

31. But recall the cautionary note struck above. See supra note 26.

32. Here it is instructive to notice the difference between the moral character of nonperformance that constitutes a breach of promise on the one hand, and nonperformance connected to a promisee's waiver of her promissory rights on the other. In this alternative casein which the promisee releases the promisor from any duties that arose under the promise-the relation that was invited by the promise is not so much betrayed as abandoned and the status quo ante in which promisor and promisee were strangers is simply restored. This observation suggests that the reasons persons have for maintaining promissory relations rather than mutually abandoning them closely resemble the reasons persons have for making promises in the first place. Some promises-for example, marriage promises on a certain (no longer popular) understanding - may present an exception to this rule. In these promises, every abandonment would indeed involve a betrayal and render future sharing of ends among the parties difficult or impossible. I say more about the general relationship between the reasons for making and keeping promises in a moment. 


\section{$* * *$}

The analogy that I have asserted between the naive case of truth-telling from which I began and the more difficult case of promising that has occupied most of my attention is now complete, and a brief summary of the argument is in order. Truth-telling in the very simplest case gives persons access to one another's minds and in this way allows them, where they would otherwise remain strangers, to construct and join in a shared theoretical perspective. Similarly, promising (and also the more complicated case of truth-telling connected to action) gives persons access to one another's wills and allows them, where they would otherwise remain strangers, to construct and join in a shared practical posture. The morality of this practical relation contains two principles, both captured by Kant's Formula of the End in Itself, which specify the conditions under which the relation is respectful and desirable. First, persons may never use one another merely as means, for to use a person in this way is to deny his personality and impose the isolation that practical life seeks to overcome. And second, persons should treat one another also as ends in themselves, for this treatment renders a shared practical posture possible.

The first principle explains why it is wrong to manipulate a person's will by lying, including by making lying promises, because lies undermine every practical sharing. The second principle, by contrast, establishes the morality of honest promises. This principle explains why persons have reasons to make promises, because a person who makes and performs an honest promise engages her promisee's practical life, by committing herself to share in his ends. The second principle also explains why persons have reasons to keep promises. A person who breaches a promise, even if it was honestly made, does not merely fail to share in her promisee's ends but renders such sharing, at least in respect of the promised performance, impossible. She does not merely return to being a stranger but instead becomes estranged.

Promises therefore render persons practically open to one another. Without promises, their wills would remain isolated (just as their minds would remain isolated without truthful communication). Moreover, when promises are broken, persons' wills become isolated (just as their minds become isolated when they lie). But when persons make and keep promises, they may overcome their isolation and enter into respectful relations with

Finally, note the difference between honest and lying promises in this connection. The promisee can waive her claim to the performance of an honest promise but cannot waive her claim not to be made the victim of a lying promise. A lying promise is a lie, and a person cannot, as 1 have argued, undo the wrong of being lied to. 
each other. ${ }^{33}$ Promise-making and promise-keeping arise, as Hannah Arendt observes, "directly out of the will to live together with others in the mode of acting and speaking." 34

\section{Making and Keeping Promises}

In a moment, I move on to fill out this general theory of promises for the special case of contract by developing a detailed account of the specific relations among persons that contracts create-the specific way in which the parties to contracts treat each other as ends. But it is helpful, before commencing with that narrower enterprise, to connect the more general reconstruction of the morality of promises that I have just presented to our practical and theoretical preoccupations concerning promising, in order to show that it can accommodate familiar elements of our promissory practices and illuminate familiar problems in the philosophy of promising. The connections that I draw all emphasize, although in very different ways, the general theory's capacity to connect the morality of making and of keeping promises.

\section{Promises and Discretion}

Our ordinary attitudes toward promise-making and promise-keeping attribute different degrees of precision, or, to use a more accurate but less elegant word, definiteness to the reasons for promise-keeping and promise-making respectively. We conventionally believe that the morality of promise-keeping gives a person a reason for keeping each and every promise that she has made. But we understand the morality of promise-making to display a much less definite character: We believe that the morality of promising rarely (if ever) requires a person to make any particular promise, ${ }^{35}$ although we also recognize that a person who makes no promises whatsoever is impoverished because of this-that she fails to

33. By uniting the wills of the parties in pursuit of shared ends, promising may even be said to serve as a private analogue to the public practice of lawmaking-as a private act of collective self-governance. The analysis that I am conducting of the respectful private community of promising may be said, therefore, to parallel the republican analysis of the respectful community of citizenship.

34. HANNAH ARENDT, THE HUMAN CONDITION 246 (1958).

35. Of course, a person may have other strong reasons, including other moral reasons, to make particular promises, as when a promise presents the best available means of discharging some independent obligation. (Imagine, for example, that a person who tortiously damages another's property promises to pay compensation.) However, the reasons for making such promises do not sound specifically in the morality of promising, but rather in features of the overall circumstance that are independent of promising, and these reasons might be satisfied by alternatives to the promise were they available. (If the tortfeasor could pay the compensation at once, then there would be no need for her to promise to do so.) 
recognize or participate in values that find an important place in a life well-lived. One might say, once again using language made familiar by Kant, that the reasons for promise-keeping underwrite perfect duties whereas the reasons for promise-making underwrite imperfect duties. ${ }^{36}$ Perfect duties require definite actions, whereas imperfect duties allow a person's proclivities or "inclinations" ${ }^{\text {"37 }}$ to influence precisely how (to what extent and in what ways) she will carry them out.

The return to Kant is useful here because Kant's general understanding of imperfect and perfect duties illuminates our everyday attitudes toward promise-making and promise-keeping. Imperfect duties arise in connection with ends that persons have a duty to promote but that may be promoted in a variety of ways and by a variety of actions, and imperfect duties apply to the range of actions that promote such ends, among which it is up to a person to choose. ${ }^{38}$ Promise-making presents precisely this circumstance: By making promises, a person can come to share ends with others and therefore to treat them as ends in themselves, something that she has a duty to $\mathrm{do} ;{ }^{39}$ but many particular promises (and perhaps even some actions that are not promises) enable persons to join in a community in this way, and each person may choose from among the many alternatives according to her own inclinations. This underwrites the commonplace view that while a life bereft of all promises is a bad one, the everyday morality of promising requires no particular promises to be made.

Perfect duties, by contrast, arise in relation to actions that display some more definite connection to obligatory ends. One form that this definite

36. See KANT, supra note 9, at 421; IMMANUEL KANT, Metaphysical First Principles of the Doctrine of Virtue, in THE METAPHYSICS OF MORALS 373, 422-23 (Mary Gregor trans., Cambridge Univ. Press 1991) (1797). For a discussion of the distinction between perfect and imperfect duties, see KORSGAARD, supra note 11, at 17-18, 20-21; and ALLEN W. WOOD, KANT'S ETHICAL THOUGHT 44 (1999). This distinction arises, in Kant, in tandem with the related distinction between "strict" and "broad" obligations. Although these distinctions are different from each other, the differences are subtle and Kant himself "does not use the four terms in a perspicuous way." KORSGAARD, supra note 11, at 20. One difference between the two distinctions is that the focus of the perfect/imperfect distinction is on the definiteness of a duty and the role open to personal inclination in its fulfillment, whereas the focus of the strict/broad distinction is on whether a duty may be fully discharged (strict) or instead imposes open-ended and ongoing obligations (broad). See generally ONORA NELL, ACTING ON PRINCIPLE 43-58 (1975) (discussing the different criteria by which Kant analyzes a duty). The main argument does not turn on these intricacies, and so I set them to one side.

37. KANT, supra note 9 , at 421 n.*.

38. See KORSGAARD, supra note 11 , at 20-21; WoOD, supra note 36 , at 325 .

39. I reject, on the basis of this observation, the surprisingly common view that where an end may be achieved with or without a promise, there is never any reason to employ a promise as a means for achieving it and, relatedly, the view that it cannot be "a reason for someone to make a promise that she would be able to fulfill it later on." Holly M. Smith, A Paradox of Promising, 106 PHIL. REV. 153, 183-84 (1997). In fact, the choice whether to pursue an end by a promise or by some other means at least sometimes involves the choice whether to pursue it communally or at most coincidentally. This means that there can be reasons - indeed, as will become plain, very strong reasons-for pursuing ends by promises, and it can be a reason to make promises that they can be kept. 
connection can take appears when an act necessarily sets an end that is directly contrary to another end that persons have a duty to pursue. The perfect duty not to lie, for example, arises because lies, including lying promises, treat their victims merely as means, which is contrary to the obligatory end of never treating others as mere means. Moreover, the connection between certain actions and obligatory ends may give rise to perfect duties in a second way also, as when an act (even though it does not involve setting a prohibited end) involves a failure to set an obligatory end at all. ${ }^{40}$ The breach of an honest promise violates a perfect duty under this alternative construction. Although a promisor who breaches an honest promise does not use her promisee merely as a means, she does foreclose the possibility of treating her promisee as an end in himself by adopting ends, at least in connection with the promised performance, in which he cannot possibly share. A person may remain a stranger to many, which is why the duty to make promises is imperfect only; but she should estrange herself from none, which is why the duty to keep promises is perfect.

Finally, the reasons for making promises become increasingly definite, and the duty to make promises becomes increasingly perfect, as other circumstances render it increasingly unacceptable for persons to remain strangers. This is most starkly illustrated by moral cultures that connect promising to other forms of intimacy, and in particular to intimacy within the family. Thus it is a familiar fact that some cultures insist that sexual relations may occur only within the confines of the marriage promise, so that a perfect duty of promise-making arises among sexual intimates. And even our own more sexually liberated culture recognizes that certain intimate relationships that grow out of sex and reproduction demand promises from persons who inhabit them, so that a parent, for example, will often come under a duty not just to offer his frightened children comfort and protection but to promise to do so. In each of these cases, and no doubt in many other cases besides these, a person's discretion concerning which promises to make diminishes and the duty of promise-making becomes commensurately more perfect. And just as it explained the general rule that the duty to make promises is imperfect whereas the duty to keep promises is perfect, so the theory of promising that $I$ have developed can explain this exception to the rule also. The duty to make promises becomes perfect insofar as a potential promisor is already embedded in a relationship (in the examples, involving sex and family) that insists upon the respectful community-the recognition of others as ends in themselves-that promises engender. The ordinarily imperfect duty to make promises

40. For a similar discussion, see WOOD, supra note 36, at 325. 
becomes perfect insofar as other moral ideals insist upon particular instantiations of the promissory relation that the theory describes. ${ }^{41}$

\section{Promises and Obligations}

The account of promising that I have proposed also illuminates a second difference in our conventional attitudes towards promise-making and promise-keeping, which involves not the substance of the reasons conventionally thought to govern making and keeping promises, but rather the relationship between these reasons and other reasons - that is, the form in which reasons for making and keeping promises conventionally intervene in our all-things-considered practical deliberations. This difference involves not so much what the reasons for making and keeping promises require as how these reasons operate.

It may seem that the differences between the reasons for making promises and those for keeping them are straightforward and, moreover, that they count against the theory of promising that I have proposed. Thus it is tempting to suppose that the reasons for promise-keeping are simply stronger or more powerful than the reasons for promise-making, so that the difference between the two kinds of reasons is just that reasons for promise-keeping are more likely than reasons for promise-making to hold sway in all-things-considered practical deliberations. It is common to observe that although there exist only weak reasons for making a promise, there are strong reasons for keeping the promise once it has been made: A person has only a weak reason to assure her friend that she will collect him at the airport, for example; but once the assurance has been given, she has a much stronger reason to follow it through. The account of promising that I have proposed is difficult to square with, and certainly cannot explain, this view. Its insistence that the reasons for making and keeping promises both arise out of the same basic vision of a moral community grounded in mutual respect renders any suggestion that one set of reasons is more substantial than the other unnatural, or at least itself in need of explanation.

But although the common suggestion that the reasons for keeping promises are stronger than the reasons for making promises responds to something real in the morality of promising, it expresses the underlying truth about promising (and the features of our conventional moral practices that reflect this truth) only poorly, and at too low a level of abstraction. Indeed, the morality of promising (even as it is conventionally understood) does not in fact systematically regard the reasons for keeping promises as

41. Note, in this regard, that when persons breach such perfect duties of promise-makingwhen they refuse to make the promises to sexual partners or children that these examples identify-then they are commonly thought to violate the morality of these relations (as libertines or child neglectors), rather than the morality of promising. 
weightier than the reasons for making them. It is not hard to imagine cases in which the reasons for making a promise are powerful indeed, and quite as powerful as the reasons for keeping it: Think of the promises involved in marriages. ${ }^{42}$ (Nor is it difficult to think of cases in which the reasons for keeping a promise are trivial: Consider someone's promise to join a group of friends who have arranged an informal dinner out.) Moreover, the suggestion that the reasons for promise-keeping are stronger than the reasons for promise-making bears the hallmarks of a by-now-familiar error: In many cases, as in the case involving assurances presented a moment ago, promises will induce reasonable reliance once they are made, and this reliance may underwrite nonpromissory, harm-based reasons for following through. But these reasons do not belong to the morality of promising, and while they may be reasons for doing what has been promised, they are not reasons for keeping the promise.

The reasons for keeping promises do figure differently in practical deliberations from the reasons for making promises, but the difference is not simply one of weightiness or strength. Instead of being quantitative in this way, the difference is qualitative and structural. The reasons for keeping a promise bear on the question whether to do the promised acts, to be sure, but they do not do so only directly (as, for example, harm-based reasons involving a promisee's reliance might do). Instead, the reasons for promise-keeping also operate indirectly, by emphasizing the promisor's intention to give her promisee authority over her ends and the community that this intention engenders. This authority entails that the promisor must prefer such shared ends over other ends, specifically by constraining the promisor from acting on certain reasons not to perform, including most notably the reason that the consequences of not performing the promise (of doing some other act instead of the one promised) are better overall than the consequences of performing. ${ }^{43}$ The justification for the constraint that principles of promise-keeping impose on the promisor's responsiveness to overall consequences may be found in the value of the promisor's intention to give the promisee power over her ends. Without this intention, the promise could not enable the promisor and promisee to share in the ends of the promise (as opposed to merely having their ends coincide), and it therefore could not enable the promise to underwrite the community in which the promisor treats the promisee as an end in himself. Promises

42. It is important to note that these examples do not undermine the earlier discussion of perfect and imperfect duties. Even for those who believe that marriage is an essential part of a good life, so that the reasons persons have for marrying are overwhelmingly strong, the duty to marry remains imperfect. It does not say whom a person must marry, but leaves this matter to personal inclination.

43. That reasons for promise-keeping serve in this way to give separate or additional support to performing promises is perhaps the source of the mistaken view that they are stronger than the reasons for making promises. 
enable persons to cease to be strangers, but only by giving them reasons that constrain them from acting on the balance of reasons that are available to strangers.

This formal account of the way in which principles of promise-keeping feature in practical reasoning evokes Joseph Raz's well-known view of the role that obligations play in our practice of promising. ${ }^{44}$ Raz observes that the reasons for promise-keeping do not just include first-order reasons directly in favor of keeping promises, but also include second-order reasons, which Raz calls exclusionary reasons, for not acting on certain first-order reasons for breaking promises (say, that breaking a promise would produce the best consequences overall). ${ }^{45}$ Raz believes that this is a genetic feature of our practice of promising, which receives expression in much of the practice's phenomenology. Principles of promise-keeping, for example, themselves constitute independent reasons (rather than just reporting on the balance of other more fundamental reasons), ${ }^{46}$ and promisors may experience principles of promise-keeping as restraints on their practical activities and feel themselves bound by such restraints to act against the balance of their first-order reasons. ${ }^{47}$

Raz argues that principles of promise-keeping that operate in this way cannot be explained by conceptions of promising (including most familiarly the utilitarian conceptions) that explain promise-keeping by reference to the costs that breaking a promise imposes. Such considerations-including, most commonly, the harms suffered by promisees who rely and the costs associated with the reduced credibility of breaching promisors-can underwrite first-order reasons for keeping promises, to be sure. But they cannot possibly explain the second-order, exclusionary effect that we commonly accord to principles of promise-keeping in the broader scheme of our practical deliberations: The legitimate influence of considerations involving harm or future credibility is exhausted once these values are taken into account in first-order reasoning; to accord them further, exclusionary effect would be to give them improper influence (to count them twice over, as it were). Instead, the morality of promising must take the decision whether to keep a promise out of the ordinary balancing of first-order reasons. It can do this, Raz proposes, only by understanding that promises, instead of invoking ordinary values that might come into play

44. See Raz, supra note 4. My views do not precisely match Raz's, however. I discuss one difference between us below. See infra note 52 .

45. See id. at 226. For more on Raz's idea of second-order reasons, see JOSEPH RAZ, THE AUTHORITY OF LAW: ESSAYS ON LAW AND MORALITY 3-33 (1979) (reprinting Joseph Raz, On Legitimate Authority, in PHILOSOPHICAL LAW: AUTHORITY, EQUALITY, ADJUDICATION, PRIVACY 6 (Richard Bronaugh ed., 1978)); and JosEPH RAZ, PRACTICAL REASON AND NORMS 49-106 (1975).

46. See Raz, supra note 4, at 219-20.

47. See id. at 223-24. 
among persons generally, constitute a special relationship, or bond, between promisors and their promisees. This special bond is the expression, in terms of our everyday moral experience, of the exclusionary effect of the obligation of promise-keeping. ${ }^{48}$

Raz recognizes that the theory of promising cannot, finally, stop at this purely formal insight; the formal conception of promises he proposes "can only be justified if the creation of [the] special relationships between people [that this conception entails] is held to be valuable." ${ }^{49}$ But he expressly makes it no part of his purpose "to defend [or] to criticize any particular view of the grounds for keeping promises,"50 or even "to argue that the special relationships the desirability of which would validate [such a formal account of promising] are indeed desirable." ${ }^{, 51}$ My own theory of promise, by contrast, begins with precisely this purpose and leads with a substantive effort to say what the special relationship between a promisor and her promisee is like and why this relationship is desirable. This effort produces an account of overcoming isolation through an intentional pursuit of shared ends whose structure closely tracks the form of obligation that Raz concludes must underlie the phenomenology of our promissory practice. The authority over her ends that a promisor gives the promisee on my account serves as an analogue to the obligation that the promisor assumes on Raz's. Moreover, when the reasons for making and especially for keeping promises are developed by reference to my account of the promissory relationship, they display the formal structure that Raz observed and so skillfully set out to explain. My argument and Raz's therefore approach promising from opposite directions but in the end join up, so that my substantive account of promising and Raz's formal account complement each other, and my account may be read to address some of the questions that Raz identifies but declines to answer. ${ }^{52}$

48. See id. at $227-28$.

49. Id. at 228 .

50. Id. at 211 .

51. Id. at 228 .

52. One difference between Raz's view and mine deserves mention. Raz believes that the special relationship upon which the exclusionary effect of principles of promise-keeping depends can be established only if promises function, phenomenologically, not as expressions of simple intentions to perform an action unless released but rather as expressions of reflexive intentions to assume, by their very expression, obligations to perform an action. Raz rejects, as he puts it, intention conceptions of promise in favor of obligation conceptions. Id. at 211 . I worry, as have I said in passing, see supra notes 28-29, and will explain in detail in the next Subsection, that insisting that promissory intentions must make reflexive reference to the obligations the promises engender introduces a vicious circle into the theory of promising, and my account of promising is expressly designed to make do without including obligation, or any of its cognates, in promissory intentions. In place of Raz's intention to assume an obligation I include a simple intention not to abandon performance without the permission of the promisee.

I take this difference to stand in a friendly, rather than a hostile, relationship to Raz's general approach. I retain Raz's basic account of the formal structure of the morality of promising and adopt his suggestion that this structure might arise out of the value of the special relationship that 


\section{The Grounds of Promise-Keeping}

Finally, and perhaps most importantly, the account of promissory obligation that I have developed can resolve a puzzle concerning the grounds of the obligation to keep promises that has long troubled moral philosophers. The central task for a philosophical explanation of promise-keeping is to connect the obligation to keep promises to the act of will (the act of making the promise) that presents the distinctive feature of our promissory practice. It turns out to be extremely difficult to give a satisfactory account of the place that the act of will involved in making a promise occupies among the grounds of the obligation to keep the promise. $^{53}$

Thus it seems incredible that the bare act of will that promise-making involves might by itself conjure the obligation of promise-keeping into existence. This sensibility led Hume to compare the idea that the act of will involved in promise-making in itself begets a duty of promise-keeping to the mystery of transubstantiation. ${ }^{54}$ For although persons may incur obligations in conjunction with willful actions in any number of ways (most commonly in connection with intentional actions, including perhaps representations of what they will do in the future, that harm others), all these obligations are grounded in the effects of the persons' wills-in the harm that they have done-and not in the bare willing in itself. Persons do not simply will these obligations into existence, and it is difficult to conceive of how they possibly could do so, because it is difficult to

promises engender. Insofar as I succeed in showing that this relationship can arise without building obligation into promissory intentions, my argument broadens the substantive foundation of Raz's formal account and in this way protects it against the charges of circularity that I mentioned a moment ago and take up in earnest in the next Subsection.

53. The discussion that follows is indebted to Liam Murphy, Promise, Practice, Contract (Nov. 6, 2003) (unpublished manuscript, on file with author).

54. DAVID HUME, Of Morals, in A TREATISE OF HuMAN NATURE 455, 524 (Oxford Univ. Press $2 d$ ed. 1978) (1739-1740). For Hume, the mystery in the origins of the obligation of promise-keeping was compounded by his sentimentalist belief that "[n]o action can be requir' $d$ of us as our duty, unless there be implanted in human nature some actuating passion or motive, capable of producing the action," and his skepticism about whether the act of will involved in promising could ever give rise to any such motivation. $I d$. at 518 . Without taking a position on the connection, if any, that exists between obligation and motivation, I observe that the view of promising that I am developing meets Hume's condition through its reference to the inner human need to act together. This need underwrites, in the ways I have described, the required motivations both to make and to keep promises.

Hume worried about promising in another way, which I identify only to set aside. He worried how promising, as an act of language, might be intelligible at all. In Elizabeth Anscombe's words, "[H]ow on earth can it be the meaning of a sign that by giving it one purports to create a necessity of doing something - a necessity whose source is the sign itself, and whose nature depends on the sign." G.E.M. ANSCOMBE, Rights, Rules, and Promises, in ETHICS, RELIGION, AND POLITICS 97, 100 (1981). I take my view of promising to answer this objection also, because there is no special mystery in how a sign might enable persons to share ends, and my theory explains how certain ways of sharing ends might give rise to obligations. 
conceive of how they could simply will anything so external as an obligation into existence. Moreover, this difficulty does not disappear just because willing a promissory obligation, through making a promise, is often in practice associated with an obligation's actually arising. As Elizabeth Anscombe observed, "[I]f a door opens when I say to it: 'I hereby open you,' that doesn't mean that my saying those words itself, in suitable circumstances, is enough to prove that the door is open." ${ }^{55}$ We still wish to know, in the case of the door, on what ground it might be open; and we still wish to know, in the case of the obligation of promise-keeping, on what ground it might arise. And it seems implausible, in each case, that this ground is just the willing in itself.

Thoughts like these have led many philosophers to find the grounds of the obligation of promise-keeping in something besides the act of will that constitutes promise-making, so that even though promise-making triggers the obligation of promise-keeping, it does not underwrite it. The most prominent efforts in this direction look either to the harm promise-breaking imposes on promisees who have relied on a promise, or to the existence of a social practice of promising to fill the gap in obligation that is opened by the will's impotence. ${ }^{56}$

But these views, even as they explain an array of duties that arise around promises, fail to capture the immediate moral experience of promising. Harm-based views fit uncomfortably with the experience that promissory obligation extends to encompass promisees' forward-looking expectations in the promised performance and not just their backwardlooking reliance. They cannot easily explain the fact that promises seem to obligate even where promisees have not relied and that a promisor cannot discharge her promissory obligations simply by compensating her promisee's reliance losses. ${ }^{57}$ And practice-based views fit uncomfortably with the experience that promissory obligation extends directly from a promisor to her promisee, rather than being mediated by a social practice of promising. ${ }^{58}$ The experience of promising does not deny that additional, nonpromissory duties might arise in conjunction with promises, but it

55. ANSCOMBE, supra note 54, at 99 .

56. The harm-based views appear, for example, in Lon Fuller \& William R. Perdue, Jr., The Reliance Interest in Contract Damages (pts. 1 \& 2), 46 YALE L.J. 52, 373 (1936-1937), and in P.S. ATIYAH, PROMISES, MORALS, AND LAW (1981). Practice-based views appear, for example, in HUME, supra note 54, at 516-25; and JOHN RAWLS, A THEORY OF JUSTICE 344-48 (1971).

57. Of course, some harm-based views-for example Fuller and Perdue's, see Fuller \& Perdue, supra note 56-seek expressly to shake these intuitions about promising.

58. This shortcoming of practice-based theories is most vivid in Rawls's approach, which explains the obligation of promise-keeping in terms of a promisor's obligation to do her fair share to support the practice of promising, which she has invoked to her benefit. See RAWLS, supra note 56 , at 346. Rawls's view suggests, against all experience, that the obligation of promise-keeping finds its grounds not between the promisor and promisee but rather among all participants in the social practice of promising. 
nevertheless focuses insistently on promise-making itself, which it recognizes as a distinctive, freestanding fount of moral obligation. Moreover, this experience suggests that the will of the promisor lies at the center of promissory morality -indeed that there is nothing, fundamentally, to promise-making other than an act of will. ${ }^{59}$ The moral experience of promising therefore insists on a distinctive form of moral obligation that the philosophy of promising has so far been unable to explain. The philosophical tendency to account for the moral obligation of promisekeeping on other, more generic grounds is not so much an effort to explain the moral experience of promising as to explain away an experience that has remained philosophically intractable.

The account of promising that I have developed can provide the necessary explanation of promissory experience without indulging in any mysticism about the generative powers of the will. It can do this because it presents a fundamentally new approach to the relationship between promise-making and promise-keeping, under which the act of will involved in promising can occupy an essential place in an account of the distinctive grounds of the obligation of promise-keeping without having to beget the obligation on its own. In particular, the traditional view so starkly confronts the task of explaining how willing can create an obligation out of nothing only because it understands the act of willing involved-promise-makingas essentially morally indifferent. On the view that I have developed, by contrast, promise-making occurs against a backdrop of ideals concerning respectful community and, relatedly, treating persons as ends in themselves. And when it is viewed in this light, promise-making no longer appears morally indifferent but is revealed, instead, to be morally required, even if this requirement does not extend to the making of any particular promise. And once this is understood, it becomes clear that when the act of will involved in making a promise gives rise to an obligation to keep the promise, it does not do so out of nothing but instead merely perfects an already present but previously imperfect duty. ${ }^{60}$ Nor is it at all surprising that a bare act of will should have this power; indeed, one of the central functions of the will is precisely to choose which among several possible ways of fulfilling an imperfect obligation to adopt.

59. It is tempting to deny this by observing that promise-making involves not just an act of will but also the communication of this will to the promisee, but this addition does not help the argument, at least not at the moment. It remains mysterious how the bare expression of an act of will might bring an obligation into existence-recall that Anscombe's example involved saying "I hereby open you." Of course, the expression of will involved in promising may trigger consequences-most notably, reasonable reliance in the promisee-and these consequences may generate obligations associated with promise-keeping. But as the main text argues, these associated obligations do not match the immediate moral experience of promising.

60 . I owe this way of putting the point to Scott Shapiro. 
Moreover, the will can play this part in accounting for the obligation of promise-keeping without bootstrapping or circularity. I have, to be sure, sometimes characterized promise-making in terms of the promisor's intention to give the promisee authority over her ends and even in terms of the promisor's intention to obligate herself to her promisee. And each of these formulations raises a specter of circularity, because it appears to assume precisely the conclusion that the moral theory of promising is trying to establish: If the forms of authority and obligation to which these formulations refer must themselves obtain in order to establish the respectful community that I have said promises create, then the value of this community cannot underwrite promissory obligation, and the theory lacks a bottom. (This difficulty would not arise, of course, if the will could conjure promissory obligation on its own bottom. But this is highly dubious, as I have observed, and would anyway do away with the need for the very ideals of respectful community that make the theory distinctive.)

These worries about circularity are misplaced, however, because the intentions that generate the respectful community upon which promissory morality depends may arise, and may be described, without making any reference to obligation or any cognate ideas. It is sufficient for respectful community that the promisor intends, as I have also said, simply to pursue the ends announced by the promise unless the promisee releases her from pursuing these ends. ${ }^{61}$ The theory of promising can therefore do without the

61. The concern to avoid circularity has also influenced Thomas Scanlon's views about promising, including his construction of the principle of Fidelity from which he argues obligations of promise-keeping arise. See T.M. SCANLON, WHAT WE OWE TO EACH OTHER 295-327 (1998); Scanlon, Promises and Practices, supra note 2. Scanlon develops his theory of promissory obligation around the idea that promisees may reasonably trust promisors to vindicate their promissory assurances, and he recognizes that his theory can avoid circularity only if the reasons behind the promisees' trust sound in something besides promissory obligation. See SCANLON, supra, at 307-08; Scanlon, Promises and Practices, supra note 2, at 212. He therefore seeks to ground promisees' faith in promissory assurances in prepromissory principles that forbid certain forms of manipulating others and require that persons exercise due care in leading others to form certain expectations. This argumentative strategy seeks to ground the wrong of making lying promises in these prepromissory values and then to ground the reasonableness of trusting promissory assurances in the fact that promisors may reasonably be expected to avoid this and related wrongs. See SCANLON, supra, at 308; Scanlon, Promises and Practices, supra note 2, at 213. And Scanlon's account of promissory intentions, like mine, therefore dispenses with any reference to promissory obligation and makes do with the simple intention to perform unless released. See SCANLON, supra, at 304; Scanlon, Promises and Practices, supra note 2, at 208-09.

Despite these structural similarities, my account and Scanlon's base promissory obligations on very different substantive values. Where Scanlon appeals to principles concerning a person's responsibility for disappointments that others suffer in connection with expectations that she has led them to form, I appeal to principles concerning the duty to share ends with others; and where Scanlon grounds his arguments in the value of the general relationship involved in seeking to live according to principles for the general regulation of behavior that others, similarly motivated, could not reasonably reject, I ground my argument in the value of the special relationship of sharing ends that promises engender. I believe, moreover, although I do not develop the point here, that the general considerations to which Scanlon appeals are inadequate to underwrite the distinctive departures of promissory and contractual obligation from the broader obligation not to 
intentions that give rise to the concern about circularity. And although the theory of promising is not entitled to express promisors' intentions in terms involving authority or obligation until it can establish itself without referring to these ideas, such references become harmless once it is clear that the theory can indeed do without them. ${ }^{62}$

Finally, although the act of will involved in promise-making, on this account, no longer stands alone among the grounds of the obligation of promise-keeping, it remains an essential part of these grounds and is not just their cause, or trigger. The form of respectful relation to which the morality of promising ultimately answers-the ideal of treating others as ends in themselves-requires that persons' wills converge, in the appropriate way, upon shared ends, and the willing of the promissory obligation is an essential component of this convergence. ${ }^{63}$ The approach to promising that I have developed therefore explains the connection between the will and the obligation of promise-keeping in a way that eludes alternative approaches and that accounts, moreover, for the distinctiveness of the immediate moral experience of promising.

\section{CONTRACT}

The value of a certain communal relation underwrites a powerful and broad-reaching moral theory of promise. In order to enter into this relation, persons must (negatively) refrain from treating one another merely as means by refraining from acting under principles that others could not accept, and also (positively) treat one another as ends by pursuing ends others share. The negative part of this theory explains the morality of lying promises: Lying promisors act wrongly because the principle of action such promises contain could not possibly be accepted by their promisees, who are deceived and to this extent manipulated as mere means. The positive

harm others--in particular the forward-looking character of promissory duties and the expectation remedy. (Scanlon attempts - to my mind, unsuccessfully - to explain these phenomena in terms of his theory in Promises and Contracts. See Scanlon, Promises and Contracts, supra note 2, at 99111.) My own efforts in this direction, which make extensive reference to the special value of the promise relation, appear in Part III.

62. One further concern bears mentioning. It may seem that expressions of promissory intentions that forswear ideas of authority and obligation avoid circularity only at the cost of infinite regress. For one might worry that a promisor's non-obligation-based intentions to perform a promise unless the promisee releases her cannot establish a communal relation unless she also intends not to abandon this intention without a release, and so on ad infinitum. But this concern notwithstanding, the first intention in the chain-to perform unless released-is sufficient to establish a respectful community whenever it obtains. And it can obtain at the moment of promising even without the subsequent intentions to the chain. (I thank Michael Bratman for helpful discussions on this point.)

63. The expression of will involved in promising - the communication to the promisee - now reappears as important to the argument, but in itself and for the relation among wills to which it belongs, rather than, as in my earlier discussion, see supra note 59 , for any external consequences that it might produce. 
part of the view explains the morality of honest promises: The reason for making honest promises is that the intentions they involve enable persons to cease to be strangers by sharing in the ends of the promises; and the reason for keeping honest promises is that breaches betray these shared ends in favor of others that cannot be shared, and in this way estrange the parties from each other. Moreover, this theory of the promise relation accounts for the most prominent features of our experience of the morality of promising: the different definiteness of the duties to make and keep promises, the place of the obligation of promise-keeping in our broader practical deliberations, and the distinctive place of the will among the grounds of promissory obligation.

But although it has achieved some substantial results, the argument has so far proceeded at an extremely abstract and general level, leaving many important points unaddressed. Most notably, I have said virtually nothing specific about the community involved in the promise relation, either about the content of the shared ends that this community invokes or about the nature of the sharing that this community incorporates. Moreover, the gap in the theory as developed so far corresponds to questions about the morality of promising that arise naturally at this point in the argument, and indeed that the theory actively encourages and invites.

For example, although I have observed that the reasons for making some promises (for example, the promises involved in marriage) are much stronger than the reasons for making other promises (for example, the promises involved in ordinary buying and selling), I have said little to explain why these differences in the strength of the reasons for promisemaking emerge. ${ }^{64}$ The explanation that naturally suggests itself is that the community created by marriage promises somehow exercises a greater draw on persons than the community created by promises to buy and sellperhaps because it involves sharing more significant ends, or even a more significant mode of sharing-but I have so far said nothing to elaborate upon or explain this intuition. Moreover, although I have observed that making promises invites community, I have not explained in any detail what promise-making consists in, and although I have observed that breaking a promise violates community, I have not said what enforcement mechanisms might protect against such violations.

These topics call for increasingly specific accounts of the several peculiar varieties of promises, and I now turn to developing one such

64. Note that when I refer, in this context, to the reasons for making promises, I mean the reasons presented by the morality of promising (based on the value of the promissory community). Many other reasons for making promises may arise besides these, and some such reasons may be quite powerful-for example, it may be a strong reason to make a promise in connection with buying that a buyer very much wants the item she promises to pay for or that the item is a bargain. 
account for one class of promises in particular, namely contract. In this Part, I elaborate upon the character of the peculiarly contractual version of the promissory community-upon the shared ends and the precise manner of sharing that are immanent in our contractual practice. Then, in the final Part of my argument, I invoke this elaboration to address still more detailed matters, involving (for example) what making a contract consists of and what remedies ought to be available in case of breach.

The argument going forward therefore abandons much of the generality of what has come before, but it continues, as it were, to be illuminated from behind. Contract presents a special case of promise, and a species always incorporates the essential characteristics of the genus to which it belongs, so that the reasons for making and keeping contracts must be expressed in terms of the reasons for making and keeping the promises that contracts involve. The focus on contract therefore represents not a new departure but a move inward - an effort, as I have said, to elaborate the precise forms of respectful community that arise in connection with the particular class of promises presented by contract.

The choice to proceed in this way partially reflects taste and inclination-my purpose in introducing the broader arguments about agreement and promise was to equip myself to join the theoretical tradition of contract scholarship that drew my interest to begin with. But the narrow focus on contract also reflects necessity. The next stage in the argument requires dispensing with general notions of respectful community and shared ends, in favor of developing a particular version of community based on the sharing of a particular class of ends under a particular conception of sharing. The class of promises is too broad and too heterogeneous to be the object of the narrower form of analysis now called for. Contract, by contrast, is narrow and homogeneous in precisely the right way, and it will be possible, in the pages to come, to develop fairly precise accounts of the shared ends that contract involves and of the manner in which they are shared.

\section{A. The Collaborative Ideal}

This move inward, from promises generally to the special class of promises that constitute contracts at law, may appear straightforward at first. As a formal matter, at least, contractual promisors, just as promisors simpliciter, intend to give their promisees authority over their ends-to pursue, within the sphere of the contract, only ends that their promisees also affirm. Indeed, contractual promisors intend to give their promisees not just moral authority but also the legal capacity to compel them to pursue the 
ends that the contract specifies. ${ }^{65}$ And insofar as contractual promisors honor their contracts-insofar as they refuse to deviate from the contractual performance without obtaining a release from their promisees - contractual promisors actually confer (legal) authority over their ends to their promisees. Just as with ordinary promises, therefore, the mechanisms of contract-making and contract-keeping enable contractual promisors to share ends with their promisees and in this way to treat their promisees as ends. And just as with ordinary promises, contracts enable the parties to them to cease to be strangers and to enter into a respectful community.

But although this application of promissory morality to the special case of contract is natural, and indeed straightforward, from the point of view of moral theory it remains unsatisfying as an account of contractual practice. The argument proceeds too quickly, and too mechanically, to give a satisfactory account of the morality of contract, in particular because it ignores the substance of the purposes with which the parties typically enter into legal contracts. And when these purposes are taken squarely into view, the suggestion that contracts establish a morally respectful community may come to appear an empty formalism.

This suggestion traffics in the idea that contracts, like all promises, invoke shared ends through which the parties to them come to treat each other as ends. But although personal promises may commonly involve a substantial sharing of ends, contracts appear, at first blush, to involve quite the opposite. Even if contractual promisors do intend to assume obligations to their promisees, and in this way to give their promisees authority over their ends, it seems strained to say that promisors thereby respect their promisees, or join in a community with them. The parties to contracts generally compete, after all, and each tries to get the best deal that she can; buyers press for low prices, for example, and sellers for high ones. This suggests that the parties to contracts ordinarily do not finally share ends, but rather pursue opposed ends. The parties to such contracts therefore do not appear to treat each other as ends in themselves at all, whatever the theory of promise might suppose. Regardless of the contractual form, the substance of contract is that each party treats the other as a means in the pursuit of her own, unshared ends. ${ }^{66}$ The moral theory of promising that I

65. I do not mean, by this remark, to prejudge the question whether the proper remedy for breach of contract is expectation damages or specific performance. I take up this question in Section III.B, where I argue that, for purposes of the collaborative view, expectation damages may vindicate the ends of a contract and therefore underwrite contractual community.

66. None of this implies that the parties to such contracts violate the first prong of the Formula of the End in Itself and use each other merely as means. Even as each party pursues the best deal that she can get, she recognizes limits on how she may behave in pursuit of this deal-for example that she may not proceed by force or fraud - that reflect the personhood of the other party. (At the same time, as I observed in the previous Part, the fact that a person recognizes that she may not treat another merely as a means is not sufficient for her to treat him as an end in himself.) 
have developed appears, on this view, to be most suited to personal, benevolent promises. Contracts seem to lie beyond its reach.

This skepticism about contractual community does not apply to every contract, of course. Some contracts generate substantive obligations of mutual concern that unquestionably support the substantive community that the general theory of promise invokes: Contracts that establish partnerships or joint ventures, for example, create fiduciary relationships among the participants. ${ }^{67}$ And other contracts - including many employment contracts and many contracts among regular suppliers-supervene on long-term, ongoing relationships that may also present such substantive community. This makes it tempting to try to rebuff skepticism about contractual community by assimilating all contracts into these thicker and more contextual - and therefore more substantively communal — patterns. $^{68}$

I resist this temptation, however, and my account of contractual solidarity proceeds in the opposite direction. I insist that the conceptual core of contract remains the discrete and self-interested exchange, in which contract stands apart from status, custom, habit, and the other thicker, more contextual forms of community that may sometimes accompany contractual activity. Rather than deny that the contractual version of community is thin and formal, or that it arises against a backdrop of self-interest, I argue that even the most self-interested, discrete, and purely transactional contractseven contracts in which the contractual promise stands alone and unadorned-invoke the moral relations of respect and community that I have articulated and that present the foundations of promissory and contractual obligation. Indeed, I propose that the thinness and formality of the contractual ideal of community is an asset rather than a liability for the theory of contract, because it allows the theory to cast contract in a central role in broader accounts of social and political organization. ${ }^{69}$

Ideas concerning the place of contract in such broader schemes of justification must abide later development, however. The burden of this Section is to make good on the claim that the transactional form of the contract relation can underwrite a freestanding community by demonstrating that the parties to contracts share ends in the contracts, and treat each other as ends through the contracts, even when the contracts

67. See, e.g., Meinhard v. Salmon, 164 N.E. 545, 546 (N.Y. 1928) (Cardozo, C.J.) ("Joint adventurers, like copartners, owe to one another, while the enterprise continues, the duty of the finest loyalty.").

68. The most prominent proponent of this approach to contract is Ian Macneil, who calls contracts that arise in such cases "relational contracts" and claims that every contract is "necessarily partially a relational contract." IAN R. MACNEIL, THE NEW SOCIAL CONTRACT 10 (1980). Macneil's theory of contract and mine represent almost exact opposites in this respect. Macneil claims that no contract is ever a freestanding source of obligation; 1 argue that every contract, including even the most isolated contract, presents a freestanding source of obligation.

69. I elaborate on this point in the Conclusion. 
involve nothing more than self-interested exchange. I seek, with this purpose in mind, to display the ends that even self-interested contracting parties share and the mode of sharing to which they commit themselves. I also seek to explain why persons who commit themselves to sharing such ends in such a way cease to be strangers and come to treat each other, affirmatively, as ends in themselves, by entering into what 1 call a collaborative community. The hallmark of this collaborative form of community is that it replaces a concern for other persons' interests-the concern that underwrites the sharing of ends involved in typical personal promises-with a concern for other persons' intentions and, ultimately, for their points of view. The morality of contract therefore identifies and elaborates a form of respect that does not rely on affection.

\section{Joint Intention}

The argument finds its starting point in ideas that Michael Bratman has developed in analyzing certain forms of joint action that Bratman calls shared intention. ${ }^{70}$ I seek to adapt these ideas to my purposes rather than to approach them on their own terms, and so my engagement with Bratman's work will proceed, once again, in the mode of borrowing rather than exegesis. I seek to show that contracts involve the patterns of intention that Bratman describes and that these intentions, in conjunction with contractual promises, establish relations of respect and community among persons who adopt them, even when these persons display no concern for each other's well-being and engage in contracting as part of the pursuit of their narrow self-interests. ${ }^{71}$

70. Michael E. BRATMAN, Shared Cooperative Activity [hereinafter BRATMAN, Shared Cooperative Activity], in FACES OF INTENTION: SELECTED ESSAYS ON INTENTION AND AGENCY 93 (1999) (reprinting Michael E. Bratman, Shared Cooperative Activity, 101 PHIL. REV. 327 (1992)); MICHAEL E. BRATMAN, Shared Intention [hereinafter BRATMAN, Shared Intention], in FACES OF INTENTION: SELECTED ESSAYS ON INTENTION AND AGENCY, supra, at 109 (reprinting Michael E. Bratman, Shared Intention, 104 ETHICS 97 (1993)).

71. The preoccupations to which I apply Bratman's ideas are therefore very different from the preoccupations in whose service he develops them, and I occasionally pause to reflect on these differences in the margin.

My most significant departure from Bratman's treatment arises because Bratman approaches joint intentional activity from the point of view of the philosophy of action, whereas I am approaching joint intentional activity from the point of view of moral philosophy. This difference causes my presentation to depart from Bratman's, even where I follow his views in substance. Specifically, Bratman says that a "commitment" to the joint activity is among the general conditions for the existence of joint intentional activity, see BRATMAN, Shared Cooperative Activity, supra note 70, at 94-95, whereas I avoid using the word "commitment" in this way. My reason for doing so is to avoid any confusion between a "commitment" to a joint activity on the one hand and, on the other hand, a moral "obligation" to the other participants in the activity. Bratman is himself quite clear about these matters and proceeds without any hint of confusion: The existence of an intention in favor of the joint activity is sufficient to give rise to a "commitment" of the type that Bratman has in mind, id. at 96, and such a "commitment" obviously carries no moral weight. Moreover, the backdrop of Bratman's argument- the broader 
The most general form of shared intention that Bratman considers involves what he calls joint intentional activity. A couple taking a walk together, two musicians singing a duet together, and two people rowing a boat together all present examples of joint intentional activity, to which it will be helpful to return occasionally to test conclusions or even just to fix ideas. Bratman wishes to know the precise character of the distinctive form of interpersonal interaction that these activities involve. There is no doubt that these and other joint activities all involve forms of coordinated and not merely correlated action: The actions of the participants do not merely coincide but rather, to use Hume's phrase, "have a reference to" each other. ${ }^{72}$ But this is a rough characterization only, and Bratman is concerned with understanding more precisely and stating more carefully what such coordination involves. His answer (modified somewhat to suit my purposes) illuminates the morality of contract by providing a strikingly precise characterization of the ends that contracting parties share, the manner of their sharing, and therefore the sense in which contracting parties treat each other as ends in themselves.

Bratman's account begins from the observation that joint intentional activity can arise only when each participant in the activity forms an appropriate intention, which Bratman characterizes, initially, as an "intention in favor of the joint activity." In order for two musicians to sing a duet as a joint intentional activity, each must intend to sing the relevant music. $^{74}$ But, as Bratman observes, this rough match of intentions is not by itself enough for joint intentional activity: A more intricate pattern of intentions is required. ${ }^{75}$ This is revealed by returning to the case of the two musicians and imagining that one intends to sing in a major and the other in

tradition of the philosophy of action-is removed from morality and does not invite any confusion along these lines. My own argument, by contrast, proceeds in the tradition of moral philosophy, and this context does invite confusion. I therefore do without the word "commitment" and instead speak directly in terms of underlying intentions.

72. HUME, supra note 54 , at 490 . As an example of correlated but not coordinated action, consider the case of two people who independently cast votes in favor of the same candidate in an election. These people, one might say, are in agreement without there being an agreement between them.

73. BRATMAN, Shared Cooperative Activity, supra note 70, at 96.

74. See id. Bratman properly insists that the activity so intended must be characterized, as he says, in a "cooperatively neutral" and not in a "cooperatively loaded" way. Id. The cooperatively loaded characterization of the intended act, for example "trying to win the championship together," would render the account of joint intentional activity circular because it "already brings in the very idea of cooperation." Id. A cooperatively neutral characterization, for example "trying to win the championship," by contrast, does not prejudge the matter but is instead consistent with both cooperative and noncooperative action. (In the example, the persons trying to win may play on the same or on different teams.)

75. Note, however, that the entire additional structure that Bratman adds to his conception of joint intentional activity all plays in the initial register of intention. In particular, Bratman imposes no requirements on the reasons that the participants in joint intentional activity have for forming their intentions. I may seek exercise and you may wish to enjoy the view, but as long as we have the right intentions we can still take a walk together. 
a minor key. It would be misleading to call such singing joint intentional activity because the jointness does not extend sufficiently deeply into the singers' intentions. Using Bratman's language, one might say that the "subplans" by means of which the singers intend to implement their intentions to sing the duet clash, and that a joint intentional activity requires more intricate coordination than this example provides. ${ }^{76}$ The coordination need not, however, be complete: One singer may intend to sing in a minor key and the other may intend to dress in black, and the duet may nevertheless qualify as joint intentional activity. Joint intentional activity requires only that the participants' subplans are not inconsistent with each other, or, as Bratman says, that they "mesh." 77

The fact of meshing subplans is, however, still not sufficient for joint intentional activity, for it remains possible that the participants' subplans mesh only accidentally, as it were, so that meshing does not figure in the participants' attitudes toward the activity. Two singers of a song may sing in the same key but only because their rehearsal patterns, involving sequences of many keys, happen to overlap, in which case it would be wrong to say that they are singing a duet together. To account for this complication, Bratman builds the meshing condition into the content of the participants' intentions: Joint intentional activity requires that the participants specifically intend to perform the actions according to meshing subplans. ${ }^{78}$

Even this is not enough for joint intentional activity. Although the discussion so far has specified the intentions that each of the participants in joint intentional activity must develop severally, it has not yet explained the relationship that must arise among the participants. ${ }^{79}$ The participants in

76. BRATMAN, Shared Cooperative Activity, supra note 70, at 98-103.

77. Id. at 99 .

78. Id. at 98-103. The example through which Bratman develops this point differs slightly from my example of the practicing singers in a way that strikes me as misleading. Bratman imagines that two people who paint a house together have subplans that happen to "agree" on red paint and that one then changes her mind in favor of blue. Id. at 99 . Insofar as the example suggests that the initial convergence on red involved more than mere coincidence (and was perhaps even the product of an "agreement"), the shift to blue raises questions of cooperative stability that are not yet at issue. My example of the practicing singers is designed to avoid this confusion by emphasizing the coincidence of the mesh.

79. My discussion remains incomplete in another way also. As Bratman emphasizes, joint intentional activity requires not only action in accordance with the participants' intentions and their subplans, but also action because of these intentions and subplans. Id at 100 . As Bratman observes, when one person kidnaps another and, overpowering her, takes her to a city to which she anyway intended to go, no joint intentional activity has taken place. $I d$. Joint intentional activity remains first of all intentional activity, and the person who is overpowered in the example hasn't intentionally traveled anywhere. At the same time, even as joint intentional activity must be voluntary, it need not be free. It is enough, in the example, for the kidnap victim willingly to make the journey, even if her intention to do so is formed in response to a threat. Joint intention fails only if the person is made to travel against her intentions, or, as one might more commonly say, against her will. 
joint intentional activity must, as Bratman says, be "mutual[ly] responsive[]" to one another. ${ }^{80}$ That the participants' intentions are mutually responsive to one another is a consequence of something that has already been said, namely that the requirement of meshing subplans is built into the content of each participant's intentions. This entails, as Bratman observes, that each participant in joint intentional activity will construct her own subplans with reference to the others' subplans, in order to secure a mesh. ${ }^{81}$ But joint intentional activity requires a further display of mutual responsiveness, not just in the participants' intentions but in their actions as well. ${ }^{82}$ The participants in joint intentional activity do not just intend to act together; they in fact do act together, so that not just their plans but their actions mesh.

This distinguishes joint intentional activity from what Bratman calls prepackaged coordination. ${ }^{83}$ In prepackaged coordination, all the jointness occurs in advance of the activity: The participants plan together and hence display mutual responsiveness in their intentions, but once the planning is done, each participant executes her part of the plan (according to her intentions) separately and without interaction with the others. In prepackaged coordination, the planning is joint-indeed, typically itself a joint intentional activity-but the action is separate. Prepackaged coordination may even reflect the dissolution of a previously joint endeavor, as when the pair of musicians, tired of their partnership, divide their mutual possessions and plan for each to collect her share from their old practice room, as they go their separate ways.

Here it is worth noting, because the point will come up again later on, that prepackaged coordination, unaccompanied by any joint intentional activity, can succeed only if the plans and intentions that it involves are perfectly complete in the sense that they specify, in every necessary detail and anticipating every contingency, the actions that each participant must eventually take in order to bring the planned coordination off. This renders the prepackaged coordination that Bratman imagines a narrow, indeed perhaps a vanishingly narrow, phenomenon and certainly renders it incapable of regulating coordination that displays even moderate extension

I have relegated this observation to the margin because it strikes me as implicit in the main discussion, indeed almost as a background assumption of that discussion, rather than as a distinctive feature of the phenomenon Bratman seeks to characterize. (Moreover, the assumption seems to me to fit more economically into the main argument by saying that each participant's subplans include participating intentionally in the activity, so that the kidnapping example presents a case of nonmeshing subplans.)

80. Id. at 106.

81. Id.

82. Id.

83. Id. Bratman speaks of prepackaged cooperation, but this is because he introduces the idea while discussing a subset of joint intentional activity that he calls shared cooperative activity. I say more about shared cooperative activity, and about cooperation in general, in a moment. 
or intensity. For, as any contract lawyer knows, the administration even of the very simplest joint plan requires constant addition, revision, and adjustment over the course of its performance.

Finally, joint intentional activity requires that these several elementseach participant's intentions to join in the activity, in accordance with meshing subplans, ${ }^{84}$ and to act in a mutually responsive way-be common knowledge among the participants. ${ }^{85}$ Two people who pursue a common intention and adjust their intentions and actions in all the ways joint intentional activity requires nevertheless fail to act jointly unless these features of their actions are out in the open between them: If each of two musicians seeking to sing a duet accommodates herself to the other but this mutual accommodation is not common knowledge between them, they are not yet singing a duet together-although they may sound as if they are. ${ }^{86}$

Putting all of this together, as Bratman helpfully does, one may say that joint intentional activity characteristically involves a pattern of intentions that are, self-consciously, interlocking, "for each agent must have intentions in favor of the efficacy of the intentions of the other. In this way, each agent must treat the relevant intentions of the other as end-providing for herself; for each intends that the relevant intentions of the other be successfully executed." 87

And yet, in spite of involving this self-consciously interlocking web of intentions, joint intentional activity may arise even among persons who are indifferent, or indeed even ungenerous, toward each other. Bratman illustrates this point through an example he calls "the case of the unhelpful singers," in which two musicians sing a duet, coordinating their voices as joint intentional activity requires, but neither has any disposition to help the other should she stumble, because each prefers the other's failure over their joint success. ${ }^{88}$ Bratman uses the example to contrast joint intentional activity generally with a second, richer form of shared intention he calls shared cooperative activity. ${ }^{89}$ Cooperation, Bratman observes, adds to joint intentional activity the requirement that each participant's intentions are such that there exists at least one circumstance in which the other requires help to perform the joint task but offers no new inducement to secure the help, and the first participant is willing to help. ${ }^{90}$ As Bratman says, this

84. Recall also that each participant must act because of these meshing subplans. See supra text accompanying note 78 .

85. BRATMAN, Shared Cooperative Activity, supra note 70, at 102.

86. This fact- that the performance sounds like a duet-may of course be evidence that each is proceeding as joint intentional activity requires, and the participants may infer the common knowledge needed to complete joint intentional activity from such evidence.

87. BRATMAN, Shared Cooperative Activity, supra note 70, at 102.

88. Id. at 103.

89. Id. at 93-94.

90. See id. at 104. Bratman adds, as a further condition, that whereas joint intentional activity need only be voluntary, shared cooperative activity must also be free. See id. at 101-02. I find this 
intention in favor of "mutual support" ensures that the joint activity is in such circumstances "minimally cooperatively stable." At the very least, the participants in shared cooperative activity cannot have interests in the activity that are opposed to each other, because this opposition would undermine the intentions in favor of mutual support upon which cooperation depends. ${ }^{92}$

\section{Collaboration}

This analysis is interesting, in the present context, because describing contract in the terms developed by the theory of joint intentional activity makes it possible to identify the ends that contracting parties share and the manner of their sharing, and in this way to specify the precise form of respectful community that contracting engenders and whose value underlies the morality of making and keeping contracts. Critically, the sharing of ends that contract invokes can be explained, by this means, in a manner that is not undermined by the recognition that contracts can involve no more than discrete transactions and that the parties to these transactions can engage each other, ultimately, in pursuit of their separate self-interests.

To begin with, contracts plainly present cases of joint intentional activity. The parties to contracts-even to very simple contracts, say, in which one person hires another to cultivate her garden at a fixed hourly wage-participate in the joint intentional activity of performing the contract. Each party intends to join in the performance (the cultivation of the garden in exchange for the payment of the wage); each party intends to do so in accordance with meshing subplans (in which the gardener composes a garden to suit the plants and tools that the homeowner provides

addition somewhat obscure. It seems to me that two singers who sing a duet under threat of violence should they fail-who give a command performance, as it were-are properly described as cooperating with each other even though they do not sing freely. They certainly have the intentions in favor of mutual support that distinguish cooperation from joint intention simpliciter. Finally, Bratman adds, in effect as background conditions, that the help does not undermine the first participant's own participation in the joint activity, and that the intentions to help are common knowledge.

91. Id. at 103, 105. Bratman in fact speaks of a "commitment" to mutual support, see id. at 103 , and this is therefore a point at which Bratman's usage and mine diverge. This is also a point at which it is important to avoid the confusion of which I have warned. The "commitment" Bratman identifies is a practical commitment to the joint activity; it is not a moral obligation to the other participants in the activity. The importance of this difference will become plain in the pages that follow.

92. The participants in shared cooperative activity need not, however, be independently concerned for each others' interests. Although such generosity is one natural source of the intentions in favor of mutual support that cooperation involves, these intentions may arise in other ways also. It is possible, for example, for purely self-interested participants in an activity to enjoy benefits from the activity that so far exceed the costs (including opportunity costs) of their participation that they are willing to assume additional costs in order to sustain the activity in case other participants stumble and place the success of the activity at risk. 
and the homeowner secures plants and tools to suit the gardener's composition); and, because even the simplest contract cannot be administered as prepackaged cooperation, each party adjusts her subplans to the other's as mutual responsiveness in action requires (so that the gardener's composition and the homeowner's provision adjust to each other as the garden develops). ${ }^{93}$

Moreover, even discrete, purely transactional contracts-including most prominently contracts for the sale of goods-involve joint intentional activity, even if (in contrast to the gardening contract described a moment ago) they do not invoke any rich culturally familiar relations among the parties, who become nothing more than buyers and sellers. Even parties to discrete, transactional contracts intend to join in the promised performance (to secure the exchange of goods for money); even parties to discrete, transactional contracts intend to perform in accordance with meshing subplans (involving, for example, the method of shipment, place of delivery, and the means of payment); and even the most discrete, transactional contract cannot fully specify in advance every component of the performance that it contemplates or every contingency that might affect the parties' intentions in this performance, and it therefore cannot be administered as prepackaged cooperation, but instead depends on some degree of mutual responsiveness in action. ${ }^{94}$

Contracts generally do not, however, involve shared cooperative activity. Some forms of promise, especially among intimates, may well invoke the intentions in favor of mutual support that constitute the core of cooperation (think of the traditional marriage vow's language "in sickness and in health" or indeed of contractual promises to establish partnerships or joint ventures ${ }^{95}$ ). But contracts can arise, as $I$ have been saying, among parties who retain opposed interests in the joint activity that the contracts contemplate and who are each unwilling, when the other stumbles and places the success of the joint activity in jeopardy, to shoulder any uncompensated increases in their shares of the burden of the joint activity. And although even discrete contracts do not necessarily involve parties who are in this sense uncooperative-although even discrete contracts may be sufficiently profitable, and the costs associated with their breakdown

93. Contracts of course also satisfy the common knowledge condition that Bratman imposes on joint intentional activity. See supra text accompanying notes 84-85.

94. The law of sales recognizes this and requires the parties to fill in the unspecified aspects of their performance in a reasonable fashion. See, e.g., U.C.C. \$ 2-503 (1997) (providing that a seller must give a buyer reasonable notification of tender); $i d$. $\S 2-504$ (providing that, except as otherwise agreed, a seller who is required to ship goods to a buyer must choose a means of shipment "as may be reasonable having regard to the nature of the goods and other circumstances of the case"); id. $\S 2-513$ (providing that, except as otherwise agreed, a buyer may make a reasonable inspection of the goods). These requirements of reasonableness all serve, among other things, to ensure that the parties to contracts display mutual responsiveness to each other in action.

95. See supra text accompanying note 67. 
sufficiently large, so that the parties are willing to shoulder additional uncompensated burdens in order to keep their contracts afloat - the legal structure of the discrete contract relation characteristically accepts such uncooperative participants. As a general matter, a material breach by one party to a contract (even if it is innocent ${ }^{96}$ ) relieves the other of its obligation of return performance. ${ }^{97}$ Moreover, the law never requires a disappointed promisee to catch a stumbling promisor and (shouldering the burden herself) ensure that the contemplated performance occurs. In place of mutual support, contract imposes only a much thinner nondefection condition on joint intentional activity. The parties to a contract need not be willing to compensate for each other's shortcomings; they need only be committed to not stumbling first. Indeed, Bratman's case of the unhelpful singers could easily be brought within the legal form of contract, and a moral theory of contractual obligation must therefore, as I have been saying, apply even to such a case. ${ }^{98}$

Bratman's ideas therefore make it possible to begin to give a precise account of the shared intentions that contracts do and do not involve. But this account seems to undermine rather than support my larger theoretical claims concerning the morality of contract. As the connection between contract and the case of the unhelpful singers brings home, Bratman's ideas on their own appear not so much to reveal the respectful and communal character of the contract relation as to pinpoint the precise failures of respect and community that the contract relation involves.

This suggestion is mistaken, however, because references to shared intention present only an incomplete account of the contract relation. Contract also involves the intention that figured so prominently in the more general theory of promising - the intention to perform unless released (or, speaking with the theory of promising already in place, to assume an obligation). Neither joint intentional nor shared cooperative activity characteristically involves this intention, so that describing the contract relation exclusively in terms of shared intention leaves a key element of contract to one side. The truly respectful and communal character of the

96. Contractual liability, after all, is strict liability.

97. See, e.g., RESTATEMENT (SECOND) OF CONTRACTS $\$ 237$ (1981) [hereinafter RESTATEMENT].

98. It is important to differentiate this discussion of contract from remarks Bratman makes under the heading "competition and levels of mesh." See BRATMAN, Shared Cooperative Activity, supra note 70 , at 107 . Bratman observes that some activities, most characteristically play at games, can involve shared cooperative activity (including intentions in favor of mutual support) at one level-involving recognizing the rules of the game, choosing a venue for play, and so onbut be noncooperative (and indeed competitive) at lower levels involving strategic action within the game. See id. The difference between contract and shared cooperative activity does not just involve the level of mesh at which the cooperation stops. (Although the depth of the mesh in contract may indeed be quite limited, as when two competitors do a deal.) Contract need not involve shared cooperative activity at any level of mesh. 
contract relation appears only when contractual obligation is returned to the center of the argument and the joint intentions that Bratman emphasizes are viewed against the backdrop of this obligation.

In spite of their complexity and richness, joint intentional and even shared cooperative activity standing alone do not yet establish the relations among persons that promises, including contracts, characteristically involve. As Hume surmised, "Two men, who pull the oars of a boat, do it by agreement or convention, tho' they have never given promises to each other." 99 And Bratman himself imagines that two musicians might sing a duet together even though they "have a clear understanding that neither is making a binding promise to or agreement with the other concerning their singing" so that each expressly "reserves the right to change her mind."100 Moreover, these reservations apply equally to shared cooperative as to joint intentional activity. Cooperation requires only a present intention in favor of mutual support; it does not require any intention to assume an obligation of mutual support or indeed even to maintain present cooperative intentions in the future. A person may join a cooperative venture, and intend to support her co-venturer's cooperative activities, and yet reserve, expressly or even just implicitly, the right to change her intentions and abandon the cooperation at any time.

If the intentions of a participant in joint intentional or even shared cooperative activity (responding, say, to changes in external circumstances) waver or change, causing her to abandon the activity, the other participants can raise no claim against her. If one of the musicians in the duet shifts from being a cooperative to being an unhelpful singer, or even stops singing the duet entirely, the other does not, without more, have any moral complaint. ${ }^{101}$ This reveals that the intentions involved in joint intentional

99. HUME, supra note 54 , at 490.

100. BRATMAN, Shared Intention, supra note 70, at 126-27; see also MICHAEL E. BRATMAN, Shared Intention and Mutual Obligation, in FACES OF INTENTION: SELECTED ESSAYS ON INTENTION AND AGENCY, supra note 70, at 130,133 (observing that in such a case, neither is obligated to the other to continue with the duet).

101. Bratman is perfectly aware that his account of joint intentional and even shared cooperative activity does not directly underwrite moral obligation, and he devotes a subsequent essay to discussing the relationship between shared intention and obligation. See BRATMAN, supra note 100 . Bratman approaches these questions by separating the problem of "describ[ing] a socialpsychological web of interlocking attitudes that plays the roles definitive of shared intention" from the problem of identifying the "normative consequences of that web." Id. at 140. These normative consequences arise, for Bratman, from the application of freestanding moral principles to the particular patterns of attitudes that shared intention describes, so that even though shared intention may be associated with obligations, "we need not see the associated normative consequences as themselves constitutive of shared intention." Id. at 141. Bratman's approach to shared intention and mutual obligation may be contrasted, in this respect, to the approach taken by Margaret Gilbert, who claims that shared intention, or (as she more commonly calls it) joint commitment, "in and of itself" involves mutual obligation, so that the relationship between the two is, as Gilbert says, "conceptual." MARGARET GILBERT, SOCIALITY AND RESPONSIBILITY 8, 17 (2000). Gilbert also presents this view in two earlier books. MARGARET GILBERT, LIVING 
and even shared cooperative activity are ultimately intentions in favor of the activity only and not in favor of the other participants. Although the jointness of these forms of activity necessitates the interlocking structure of intention that Bratman describes-in which each participant's intentions are in favor of the success of certain of the others' intentions-this entire interlocking structure depends, in the cases Bratman addresses, wholly upon each participant's individual interest in the activity. Even though the participants in joint intentional and even shared cooperative activity intend to adjust to each others' intentions, each participant's adjustments answer exclusively to her own engagement with the activity. The participants do not intend to subordinate themselves to each other's wills. And joint intentional and even shared cooperative activity therefore do not establish a moral relationship among the persons who engage them.

Contract stands in stark contrast to joint intentional and shared cooperative activity simpliciter in this respect. Whereas joint intentional and shared cooperative activity involve intentions in favor of the activity that invoke the other participant only through the activity, contract, being a species of promise, adds to these an intention in favor of the other participant, which has as its subject the performance of the joint activity. After all, a contractual promisor, including even a promisor in a discrete, transactional contract, intends not to abandon the promised performance unless released from the contract. Rather than intending, as in both joint intentional and shared cooperative activity, just that the intentions of her promisee succeed, a contractual promisor intends, in effect, to give her promisee authority to require her to promote the success of his intentions. She intends, within the sphere of the contract, to subordinate her will to her promisee's, and she comes, in this way, to treat her promisee, and not just the joint activity of the contract, as an end in himself. Although contract involves less extensive sharing than shared cooperative activity-it

TOGETHER: RATIONALITY, SOCIALITY, AND OBLIGATION (1996); MARGARET GILBERT, ON SOCIAL FACTS (1989).

My account of contractual obligation has Bratman's structure rather than Gilbert's (although, as I discuss in a moment, see infra note 104, the substantive moral principles to which Bratman appeals are very different from the ones that figure in my argument). I describe a pattern of intentions-involving joint intentional activity coupled with intentions not to defect from this activity unless the other participants consent-and then argue that this pattern gives rise to moral obligation by reference to freestanding moral principles concerning the value of respectful community. It seems to me that this is the only plausible approach to take to the relationship between shared intention and obligation. To begin with, cases clearly exist in which shared intention appears without obligation (as in Bratman's case of the singers who each expressly reserve the right to abandon their duet, see supra text accompanying note 100). Furthermore, and more fundamentally (because the first objection may perhaps be answered by narrowing the scope of shared intention to exclude such cases), Gilbert's approach requires that intentions display the potency (to ground obligations) that Hume and Anscombe so powerfully argued they cannot have. Theories that draw the connection between shared intention and obligation in terms of freestanding moral values avoid this embarrassment. 
involves only nondefection as opposed to mutual support-such sharing as contract does involve proceeds along a different axis from the (greater) sharing in shared cooperative activity. This axis takes the form of intentions running directly from participant to participant, rather than through the activity. And in spite of the thinness of the sharing that it involves, contract therefore establishes a moral relation among the persons who engage it that joint intentional and even shared cooperative activity do not. ${ }^{102}$

I have said from the start that the intentions to assume obligations that lie at the heart of even self-interested, discrete contracts entail that contracts underwrite some form of moral recognition among the parties to them. ${ }^{103}$ But I have worried that the thin and formal character of such contractual obligations might undermine efforts to base the morality of contract on the relations of recognition that contracts involve. Casting the contractual form as a species of joint intentional activity makes it possible, now, to overcome this worry by identifying the precise character of the respect that contract transcendentally evokes and therefore the precise form of community that contract underwrites.

Notwithstanding the seif-interest with which persons typically approach their contracts, each party to a contract forms self-consciously interlocking intentions, in which she adopts the success of certain intentions of the other party as her own ends. Moreover, each party intends to give the other authority over her intentions: She intends for the other party to exert a claim

102. One can say, therefore, that the intentions associated with joint intentional activity and even shared cooperative activity are not sufficient to establish the respectful community upon which the morality of promise and contract depends. The intention not to defect from the promise or contract unless released is also necessary because without this intention the deference to the person of the promise- -without which the promisor does not treat the promisee as an end--is not established. At the same time, adding the intention not to defect is sufficient for establishing the required respectful community. This community is sustained by the fact of deference to the promise, and there is no need (recall the discussion in Subsection I.C.3) to cast this deference in terms of obligation or any of its cognates.

103. It is a transcendental condition of the possibility of contractual obligation that the parties to contracts are full-fledged legal persons-as the law acknowledges when it declines to recognize contracts with persons who lack contractual capacity. See RESTATEMENT, supra note 97, $\$ \S 12-16$. Notice, moreover, that persons, for example minor children, may lack contractual capacity but nevertheless sue and be sued in tort, so that having contractual capacity indicates a higher legal status than merely enjoying the right not to be harmed. Compare W. PAGE KEETON ET AL., PROSSER AND KEETON ON THE LAW OF TORTS § 134 (5th ed. 1984) (stating the "general rule" that "an infant has no tort immunity based solely on the fact of infancy" and describing exceptions), with E. AlLAN FARNSWORTH, CONTRACTS $§ 4.4$ (3d ed. 1999) (reporting that "common law courts early announced the prevailing view that a minor's contract is 'voidable' at the instance of the minor"). The two rules clash when a minor fraudulently induces a person to enter into a contract, in which case he may be held liable in tort for fraud but not in contract. See KEETON ET AL., supra, § 134 (reporting cases).

This pattern in the law should not be surprising, given what $I$ have said so far: Tort law grows out of a relatively primitive but broad-based objection to using other persons merely as means; contract law reflects a more advanced but narrower ideal in favor of treating other persons as ends, and in particular as ends in terms of their capacity to adopt an independent point of view, at least insofar as they are capable of sustaining this treatment. 
against her in connection with these interlocking intentions, a claim not to be the first to defect from the joint performance that the intentions characterize. Some practices of promising (for example, marriage) introduce the promissory relation-involving intentions to assume obligations that run directly from person to person-among persons who seek broadly to make common cause. They therefore present conceptions of community that are impassioned and intimate in two ways: First, the ends that the parties share encompass the general pursuit of their substantive interests; and second, the parties understand the mode of their sharing to include broad patterns of reciprocal concern and open-ended obligations of mutual aid.

Contract, by contrast, introduces the promissory relation among persons whose engagement is much narrower. It therefore presents a conception of community that is in both ways impassive and detached: Both the ends that the parties share and the mode of their sharing are circumscribed by the particular terms of their agreement. Contract therefore presents a much sparer and more formal conception of community than is common to many personal promises, both in the narrowness of the ends that are shared in contract and in the narrowness of the mode of sharing itself. One might say, adopting a term of art, that whereas the community constituted by marriage, for example, is fully cooperative, the community constituted by contract is only collaborative.

Collaborative communities, in spite of their narrowly formal character, involve genuine respect and remain true communities. They invoke the shared ends and modes of sharing that this Section has described in considerable detail. Indeed, collaboration exhibits forms of respect that arise only unnaturally in connection with cooperation, if they arise at all. The contrast between the circumscribed character of collaborative communities and the open-ended character of cooperative communities gives collaborators a measure of control over how they are treated in the name of community that cooperators do not enjoy. The role that joint intention plays in collaboration, and the specificity that collaborative intentions therefore display, entail that a collaborator must constrain her actions to respect her partner's point of view concerning the collaboration, whereas the open-endedness of cooperation can allow a cooperator to pursue her partner's interests as she sees them, even against his own, differing, view of what his interests involve. Finally, this difference matters in practice: Collaborative conceptions of community are less likely to recommend paternalism than cooperative conceptions, and paternalism is indeed both less practiced and less accepted in connection with contracts than in connection with personal promises. Collaboration presents a moral ideal of community and respect-indeed an ideal that is distinctive in its own right and not just cooperation's poorer cousin. And contract therefore 
describes a distinctive moral relation between persons - and moral reasons for both making and keeping contracts arise-in spite of the fact that persons also approach contracts in pursuit of their narrow, and often competing, self-interests.

This should not in the end come as any surprise, because the ideal of moral community (rendered articulate through the Kantian Formula of the End in Itself) from which my argument hegan presents a capacious moral ideal that encompasses, as I have said, the sharing of many substantive ends under many modes of sharing. The existence of the intention to become obligated transmutes the pattern of intentions that contract involves into a relation not just of each party to the joint activity, but rather directly between the parties, whose ends are not merely coincidental nor even correlated, but are instead shared - even if the ends are more formal, and the sharing more limited, than in other promissory relations. By sharing ends in this fashion the parties to contracts come, as Kant would say, to treat each other as ends, which is to say that they cease to be strangers and enter into a moral community together.

Moreover, when one party breaches a contract, she pursues an end that is inconsistent with the shared ends of the contract, an end in which the other party to the contract cannot share. She thus forecloses treating the other party as an end in himself, at least in respect of the contract's subject matter. The morality of contract therefore displays the same structural components as the morality of promise of which it represents a special case. The reasons for making contracts include that persons who do so enter into a moral relation in which they treat each other as ends in themselves. And the reasons for keeping contracts include that breaches do not merely undo whatever sharing of ends a contract relation involves, but rather render sharing ends, at least in respect of the contemplated performance, impossible. Contracts enable persons who are not intimates nevertheless to cease to be strangers; and breaches do not just reinstate the persons' prior status as strangers but instead leave them actively estranged. ${ }^{104}$

104. Bratman's own account of the morality of shared intention proceeds along very different lines. Instead of developing the possibility that joint intentional activity, coupled with the appropriate form of intention to be obligated, can produce a morally significant relation among the participants, Bratman approaches the morality of shared intention in light of the participants' several separate interests. This leads him to a harm-based view that understands the morality of shared intentions as arising out of each participant's reliance on the other's expressed intentions, under an application of Scanlon's Principle of Fidelity. See BRATMAN, supra note 100. Such harm-based views cannot, however, adequately explain the morality of promise and contract, because they cannot account for the fundamental place of the will among the grounds of moral obligation. I develop this point in greater detail elsewhere. See Daniel Markovits, Making and Keeping Contracts (Mar. 2003) (unpublished manuscript, on file with author).

One general advantage of Bratman's approach over mine is worth noting, although it is not relevant in the specific context of promise and contract. Bratman's view applies based on the attributes of joint intentional activity simpliciter, without reference to the additional element of intentions running directly between the participants that my characterization of contract invokes. 


\section{B. Who Can Collaborate}

Contracts, including contracts concerning discrete transactions among self-interested parties, invoke the distinctive ideals of respect and community that explain the morality of promising, albeit in a collaborative rather than fully cooperative form. The argument has therefore answered the challenge that I posed at its earliest beginnings: It has explained how the scope of the morality of promise might encompass even the constrained, instrumental, and therefore distinctly impersonal promises that contracts typically involve. But contracts may be impersonal in another way also, which I have not yet emphasized, and which refers to the character not of the promises that contracts contain but rather of the parties who make these promises. This second kind of contractual impersonality addresses only the scope of the collaborative view's application and not the view's persuasiveness tout court, and so presents a less fundamental challenge to the collaborative account of contract than the first. Yet it is worth addressing nevertheless, if only to help clarify the ambitions and structure of the collaborative view.

The parties to contracts need not be individuals (that is, natural persons) but may be, and indeed often are, organizations (that is, artificial persons) including, typically, economic firms. Contracts may therefore be sorted, by reference to the character of the parties who make them, into three classes: contracts between individuals, contracts between organizations, and contracts between individuals and organizations. ${ }^{105}$ I have developed the collaborative theory of contract with the first class of contracts, between individuals, in mind. This is a natural emphasis given the theory's origins and ambitions: Both the Kantian ideals of respect out of which the theory has grown and the liberal ideals of political legitimacy to which the theory aspires focus attention on individuals and away from organizations.

But it is important also to say how the collaborative view stands with respect to the other two classes of contracts, which involve organizations as parties. In this Section, I observe that the collaborative view does not apply in any straightforward way to contracts involving organizations. I also argue, however, that contracts involving organizations present very

\footnotetext{
Bratman's account of the morality of shared intention therefore has a broader range of application than mine and has been applied, for example, to explain the duties of legal officials to support a legal practice characterized as a joint intentional activity. See, e.g., JULES L. COLEMAN, THE PRACTICE OF PRINCIPLE 98 (2001); Kenneth Einar Himma, Inclusive Legal Positivism, in THE OXFORD HANDBOOK OF JURISPRUDENCE AND PHILOSOPHY OF LAW 125, 134-35 (Jules Coleman \& Scott Shapiro eds., 2002); Scott Shapiro, Law, Plans, and Practical Reason, 8 LEGAL THEORY 387 (2002). I take no view of the scope of my alternative approach to the morality of shared intention, which may or may not be confined to the special cases of promise and contract.

105. This typology follows the general approach taken in MEIR DAN-COHEN, RIGHTS, PERSONS, AND ORGANIZATIONS 83 (1986), and, for the particular case of contract law, Schwartz \& Scott, supra note 3, at 544 .
} 
different problems-morally and indeed conceptually-from contracts among individuals. The fact that the collaborative view does not straightforwardly reach contracts that involve organizations therefore does not represent a theoretical failure so much as the natural intellectual division of labor. These observations do not, of course, settle the questions whether there should be one law of contract or two, and if there should be only one, whether considerations relevant to individuals or to organizations should dominate. Although I do not seek to settle this question, I argue that contracts involving individuals properly occupy the center of our intuitive conception of contract, and I identify costs of allowing contracts that involve organizations to be governed by a legal regime that departs from the collaborative ideals that I am developing. These arguments remain inevitably incomplete, however, because they invest the collaborative ideal with a weight that remains asserted only, and not yet earned, and whose final justification must abide future work connecting collaboration to the mainstays of liberal political authority.

Organizations clearly cannot participate directly in the moral ideals by whose terms the collaborative view explains contractual obligations. The collaborative view describes the distinctive forms of respect and community that contracts engender, but these broader notions do not directly apply to organizations at all. Individual persons have reasons to respect and seek community with each other because individual persons' moral status commands that they be treated never merely as means but always as ends in themselves. Organizations, by contrast, have no comparable moral status, even when there are treated, artificially, as persons at law. Quite to the contrary, organizations should be treated precisely as mere means, and someone who treats an organization as an end in itself makes, at least presumptively, a moral error. Organizations are simply not the kinds of creatures to which the broader moral framework that supports the collaborative ideal directly applies, so that relations involving organizations-that is, between organizations or between organizations and individual persons - cannot directly participate in the value of contractual collaboration.

This much is straightforward. But it remains possible that contracts involving organizations might generate a morally valuable collaborative relation indirectly, in one of two ways: First, contracts involving organizations might engender collaboration among the individual persons who, as stakeholders in the organizations, stand behind the organizations and bear the consequences of their contractual activity; and second, contracts involving organizations might engender collaboration among the individual persons who, as the organizations' agents, front the organizations and contract on their behalves. I remain open to these possibilities and accept that my views here are preliminary only, so that contracts involving 
organizations may perhaps be brought within the collaborative framework by some argument I have not anticipated. But I am inclined nevertheless to reject both suggestions, and indeed for analogous reasons.

On the one hand, contractual promises made to organizations address only the organizations and not their agents or stakeholders. Such promises may be received by the organizations' agents and may inure to the benefits of the organizations' stakeholders, but this is not sufficient to make them promises in favor of the agents or stakeholders, who never become promisees themselves. The intentions in such promises make no reference to these individual persons but only to the organizations, so that a contractual promise made to an organization does not address the individual persons associated with the organization at all. A promisor in such a case simply does not adopt, through her promise, any intentions toward these associated persons, although the promise may of course affect these persons, and the promisor may carry previously existing intentions toward them (for example, intentions to benefit them) with her into the promise.

And, on the other hand, contractual promises that bind organizations also regard only the organizations and not their agents or stakeholders. Such promises may be triggered by the organizations' agents and may burden the organizations' stakeholders, but this is not sufficient to make the promises count against the agents or stakeholders, who never become promisors themselves. The intentions in such promises again make no reference to these individual persons (even if they are intentions of the individual persons who, as agents, actually speak the promises), but refer only to the organizations, so that a contractual promise made on behalf of an organization does not bind the individual persons associated with the organization at all. Nor do these persons adopt any intentions through the promise, although the promise may, of course, influence their intentions, not least because they may carry into the promise previously existing intentions that their organizations should keep their contracts.

One might say, therefore, that organizations are, as a general matter, freestanding with respect to the intentions and obligations in which the collaborative account of contract traffics. ${ }^{106}$ Promises that make reference to

106. Meir Dan-Cohen, writing in a related context, calls organizations impermeable and emphasizes that actions taken against organizations, even if they affect individual persons associated with the organizations, are not yet taken against these individual persons. DAN-COHEN, supra note 105 , at 35,64 . Dan-Cohen imagines cases in which intentionally injuring a corporation reduces its profits and harms its employees, and observes that while the harm to the employees may be foreseeable, it need not be intentional. See id. at 68 . This metaphor is vivid, to be sure, but it is perhaps also a little misleading. It suggests that organizations act as shields-or, as Dan-Cohen says, "buffers," id. at 69-that stand between those who act against organizations and the individual persons connected to the organizations, whom these actions affect. That is the wrong image, however, because the organizations do not so much stand in front of these individuals as beside them. Evidence for this is that any "shielding" presented by an organization may at once be overcome by a person who simply aims his intentions in another direction, namely 
organizations do not generally implicate the agents and stakeholders, out of whose actions they arise and to whose interests they inure, in any promissory relations of their own. This is not a hard and fast rule, to be sure, and some contractual promises that formally involve organizations only may in substance address the organizations' stakeholders or agents: When an organization is very small it may, within the relevant contractual practice, be understood as indistinguishable from its stakeholders, and even when an organization is larger, particular agents or stakeholders may become personally engaged in the organization's contracts, perhaps because of the intimacy or intensity of their involvement with the contractual practice in question. ${ }^{107}$ In such cases, an individual person becomes, in the context of a contractual relation, identified with an organization, and may therefore participate in the intentional relations that the contract involves. But these are by their nature unusual cases, and in the more typical circumstance organizational contracts will not draw individual persons associated with the organizations into any collaborative relations.

The collaborative account of contract therefore seems not to apply, either directly or indirectly, to contracts that involve organizations. ${ }^{108}$ Organizations cannot engage the values of respect and community that underwrite the collaborative ideal, and an organization's contracts draw neither its agents nor its stakeholders into collaboration. The theory of contractual obligation that I develop in these pages therefore does not, at least in any straightforward way, encompass contracts that involve organizations. This limitation does not, however, undermine the collaborative view's claim to capture the essence of contract or indeed its practical importance. To begin with, alternative approaches to contracts involving organizations succeed only on terms that reveal such agreements to be far removed from contract's conceptual core. And moreover, there may be good reason to assimilate contracts including organizations to the collaborative view in order to protect collaboration among individuals.

The collaborative view does not stand alone in failing to apply directly to contracts involving organizations. Rather, a similarly restricted scope applies quite generally to theories of contract that find the roots of contractual obligation in practical properties of the individual wills of contracting parties. Thus it is a familiar observation, for example, that theories that ground contractual obligation in the autonomy of the contracting parties-that understand contractual obligation as either

straight at the individual persons who are said to be shielded. A person who injures a corporation in order to harm its employees does intentionally harm them.

107. In observing these possibilities I do not, of course, take myself to be presenting a substantive account of when individual persons should be legally, or morally, bound by organizations' contracts.

108. Note that organizations may themselves present instances of contractual collaboration. A partnership, for example, certainly involves contractual collaboration among the partners. 
promoting or respecting this autonomy-cannot explain contract as it applies to organizations, and fail to do so for reasons that closely resemble the considerations that I have developed here. Meir Dan-Cohen, for example, concludes that the autonomy paradigm applies to contracts involving organizations only instrumentally and only in the narrow case in which the organizations in question serve the autonomy of individuals. ${ }^{109}$ And Alan Schwartz and Robert Scott, who develop a theory specifically of contract among organizations (and, in particular, economic firms) take the proposition that "the business firms that make commercial contracts are artificial persons whose autonomy the state need not respect on moral grounds" to be so straightforwardly obvious as to justify excluding the value of autonomy from the theory of contracts among organizations without further argument. ${ }^{110}$ As a result of these and related arguments, theories that explain contract in terms of the practical properties of individual persons' wills must quite generally leave space, in addressing contracts involving organizations, for economic and broadly utilitarian modes of analysis. Thus it seems natural for Schwartz and Scott to say, in setting the scene for their theory of contracts among organizations, that "[t]he contract law of commercial parties is about efficiency," so that "contract law should facilitate the ability of firms to maximize welfare [by which Schwartz and Scott mean contractual surplus] when making commercial contracts." "11

But although this economic approach is surely more naturally suited than the collaborative view to explaining business and exchange relations among organizations, the economic view of these arrangements turns out, on reflection, not to describe a practice of contract, properly speaking, at all. Even as the economic approach succeeds at analyzing organizational practices upon which the collaborative view has no immediate purchase, its successes reveal that the collaborative view's failures do not undermine its aspirations to present a theory of contract. The success of the economic analysis of business arrangements among organizations serves, rather, to reveal that the distinctive essence of contract lies where I have found it, in contracts among individual persons.

Schwartz and Scott's discussion of the underpinnings of their economic account of contracts among business organizations vividly illustrates these observations. In defending their view that contract law for economic firms should be designed single-mindedly to maximize contractual surplus, Schwartz and Scott introduce a series of further ideas-besides the claim that autonomy-based values do not apply to organizations- that emphasize

109. DAN-COHEN, supra note 105 , at 77.

110. Schwartz \& Scott, supra note 3, at 556.

111. Id. (emphasis omitted). 
the divergence between the business arrangements among economic firms that they take for their subject and contract's distinctive conceptual core. Specifically, although Schwartz and Scott do not deny that the law might, in some circumstances, properly be concerned not only with efficiency but also with justice, they reject the idea that this concern for justice, in either its corrective or distributive forms, should influence the law governing business arrangements among firms. Thus Schwartz and Scott observe, with respect to corrective justice, that firms' broad-ranging contractual engagements generally cause them to occupy both sides of contractual relationships, so that corrective-justice-inspired preferences for one side or the other (for buyers, say, or for licensees) will inevitably come out in the wash and will therefore be rejected by the firms themselves, who will never benefit from corrective principles that shift surplus around in particular contracts at the cost of reducing the overall surplus that is available. ${ }^{112}$ And Schwartz and Scott add, with respect to distributive justice, that because the individual persons who own firms will (and should) diversify their holdings, even legal rules that did prefer firms on one side of business transactions would have no distributive effects across owners. ${ }^{113}$ Diversified owners, as Schwartz and Scott point out, will own shares in both the firms that are benefited and those that are burdened by any particular legal rule. ${ }^{114}$ Such owners look to the total value of their portfolios and are indifferent to increases in the values of some of their holdings that come at the expense of decreases in the values of others. ${ }^{115}$ All these arguments come together to support Schwartz and Scott's "principal normative claim," which is, once again, that the law governing business transactions among firms should be arranged so as to maximize the total gains that such transactions produce. ${ }^{116}$

But even as these arguments make a case for Schwartz and Scott's approach to business transactions among firms, they reveal the distance that separates such transactions, as Schwartz and Scott conceive them, from contract's conceptual core. Specifically, Schwartz and Scott undermine every sense of the moral separateness or distinctness of the parties to the transactions that they analyze. They deny that firms have practical properties, such as autonomy, that might cast distinct firms as morally valuable in themselves. They deny that firms should be understood, by reference to principles of corrective justice, to have distinct moral entitlements to certain shares of the surplus created by the transactions that firms make. And they deny that the law governing transactions among firms

112. Id. at 555 .

113. Id. at 555-56.

114. Id.

115. Id.

116. Id. at 556 . 
should seek to serve any distinctive distributive entitlements of the firms' owners.

These observations, taken together, paint a picture of commercial transactions among business firms in which the only morally freestanding principal is the representative owner of a fully diversified portfolio of shares in all the firms that engage in the transactions Schwartz and Scott take as their subject. The firms themselves are mere instrumentalities that interact with each other on behalf of this common owner, who has a perfectly balanced share in both sides of every transaction. Schwartz and Scott's search for an efficient law of economic transactions among firms may naturally be understood as an effort to say what legal rules governing the conduct of such instrumentalities will maximize the total value of this representative owner's diversified portfolio.

Schwartz and Scott are engaged, therefore, in an exercise in transaction-cost economics, broadly viewed. Indeed, their arguments resonate directly with the Coasean theory of the firm. Coase observed that "a firm will tend to expand until the costs of organizing an extra transaction [by command and control] within the firm become equal to the costs of carrying out the same transaction by means of an exchange [a contract] on the open market." 117 The return to capital will therefore necessarily be reduced in light of the need to bear at least the smaller of these transaction costs, and Schwartz and Scott may be understood as asking what rules of law will minimize the transaction costs on the market side of the firm's boundary (with the consequence that the legal rules Schwartz and Scott identify will minimize the optimal size of the firm ${ }^{118}$ ).

Putting the argument into this frame casts the instrumental character of firms as Schwartz and Scott understand them into sharp relief: Firms should exist only insofar as they are less transaction-costly means than markets of putting capital to work, and they are therefore not just instruments, but undifferentiated instruments, which may be created, manipulated, and destroyed always in the service of a single, diversified owner. And this reveals, finally, the gap between Schwartz and Scott's chosen subject and contract's conceptual core: Contract, in its essence, involves two distinct, independent parties, but the transactions that Schwartz and Scott describe countenance just one.

Taken together, these arguments create the condition that I announced at the start of the discussion of contracts involving organizations and

117. RONALD COASE, The Nature of the Firm, in THE FIRM, THE MARKET, AND THE LAW 33, 44 (1988) (reprinting R.H. Coase, The Nature of the Firm, 4 ECONOMICA 386 (1937)).

118. Coase himself observed that policies that increase the cost of market transactions but not the cost of the same transactions within the firm will increase the optimal size of the firm. Id. at 41. Coase had in mind sales taxes and price controls, but inefficient legal rules governing market transactions among firms have the same effect. 
toward which I have been steadily working ever since. The collaborative view does not immediately apply to obligations generated by contracts involving organizations, including in particular economic firms. But alternative accounts of contracts between organizations, even as they succeed at explaining the obligations involved, cast these obligations in a light that reveals them to be enormously different from the obligations that the collaborative view seeks to explain, and indeed, at least from the perspective of the pretheoretical intuitions that motivated the collaborative view, not to be contractual, properly speaking, at all.

None of this means that the obiigations that organizations, including economic firms, assume when they make agreements are illusory or involve conceptual confusion. Nor does it deny that firms ought to be capable of obligating themselves and that inquiry into the legal rules governing such obligations-the inquiry Schwartz and Scott have taken on-presents an important and challenging subject. I claim only that the two subjectsagreements among individual persons on the one hand and agreements among organizations on the other-are sufficiently different that the collaborative view's failure to account for the second should not count against its explanation of the first.

These observations present a theoretically satisfying division of contract into structurally distinct and normatively distinctive species (although they do not underwrite any account of contracts that involve both individuals and organizations, which cannot be satisfactorily explained on either the collaborative or the economic view). But they do not yet present a practically satisfying account of contract law, which continues to operate, in large measure, at a generic level, without expressly distinguishing between individuals and organizations. This makes it natural to ask whether considerations relevant to individual persons or to organizations-to collaboration or to efficiency - should dominate contract law. Schwartz and Scott propose that contract law should focus on firms. They claim that the doctrines commonly identified with contract-in the common law of contracts and in the Uniform Commercial Code (UCC)-take agreements among firms as their principal subject, leaving contracts involving individuals to be governed by outlying doctrinal regimes, for example family law, consumer protection law, and employment law. ${ }^{119}$ Schwartz and Scott seek to encourage this approach by developing traditional contract law into a "law merchant for our time." 120

My view, however, is quite different. It seems to me that, as a descriptive matter, contracts among individual persons-governed by the doctrines of traditional contract law-play a fairly prominent role in many

119. Schwartz \& Scott, supra note 3, at 544.

120. Id. at 550 . 
individual persons' moral and legal lives. Individual persons, acting within the doctrinal categories that Schwartz and Scott associate with contract proper, commonly make contracts involving the purchase and sale of personal property (including, increasingly, over the Internet ${ }^{121}$ ) and of services in many forms, including childcare and elder care, day labor, and services associated with any number of trades and professions. ${ }^{122}$ Moreover, and prescriptively, these contracts all engender valuable collaborative relations among the individual persons who participate in them, and contract law should foster these relations and resist doctrinal developments that serve efficiency only at the cost of undermining contractual collaboration. Collaboration, as I contend in concluding this Article, and as I will expound more systematically in subsequent work, lies at the center of the distinctively liberal approach to sustaining social and political order, and it is therefore much too important a value to sacrifice in the service of efficiency. Contract law as it stands is therefore less focused on firms than Schwartz and Scott suggest, and contract law ought to be less dominated by considerations involving firms than Schwartz and Scott propose.

Contract law's primary purpose-which infuses not only the outlying doctrinal regimes to which Schwartz and Scott relegate contracts involving individuals, but also the center of the common law of contract-is not to encourage efficient agreements among firms but rather to sustain collaborative agreements among individual persons. A specialized law merchant of the sort Schwartz and Scott develop must be consistent with this primary purpose if it is to be justified, so that the boundaries of their project must shift in respect of an alternative conception of the core of traditional contract law. Whether a specialized law merchant may be rendered consistent with this conception of contract will depend upon a host of considerations, including both the degree of substantive divergence between collaboration- and efficiency-promoting legal rules and the difficulties introduced by hybrid contracts, which involve both individuals and organizations, and in which collaborative and other ideals may strain

121. For example, such contracts occur through eBay, which posted nearly fifteen billion dollars in sales in 2002. See About eBay: Company Overview, at http://pages.ebay.com/ community/aboutebay/overview/index.html (last visited Dec. 8, 2003).

122. How commonly these contracts involve collaboration depends, of course, on how readily the existence of an organizational form cuts off collaborative possibilities. I set this question aside in my earlier discussion of collaboration and contracts involving organizations, see supra note 107 and accompanying text, and I do not take it up fully here. I do insist, however, that contracts involving, say, a nanny, or an electrician, or a lawyer can engage collaborative values even though the nanny belongs to a small cooperative, the electrician has incorporated her business, or the lawyer has a partner or two. Indeed, Schwartz and Scott themselves exclude corporate entities with fewer than five employees from the class of firms to which they take their views of contract to apply. Schwartz \& Scott, supra note 3, at 545. 
against each other in any number of ways. ${ }^{123}$ Here it will also matter that even though contracts involving organizations cannot, strictly speaking, engender collaborative community, they will commonly share much of the morphology of collaboration: Even though organizations that contract through agents do not (strictly speaking) collaborate, their agents will nevertheless form a web of interlocking intentions that is practically identical to the intentions that true collaboration involves. This means that a contract law for organizations that violates collaborative norms will risk offending, or perhaps even undermining, collaborative ideals that individual persons carry with them from their individual contracting. This phenomenon, in which associated practices are regulated together, is familiar from other settings: Computer-generated child pornography, for example, offends our ideals of the sanctity of children even though no child is actually harmed and these ideals are not straightforwardly violated. Moreover, similar associations arise directly within contract law, as in the familiar fact that businesspeople feel personally implicated in contracts that they make as agents on behalf of organizational principals. ${ }^{124}$

A great deal will therefore depend upon the capacities of individual persons to resist any confusion that a distinctive law merchant introduces into their own contractual relations and to sustain collaborative intentions in the face of the offense that it evokes in them. But however these matters are resolved - and I do not seek to resolve them here-it should be clear that the importance of the collaborative approach to contract is not undermined by the fact that it does not immediately encompass contracts among organizations.

It has been the burden of this Part precisely to characterize contractual collaboration, to reveal that (in spite of presenting a paler prospect than full-blooded cooperation) contracts among individual persons participate in the Kantian ideal of moral community, and to argue that such arrangements among individual persons present the essence of contract. The thinness of

123. Collaboration- and efficiency-based doctrines may of course converge upon each other, and any such convergence will dampen any tensions that arise between my approach and Schwartz and Scott's.

124. This comes out, for example, in Stewart Macaulay's classic study of the behavior of businesspeople in and around contracts. Macaulay reports that "[b]usinessmen often prefer to rely on 'a man's word' in a brief letter, a handshake, or 'common honesty and decency"' over fully specified and formalized contractual forms. Stewart Macaulay, Non-Contractual Relations in Business: A Preliminary Study, 28 AM. SOC. REV. 55, 58 (1963). In spite of Macaulay's title, and his own association of contract with careful planning and active enforcement, see id. at 56 , these informal relations are palpably contractual in my collaborative sense. Collaboration, far from being undone by informality, in fact depends on some measure of informality and open-endedness in order not to descend into prepackaged coordination. See supra note 83 and accompanying text. 
the collaborative ideal will no doubt influence the part that the morality of contract plays in persons' all-things-considered practical deliberations. As I have already explained, ${ }^{125}$ the nature of the community that a particular type of promise establishes influences the character of the reasons that arise for making and keeping such promises. The nature of this community also, of course, influences the weight that such reasons carry when set against other moral or more broadly practical considerations. I have been exclusively concerned in these pages with demonstrating that, in spite of its pragmatic and self-interested context, contract constitutes a moral relation. I have not sought to say what role this relation plays in the broader scheme of moral and political justification. I shall, on another occasion, take up this question and argue that the thin, collaborative form of community that contract establishes plays an essential part in the larger liberal scheme of political and social legitimation. But I am content, for now, to elaborate upon the collaborative conception of contract in greater practical detail, by illustrating how it has been developed and expressed in the law.

\section{ILLUSTRATIONS AND ELABORATIONS}

I now attempt to connect the collaborative ideal that I developed in the last Part to the concrete law of contract as it is articulated by courts and legislatures, or at least to certain features of contract law. I do not seek to develop a general or complete account of contract law, preferring instead to proceed impressionistically, focusing on particular doctrines that have received substantial theoretical attention from others. I claim that the collaborative idea illuminates (and perhaps even resolves) several doctrinal puzzles that have remained intractable in the face of alternative theoretical approaches to contract. I present this discussion with two aims in mind: First, the references to specific doctrinal categories will make it possible to elaborate in greater detail what the collaborative view of contract involves; and second, the resonances between the collaborative ideal and the law's handling of specific doctrinal problems will render plausible the view that the theory of contract I am proposing is no mere academic conceit but is instead immanent in our actual legal practice.

The second of these claims leaves me deeply uncomfortable. I am certainly not saying that individual legal actors (judges and legislators) adopted the legal doctrines at issue in pursuit of the collaborative ideal that I now see in them. Nor am I proposing some causal or functional evolutionary account according to which collaborative rules are selected for

125. See supra Section I.C. 
in the process through which doctrine is made. ${ }^{126}$ I disavow these causally ambitious explanations because I have no evidence for believing them to be true, although I also have no evidence for thinking them false. But this disavowal leaves me in the awkward position of purporting to find a fundamental ideal at the root of a body of legal doctrine while offering no explanation as to how the ideal in question got there. I can offer no relief from this awkwardness except to say that insofar as my position is rendered more awkward still by the relative unfamiliarity of the collaborative ideal that I am expounding - so that the interpretation of legal doctrine that I am proposing appears to lack not only causal foundations but also a connection to our broader practices and institutions-I hope in future work to relieve some of the strain. I shall seek, in the future, to connect the collaborative ideal to the most fundamental ambitions of liberal social institutions and thereby to reassert the centrality of contract, understood in collaborative terms, within the liberal legal order. Insofar as I succeed at this task, it will not seem surprising that judges steeped in this legal order should adopt contract doctrines that express its core commitments.

Finally, I add one last methodological observation before commencing the first-order doctrinal analysis that fills out the remainder of this Part. In conducting that analysis, I focus my attention on self-consciously articulate statements of generally applicable legal rules, such as may be found in appellate opinions, the Restatement of Contracts, and the Uniform Commercial Code. In reviewing Grant Gilmore's The Death of Contract, Robert Gordon worried that such a doctrinal focus-raised, in Gilmore's case, to the level of near monomania by a self-confessed "complete[] uninterest[]" in sociological accounts of the practice of contract on the ground $^{127}$-might render legal analysis irrelevant to the actual workings of the law. ${ }^{128} \mathrm{My}$ argument shares in the high abstraction and narrowness of focus that Gilmore's displayed (and insofar as I have replaced Gilmore's history with philosophy, my argument may be more limited still in this regard). And Gordon surely was right to worry that this line of approach threatens to leave everything that is most important about the law somewhere off the page.

There is, however, another side of the question. As Gordon himself recognized, proponents of doctrinal legal scholarship may say that

126. I am not proposing any analogue to George Priest and Benjamin Klein's account of the evolution and efficiency of common law rules. See George L. Priest \& Benjamin Klein, The Selection of Disputes for Litigation, 13 J. LEGAL STUD. 1 (1984).

127. See Grant GILMORE, THE Death of ConTraCt 3 (1974) (stating, in reply to those who said that legal scholars "should engage in sociological analysis rather than in historical or philosophical synthesis," that he found himself "not so much in disagreement with their aims as completely uninterested in what they are doing").

128. See Robert Gordon, The Death of Contract, 1974 WIS. L. REV. 1216 (reviewing GILMORE, supra note 127). 
the process of contract case law adjudication is worth the closest attention because it is a microcosm of fundamental social principles. In this view appellate courts are given the heroic role of expressing the inarticulate purposes of the community, and, by tiny stages, developing the norms that will harmonize the combat of social purposes to the end of the greatest good. ${ }^{129}$

When it is purged of implications of heroic or farseeing agency on the part of judges, I become sympathetic to this view. I have this sympathy not because I believe that I can reconstruct processes by which appellate courts (and cognate institutions) discern and articulate the basic norms that I find in their doctrinal pronouncements; indeed I have just admitted that I cannot. But I do believe (although this itself may be an article of faith) that the public expression of such basic norms, and their embodiment in the law, are essential to sustaining any political and social order over time. Moreover, I observe the public expression through legal doctrines-including through the doctrines of the law of contracts - of basic norms that might sustain a stable social order and, simultaneously, observe the existence of the social order itself that might be so sustained. I am prepared to infer, from these observations, that the norms contribute to the social order, ${ }^{130}$ and I therefore conclude that connecting these norms to their doctrinal expressions presents an important task for legal scholarship.

With respect to the case of contract in particular, I believe that contract doctrines elaborate or give expression to an ideal of collaboration that is at once fragile and also fundamental to our social order. I shall explain the fragility and importance of collaboration in future work. This Article is devoted first to articulating the collaborative ideal and now, in this Part, to tracing its expression in the law.

129. Id. at 1228 .

130. Even accepting the background observations needed for making it respectable, this inference remains far from secure. It is always possible that those who participate in the practice of contract on the ground do not recognize the principles that I find in contract doctrine, not even as aspirational ideals. Alternatively, it is possible that these principles mask rather than display the true values at play in contract, perhaps even in the service of one class within the society as against another. In each of these cases, my faith in doctrinal reconstruction would be misplaced: In the former case, the principles that $I$ find in contract doctrine would be reduced to an anthropological curiosity; in the latter case, they would be unmasked as ideology.

I recognize these possibilities, of course, and do not purport to have settled any methodological debate in favor of the approach that I adopt. But I do find the observations in the main text sufficient to shift the burden of persuasion back onto those who reject the enterprise of doctrinal reconstruction. If doctrine does not matter, it is not because there is in general no connection between doctrine and what does matter, but rather because specific circumstances break this connection in particular cases. And it is up to those who would slight doctrine to trace the circumstances and identify the cases. 


\section{A. Consideration}

The modern doctrine of consideration is simply expressed by the Restatement (Second) of Contracts, which says:

(1) To constitute consideration, a performance or a return promise must be bargained for.

(2) A performance or return promise is bargained for if it is sought by the promisor in exchange for his promise and is given by the promisee in exchange for that promise. ${ }^{131}$

The application of the doctrine is anything but straightforward, however, and has generated a host of familiar controversies and puzzles. The collaborative theory of contract generates new insights into these difficulties, and in particular into the law's puzzling emphasis on the bargain context.

\section{The Conventional Wisdom}

The root cause of the many difficulties presented by the doctrine of consideration lies in the fact that the doctrine contains two basic propositions that are in tension with each other. ${ }^{132}$ First, the doctrine insists that the law will not enforce every promise or voluntarily assumed obligation, but only those that involve a bargained-for exchange-or, as Holmes put it, "reciprocal conventional inducement." law remains completely unconcerned about the terms of the bargain. The doctrine of consideration, one might say, insists on the fact of a bargain but takes no interest in the adequacy of the bargain. ${ }^{134}$

The tension between these two elements of the doctrine is immediate and indeed appears directly in the comments to the Restatement. Thus comment $\mathrm{c}$ to section 79 explains that "[o]rdinarily ... courts do not inquire into the adequacy of consideration" and adds that "[g]ross inadequacy of consideration may be relevant to issues of capacity, fraud, and the like, but the requirement of consideration is not a safeguard against imprudent and improvident contracts except in cases where it appears that there is no bargain in fact." ${ }^{\prime 135}$ Comment $d$, by contrast, at once presses in the opposite

131. RESTATEMENT, supra note $97, \S 71$.

132. This presentation follows FRIED, supra note $i$, at 29.

133. Oliver Wendell Holmes, JR., THE COMMON LAW 293-94 (Dover Publications, Inc. 1991) (1881).

134. The law does not even require the bargained-for consideration to motivate the promise in exchange for which it is received. See RESTATEMENT, supra note $97, \S 81$.

135. Id. § $79 \mathrm{cmt} . \mathrm{c}$. 
direction, in order to prevent the liberality expressed by comment $\mathrm{c}$ from rendering the requirement of consideration a nullity: "[D]isparity in value, with or without other circumstances, sometimes indicates that the purported consideration was not in fact bargained for but was a mere formality or pretense. Such a sham or 'nominal' consideration does not satisfy the requirement of [consideration]." ${ }^{136}$ In other words, in spite of the earlier comment's disavowal of inquiry into the adequacy of consideration, the "cases where it appears that there is no bargain in fact" 137 are not limited to circumstances involving force or fraud but may instead be identified directly by reference to the inadequacy of consideration.

The cases, predictably, apply these rules in both directions. On the one hand, it is not hard to find venerable opinions that say, for example, "It is the general rule that where there is no fraud, and a party gets all the consideration he contracts for, the contract will be upheld,", 138 and that "a rose, a hawk, or a peppercorn will suffice [for consideration] provided it is what is asked for by the promisor." 139 And, on the other hand, it is equally easy to find venerable opinions that say, for example, "The consideration was not only unequal, but grossly so. ... [and] at best, purely technical and colorable, and obviously... wanting in that degree of equitable equality sufficient to support the promise declared upon," 140 or that "[t]he parties may shout consideration to the housetops, yet, unless consideration is actually present, there is not a legally enforc[ea]ble contract."141

Now it is perhaps possible, on a purely formal and doctrinal level, to reconcile these rules and the cases that announce and apply them. One might say that the law does not require enforceable bargains to be fair, or even reasonable, but that it does require them at least to be real and to serve, for the parties, some purpose other than the parasitic one of satisfying the demands of the bargain requirement. As Corbin observed, "[W]hen the consideration is only a 'peppercorn' or a 'tomtit' or a worthless piece of paper, the requirement of consideration appear[s] . . to be as much of a mere formality as is a seal." 142 A seal standing alone is nowadays generally disfavored as a means of securing the legal enforcement of promises. ${ }^{143}$ It is

136. Id. cmt. d.

137. Id. $\mathrm{cmt}$. $\mathrm{c}$.

138. Wolford v. Powers, 85 Ind. 294, 296 (1882).

139. Lucky Calendar Co. v. Cohen, 117 A.2d 487, 495 (N.J. 1955) (internal quotation marks omitted). The opinion goes on to say that "[t]he law will not inquire as to the adequacy of consideration when the thing to be done is asked to be done, be it ever so small." Id.

140. T.P. Shepard \& Co. v. Rhodes, 7 R.I. 470, 475 (1863).

141. In re Greene, 45 F.2d 428, 430 (S.D.N.Y. 1930).

142. ARTHUR LINTON CORBIN, CORBIN ON CONTRACTS $\S 127$ (1952).

143. See U.C.C. $\$ 2-203$ (1997); RESTATEMENT, supra note 97 , ch. 4, topic 3 introductory note \& statutory note; 1 WALTER H.E. JAEGER, WILLISTON ON CONTRACTS $\S 219 \mathrm{~A}$ (3d ed. 1957); Robert Braucher, The Status of the Seal Today, PraC. LAW., May 1963, at 97. English law, by contrast, continues to recognize the seal. See G.H. TREITEL, THE LAW OF CONTRACT 120 (6th ed. 1983). 
natural to read the cases concerning consideration-insofar as they at once refuse to inquire into the adequacy of bargains and yet insist that bargains be real rather than artificial- - to develop the doctrine so as to prevent the parties from reinserting the seal into the law, now in the form of a bare assertion of consideration.

This approach may organize the cases, but it remains difficult to construct a satisfying theoretical defense of the insistence on the fact of a bargain, when coupled with unconcern for the bargain's character; and the reference to the seal merely pushes the problem back one level, since it is difficult to square the doctrine's indifference to the adequacy of consideration with its conclusion that a seal cannot stand in for the very consideration whose adequacy has been declared irrelevant. Fried, for one, attacks the consideration doctrine on precisely this ground. He thinks that, by refusing to police the adequacy of consideration, the law "affirms the liberal principle that the free arrangements of rational persons should be respected." 144 But he also thinks that when the law nevertheless insists that enforceable promises involve some consideration, when it "limit[s] the class of [enforceable] arrangements to bargains," then the law "holds that individual self-determination is not a sufficient ground of legal obligation." 145 Fried concludes that the consideration doctrine is deeply "internally inconsistent" and therefore indefensible. ${ }^{146}$

Fried's diagnosis of the internal tensions in the consideration doctrine represents the conventional wisdom, although not all those who discuss the doctrine share in his conclusion that it should be abandoned. To some, less concerned than Fried with purity of principle, the internal tensions in the consideration doctrine represent less of a failure. Indeed, beginning with Lon Fuller's classic article Consideration and Form, ${ }^{147}$ a large literature has developed increasingly sophisticated, if expansively heterogeneous and unabashedly pragmatic, arguments roughly in favor of the consideration doctrine's formal approach to the bargain requirement-its broad willingness to overlook inadequacies in the substance of bargains coupled with its emphatic demand that the bargains in fact exist.

Fuller inaugurated the approach by proposing three broadly instrumental purposes that the consideration doctrine's formal emphasis on bargains serve: First, bargains provide evidence of a contract that aids the legal process of enforcement; second, bargains caution those who make them of the commitments that they accept and in this way discourage rash and impulsive conduct; and third, the preference for bargains channels

144. FRIED, supra note 1 , at 35.

145. Id.

146. Id.

147. Lon L. Fuller, Consideration and Form, 41 COLUM. L. REV. 799 (1941). 
persons into a legal framework within which they can reliably effectuate their intentions. ${ }^{148}$

Those who follow in Fuller's footsteps have added variations to his basic themes. Some of these variations render the main argument in favor of the law's preference for bargains less certain: Where Fuller characterized gifts as economically "sterile," 149 for example, later commentators observe that enforcing unbargained-for promises might serve recognizably economic ends related to the fact that a promised performance becomes more valuable to the promisee as it becomes more certain. ${ }^{150}$ But other variations reinforce the argument: Melvin Eisenberg, for example, emphasizes that gift promises often contain implicit excuses for nonperformance (for example, a worsening of the promisor's economic position or ingratitude by the promisee) that the law cannot easily administer; ${ }^{151}$ Richard Posner observes that promisees often possess informal social means of enforcing gift promises that render legal enforcement superfluous and indeed undesirable; ${ }^{152}$ and Charles Goetz and Robert Scott add that legal enforcement of promises outside of the bargain context (and especially in the context of gift promises) will tend inefficiently to depress the supply of such promises. ${ }^{153}$

These and related arguments may, taken together, make a persuasive case for the proposition that not all promises should be enforced through law. But it is plain, even without addressing the several arguments' substantive merits, that such instrumental approaches to the doctrine of consideration cannot possibly account for the law's monotonous, strangely precise, and highly formal focus on reciprocal bargains as the touchstone of enforceability. For if bargains play only an instrumental role in the consideration doctrine, then it is natural to suppose that the doctrine's effectiveness would be enhanced if at least some other instruments were also admitted to the doctrine and allowed to serve alongside bargains in promoting the doctrine's ends.

Most immediately, the consideration doctrine's formal emphasis on the fact of a bargain cannot be defended on instrumental grounds: Any instrumental function that can be performed by a bargain regardless of its adequacy can surely aiso be performed by the parties' express insistence

148. See id. at 800-02. Fuller's ideas, and even his language, have achieved canonical status. See, e.g., RESTATEMENT, supra note $97, \S 75 \mathrm{cmt}$. a ("[T] he fact of bargain . . . tends to satisfy the cautionary and channelling functions of form.").

149. Fuller, supra note 147, at 815.

150. See, e.g., Goetz \& Scott, supra note 3, at 1278 n. 40.

151. See Melvin Eisenberg, Donative Promises, 47 U. CHI. L. REV. 1, 13-15 (1979).

152. See Richard A. Posner, Gratuitous Promises in Economics and Law, 6 J. LEGAL STUD. 411,417 (1977). Charles Goetz and Robert Scott make the same point. See Goetz \& Scott, supra note 3 , at 1304 .

153. See Goetz \& Scott, supra note 3, at 1304. 
(shouted to the housetops) that they have struck a bargain. If the adequacy of a bargain has no role in its instrumental effectiveness, then there is no reason to think that the mere fact of a bargain (however inadequate) is any more instrumentally effective than the express (even if nominal) insistence that this fact obtains. As Peter Benson remarks, "If the fundamental role of consideration is that it fulfills the functions of form, the fact that parties expressly treat something as a consideration for the shared reason of giving legal effect to their intentions should be sufficient or at least relevant" to enforceability at law. ${ }^{154}$ Indeed, several of those who follow Fuller's justification of the consideration doctrine nevertheless reject the doctrine's refusal to enforce promises that involve expressly asserted but ultimately nominal consideration, and lament the law's refusal to allow the parties to manufacture enforceability by asserting a bargain's existence or resorting to a seal. ${ }^{155}$ The functional theories of consideration can perhaps explain why not every promise should be enforceable at law and even why the bargain context is relevant to the question of enforceability, but they simply cannot (nor, finally, do they purport to) account for the consideration doctrine's formal yet insistent focus on the fact of bargains.

Fried found a paradox in the law's concern for the fact but not the adequacy of bargains, and on this basis rejected the doctrine of consideration altogether. The doctrine's instrumental defenders never address this paradox and instead argue that the doctrine, whatever its internal structure, achieves worthwhile external ends. The paradox, however, reasserts itself (as the argument of the previous paragraph reveals), because the law seems to insist on the fact of a bargain even where this fact has no possible instrumental or functional significance. The instrumental mode appears ill-suited to explaining a legal regime that is so narrowly yet insistently formal as the consideration doctrine.

\section{The Collaborative View}

A more direct explanation of the doctrine's narrow emphasis on the fact of a bargain would therefore surely be preferable. And indeed, the logical

154. Benson, supra note 1 , at 167.

155. As Goetz and Scott have observed,

At common law, the formal contract under seal provided a means for promisors to assure enforcement of gratuitous promises. A sham bargain performs a similar function in encouraging deliberation, preserving evidence, and identifying the promisor's intention. Although devices such as seals and sham bargains entail significant administrative costs, the voluntary use of these formal mechanisms suggests that the benefits to both parties of the additional reassurance from legal enforcement outweigh[] the transactions costs.

Goetz \& Scott, supra note 3, at 1303 (footnotes omitted); see also Posner, supra note 152, at 420 (calling the abolition of the seal a "mysterious development" and lamenting the tendency to reject parties' efforts to manufacture nominal consideration). 
space for such an alternative account remains open. All mystery and paradox surrounding the consideration doctrine would dissolve if the bargain form (quite apart from the fairness or adequacy of its substance) could be shown to be in itself valuable and, indeed, to display a distinctive connection to the values that underlie the morality of contract more generally. ${ }^{156}$

I aim to make precisely this showing, and the intrinsic value of the bargain form constitutes the centerpiece of the account of consideration that I propose. I have argued that the morality of contract derives from the value of the collaborative community that contracts engender. Through making and keeping contracts with each other, persons may cease to be strangers: Contracts establish relations in which persons do not just negatively refrain from using each other merely as means but also, and affirmatively, treat each other as ends in themselves. I now argue that the bargain form is intimately connected to the conception of collaboration that lies at the root of the morality of contract-indeed, that the bargain form is characteristic of collaborative relations - and that contract law is therefore right to emphasize this form. I present this defense of the consideration doctrine in three stages, which emphasize the three central features of the doctrine's administration. The first argues that the bargain form is sufficient to underwrite collaboration regardless of a bargain's substantive fairness. The second identifies a class of non-bargain-based voluntary obligations that do not underwrite collaborative relations and that the consideration doctrine, by insisting on bargains; therefore properly refuses to recognize. And the argument's third stage observes that some voluntary obligations may underwrite collaboration in spite of falling short of the technical requirements of the bargain form, and it interprets exceptions to the consideration doctrine's strict insistence on bargains, including courts' efforts to find consideration where none technically exists, as identifying these obligations.

The bargain form incorporates all the elements of collaboration upon which the morality of contract depends. Bargains are, as J.E. Penner says, "bilateral," which is to say that they involve "mutual decisions-that is,

156. It is worth noting here that although the express requirement of consideration is a distinctive feature of the common law of contract, other legal cultures also emphasize bargains and treat them specially, and may even display doctrinal counterparts to consideration. See, e.g., JoHn P. DAWSON, GifTS AND PROMISES: CONTINENTAL AND AMERICAN LAW COMPARED 199-207 (1980); Arthur T. von Mehren, Civil Law Analogues to Consideration: An Exercise in Comparative Analysis, 72 HARV. L. REV. 1009 (1959). Moreover, the recognition of the importance of bargains is no mere surface phenomenon, but is instead connected to the idea, at least as old as Aquinas, that promises establish an order of one person to another. See ST. THOMAS AQUINAS, ON LAW AND JUSTICE: EXCERPTS FROM SUMMA THEOLOGICA 1566-67 (Legal Classics Library spec. ed. 1988). Aquinas applied this idea in a broader context than the present one; rather than distinguish among subclasses of promises, he argued that all promises must be communicated to be binding. 
decisions made by more than one person-and they concern 'joint' projects or concerns of some kind where the parties each participate to some extent in whatever the agreement contemplates."157 Moreover, my earlier arguments make it possible to give this observation a more precise expression and to capture its moral importance. Bargains involve precisely the scheme of interlocking intentions-in which each party takes the other's intentions as authoritative for her own - on which the collaborative ideal at the heart of contract depends. Bargains are in their nature wanted by, and invoke the intentions of, all participants. Each party to a bargain expressly intends to give the other authority to require performance, and each party expressly intends to exercise the authority that she enjoys in this connection.

Indeed, the law adopts almost precisely this account of bargains, right down to the language of intention, saying, in the official comments to the Restatement, that the bargain requirement "means that the promisor must manifest an intention to induce the performance or return promise and to be induced by it, and that the promisee must manifest an intention to induce the making of the promise and to be induced by it." 158 Bargains therefore generate relations in which the bargainers engage each other, and subject themselves to each other's authority, in precisely the pattern that collaboration requires. Bargains also underwrite such collaborative relations simply by virtue of their formal structure, and regardless of their substantive fairness. Collaboration, as I have repeatedly emphasized, is a thinner notion than cooperation and allows persons to cease to be strangers without becoming allies or even intimates. Even competitors can collaborate, and even as they each seek to extract as much of the surplus generated by the collaboration as they can. The fact that one competitor is more successful in this effort than another, and that the resulting bargain might be thought substantively unfair, therefore does not undermine the bargain's collaborative character. The bargain form is sufficient for collaboration, and the consideration doctrine, attending to the intrinsic value of this form, properly places bargains at the core of contract. ${ }^{159}$

157. J.E. Penner, Voluntary Obligations and the Scope of the Law of Contract, 2 LEGAL THEORY 325, 329 (1996). Penner, I should add, fleshes this idea out in a manner very different from mine.

158. RESTATEMENT, supra note $97, \S 81 \mathrm{cmt}$. a. The Restatement adopts this collaborative account of bargains in express preference over alternative accounts that would require consideration to motivate a promisor or to be "the object of the promisor's desire." Id.

159. Carol Rose has also observed that bargains-or, as she says, exchanges-have an intrinsic value beyond their capacity to promote the self-interests of the persons who are party to them: " $[T]$ he just-plain, unsentimental rhetoric of exchange conceals something about how exchanges really work - their reliance on goodwill, and their potential to get the actors to think from other people's points of view." Carol M. Rose, Giving Some Back-A Reprise, 44 FLA. L. REV. 365, 377 (1992). Rose initially developed this view in Carol M. Rose, Giving, Trading, Thieving, and Trusting: How and Why Gifts Become Exchanges, and (More Importantly) Vice Versa, 44 FLA. L. REV. 295 (1992). For Rose, bargains are valuable because there is, as she says, 
The consideration doctrine's emphasis on bargains also serves to exclude certain noncollaborative classes of voluntary obligations from the realm of contract. That such voluntary obligations exist should not be surprising. Corbin, for example, observed that a "mutual, present and fully effective" exchange "creates no special right in one party by which to compel a subsequent performance by the other," and this led him to place such exchanges outside of contract. ${ }^{160}$ This exclusion appears natural, on my view, because such exchanges do not involve any forward-looking intentions in those who make them and certainly do not involve intentions to give others authority over future intentions. ${ }^{161}$ They therefore do not present examples of persons engaging one another or participating in the collaborative ideal that gives contract its moral value. ${ }^{162}$

Other forms of voluntary obligation also fail to underwrite collaborative relations, and the consideration doctrine, through its emphasis on bargains, takes aim at these also and properly excludes them from the class of legally enforceable contracts. ${ }^{163}$ Most straightforwardly, vows and resolutions-

\begin{abstract}
"an element of giving at the center of quite normal kinds of exchanges." Id. at 311 . This is because, Rose observes, the person who first performs her half of a bargain does so in the face of some uncertainty about whether her opposite number will reciprocate. $I d$. at 311-12. The first performance therefore takes on something of the quality of a gift, and the first performer displays a confidence, or trust, in her partner in the bargain. Id. at 313.

Although Rose and I agree that bargains are valuable, we give very different accounts of what values bargains involve. And although the two accounts do not contradict each otherbargains might display both forms of value-I am not sure that I find Rose's view persuasive. To begin with, it is possible (as I suspect Rose would acknowledge) to disrespect a person in spite of trusting her and indeed to disrespect a person through trusting her. This is, I take it, a plausible account of P.T. Barnum's attitude toward his exchange partners when he said that "there's a sucker born every minute." Rose's trust therefore does not signal a valuable relationship even when it is present. (By contrast, it is not possible to disrespect a person through collaborating with her, through treating her intentions as end-producing for oneself. Insofar as P.T. Barnum sought to please his customers, even he respected them.) Furthermore, as Rose straightforwardly admits, external enforcement mechanisms render bargains possible even without the trust that Rose describes. Id. at 314-15. And although Rose is surely right to point out that these mechanisms themselves require trust to get going, it is not clear how to relate this fact to the claim that exchanges within these mechanisms continue to incorporate trust. The genealogy of a practice may involve (and may even depend upon) a value that the practice itself no longer displays.
\end{abstract}

160. CoRBIN, supra note $142, \S 4$.

161. Present and fully effective exchanges resemble Bratman's "prepackaged" coordination. See supra note 83 and accompanying text.

162. Such presently effective exchanges are not, of course, devoid of all moral content, and the parties to them remain under a duty not to use each other merely as means. But this duty arises, as I have said, even among strangers. And the form of the presently effective exchange, because it is not forward-looking, involves no further engagement between the parties to treat each other as ends in themselves.

163. The modern doctrine, moreover, represents an improvement, in this respect, over an older version of the doctrine, which did not require a bargain or exchange but rather found consideration "either in some right, interest, profit, or benefit accruing to the one party, or some forbearance, detriment, loss, or responsibility given, suffered, or undertaken by the other." Hamer v. Sidway, 27 N.E. 256, 257 (N.Y. 1891) (internal quotation marks omitted). Grant Gilmore observes that the bargain theory of consideration is more restrictive than the older benefits/detriment view and that it became a "tool for narrowing the range of contractual liability." GILMORE, supra note 127 , at 21 . Gilmore also claims that the bargain theory originated, 
that is, obligations undertaken in the name of some ideal or in the obligor's own name, respectively-do not underwrite collaborative relations among persons. They may, to be sure, benefit persons, including perhaps by the obligations that they generate, as when one person makes a binding vow or resolution to perform some action that profits another. But even in these cases, vows and resolutions do not underwrite collaboration, because those who make them do not engage their beneficiaries and certainly do not subject themselves to the beneficiaries' authority. Whatever moral obligations vows and resolutions underwrite (and I express no opinion about whether vows and resolutions are morally effective in this way) arise in light of the obligors' relations to the ideals or to their own integrity, rather than in light of the obligors' relations to their beneficiaries. ${ }^{164}$ And because the moral foundations of contract law rest upon a collaborative relation in which vows and resolutions do not participate, the consideration doctrine correctly denies these practices legal recognition in contract. ${ }^{165}$

Moreover, nonbargain promises may similarly fail to underwrite collaborative relations and are also properly denied legal enforcement by the consideration doctrine, although these cases involve some additional complexities. Promises, to be sure, are different from vows and resolutions in that the obligations that they create are not just in favor of promisees but are also owed to promisees: Whereas a person who breaks a vow offends against the ideal in whose name the vow was made and a person who breaks a resolution offends against her own integrity, a person who breaks a promise wrongs her promisee. But promises are distinctive in a second way also. Promissory obligations are not only owed to promisees but are also, one might say, owned by them: Promisors subject themselves to their promisees' authority. Both elements of promise were necessary, in Parts I and II, for explaining the sense in which promisors come to treat their

without precedent, in Holmes's lecture, The Elements of Contract, and that Holmes was, "quite consciously, proposing revolutionary doctrine." $I a$ '. at 20. Gilmore's historical characterization of Holmes's engagement with the consideration doctrine has come under criticism. See, e.g., DAWSON, supra note 156, at 199-204; Richard E. Speidel, An Essay on the Reported Death and Continued Vitality of Contract, 27 STAN. L. REV. 1161, 1168-71 (1975).

164. Vows and resolutions might of course also generate harm-based obligations, insofar as persons reasonably rely on them. I do not comment on this tort-like approach except to observe its obvious distance from the collaborative account of contract that I am proposing.

165. The contrast between vows and resolutions on the one hand, and bargains on the other, invites characterization in terms of the theory of speech acts. See generally J.L. AUSTIN, HOW TO Do THINGS WITH WORDS ( $2 \mathrm{~d}$ ed. 1975). One may distinguish among three types of speech acts: locutionary acts, which involve simply the utterance of a sentence; illocutionary acts, in which a speaker does something by uttering a sentence; and perlocutionary acts, in which a speaker, by uttering a sentence, does something that involves bringing about appropriate effects in the hearer. The account in the main text illustrates that gratuitous vows and resolutions are illocutionary but not perlocutionary speech acts. See David H. Jones, Making and Keeping Promises, 76 ETHICS $287,289-90$ (1966). The argument in the main text also reveals what is less commonly understood-namely that bargain promises involve perlocutionary speech acts and that important elements of the morality of bargain promises turn on this fact. 
promisees as ends in themselves, the sense in which promises establish a form of respectful community.

These observations raise the problem of the passive promisee-the promisee who does not exercise her ownership of the promissory obligation, who remains disengaged from the promise and does not interfere in the promised performance, either to command or to release it. And because passive promisees do not participate in the promises owed them, it becomes uncertain how such promises might engender community between them and their promisors-how such promisees might exercise the authority over their promisors upon which the promise relation depends. When promisees remain passive, it becomes unclear how promisors can come to engage them and treat them as ends in themselves.

In personal promises, at least insofar as personal promisors are motivated to promote their promisees' interests, this benevolence may perhaps help underwrite the respectful relation upon which promissory morality depends. A promisee's interests may assert themselves even without the promisee's active participation-a personal promisor's benevolence may, as it were, stand in for the promisee's management of the promise. And a personal promisor's special efforts to serve these interests-for example, by adjusting her performance as her promisee's interests change-may support a distinctive engagement with her promisee, whose value justifies insulating promises from the overall balance of reasons as the role of obligation in promissory morality requires. ${ }^{166}$

But this approach to the problem of the passive promisee, whatever its appeal in the case of personal promises, is not available in connection with contract. Contractual promisors, as I have repeatedly observed, are characteristically concerned exclusively for their own, and not for their promisees', interests. Contractual promises therefore include no motives

166. I have not of course developed this idea in any detail, but I take the suggestion that committed benevolence may underwrite morally valuable relations, and so support obligations, to be uncontroversial as a generic matter. It is at play, for example, in friendship or romantic love, both of which generate relations whose moral value is closely connected to the unusual benevolence that they involve. Thus it is common, in both high theory and low practice, to develop the morality of these relations by reference to the forms of benevolence that arise within them. Aristotle, for example, proposed that a perfect friendship can arise only among "men who are good, and alike in virtue," so that a person engages his friends almost by analogy to his own self-love. ARISTOTLE, Nichomachean Ethics (W.D. Ross trans.), in THE BASIC WORKS OF ARISTOTLE 1094a, 1156b (Richard McKeon ed., Random House 1941). And the customary understanding of modern romantic love emphasizes the willingness of lovers to accept great self-sacrifice almost as the measure of their love's value. Moreover, it is common to conclude that friendships or loves that involve less benevolent motives do not constitute morally valuable relations, as in the Aristotelian accusation that a friendship is merely one of pleasure or utility, see $i d$. at $1156 \mathrm{~b}-1157 \mathrm{~b}$, or the contemporary accusation that a person is "using" her lover.

An effort to develop the morality of personal promises by reference to the benevolence that they involve would proceed along parallel lines, articulating the precise forms of benevolence at issue in such promises and identifying the false or depraved variations from which true personal promises must be distinguished. 
that might stand in for the promisees' active participation in the promises, because a contractual promisor's only engagement with the promisee is through the promisee's actual, active participation in the promise. The special relation whose value underlies the morality of contract therefore cannot possibly be constructed out of a contractual promisor's participation standing alone, but must instead look to the promisee's activities as well. The collaborative ideal that I developed in Section II.A reflects these features of contract--it entirely ignores questions of motive or benevolence and focuses exclusively on the collaborators' intentions. And because passive promisees contribute no intentions to the promise relation, they therefore render the collaborative engagement upon which the morality of contract depends impossible. ${ }^{167}$ Bargains, of course, are never passive: Each party to a bargain intends actively to insist on the performance it is due. The consideration doctrine, through its bargain requirement, therefore properly denies enforcement to contractual promises that involve passive promisees.

Taken together, these arguments reveal the considerable appeal of contract law's focus, through the consideration doctrine, on the bargain form. On the one hand, the bargain form can underwrite a collaborative relation without regard to a bargain's substantive fairness or adequacy, so that every obligation that the consideration doctrine renders enforceable may be brought within the collaborative view. On the other hand, the bargain form excludes from legal enforcement a range of obligationsincluding vows, resolutions, and promises to passive promisees - that do not underwrite collaborative relations and cannot be brought within the collaborative view. The consideration doctrine, and in particular the doctrine's formal emphasis on bargains, therefore serves as a useful

167. It might be thought that the doctrines requiring contractual promises to be accepted before they become legally binding are sufficient to ensure that contracts involve truly collaborative relations and to exclude cases involving passive promisees from legal enforcement. Fried, for example, observes that "[a] promise is relational" and connects this observation to the doctrinal requirement of acceptance. See FRIED, supra note 1, at 40-43. But although a promisee's acceptance may establish some relationship with her promisor, it is insufficient to establish the collaborative relation upon whose value contractual obligation depends. Collaboration requires that promisees contribute to the interlocking web of intentions that I described in Section II.A, and therefore that promisees adopt a forward-looking and responsive engagement with the collaborative activity. Acceptance standing alone involves no such engagement-a person may accept a promise as she would a donation - and it is therefore insufficient for collaboration or for contract.

Moreover, even as acceptance is not sufficient for generating the special relation whose value underwrites contractual obligation, it may not be necessary for generating the special relation whose value underwrites the obligations involved in benevolent personal promises. The brief and, of course, preliminary account of the personal promise relation that I have sketched interstitially in these pages makes no mention of acceptance. And the view that personal promises may obligate without being accepted (which must of course be distinguished from the very different view that they may obligate even if rejected) is far from unprecedented. It is entailed, for example, by David H. Jones's view that promises are illocutionary but not perlocutionary speech acts. See Jones, supra note 165, at 289-90. 
touchstone for identifying obligations to which the collaborative view of contract applies.

The bargain form is not, however, a perfect proxy for the collaborative relations that justify enforcing promises at law. In particular, some promises give rise to collaborative relations, and therefore merit legal enforcement, even though they do not quite satisfy the technical requirements of the bargain form. The consideration doctrine, read literally, is therefore somewhat too restrictive from the collaborative point of view. And indeed, exceptions to the doctrine and familiar efforts, undertaken in connection with administering the doctrine, to manufacture consideration may profitably be understood to remedy this defect by granting legal recognition to promises that, while technically lacking consideration, nevertheless manifestly underwrite collaborative relations.

These efforts to correct for the consideration doctrine's inadequacies as a test of collaboration appear in a range of factual settings, and I shall briefly identify three in particular. ${ }^{168}$ First, they arise in circumstances in which the reality of contractual collaboration is apparent from the conduct of the parties but the technical requirements of bargain-based consideration are not quite satisfied. Courts might, for example, read a best-efforts term into an exclusive dealings contract between a fashion designer and a sales agent when the designer seeks to invalidate the contract for lack of consideration by claiming that the agent, even though he has been actively representing her, never undertook an express obligation to expend any efforts on her behalf. ${ }^{169}$ And courts might read a reasonable quantity term

168. A fourth possible line of argument involves the reliance claims countenanced under section 90 of the Restatement. Section 90 ("Promise Reasonably Inducing Action or Forbearance") is commonly viewed as hostile to the consideration doctrine. Grant Gilmore, analogizing to antimatter in physics, even went to far as to call it "anti-contract." GILMORE, supra note 127 , at 68 . But section 90 may perhaps be brought within the approach to consideration that 1 am proposing, which treats the bargain requirement as a proxy for collaboration and then interprets the doctrines that have arisen around the requirement as correctives for the imperfectness of the proxy. Section 90 reliance may be understood, along these lines, as an effort to identify and enforce noncontractual collaborative arrangements.

I do not try to develop this speculative suggestion here. To do so would require elaborating a theoretical account of noncontractual collaboration and reconstructing the cases to reveal that courts apply section 90 reliance to select for legal enforcement of precisely those noncontractual arrangements that are collaborative in this way. I do not, as I say, try to execute these tasks here, except to observe two points. First, a watershed in the argument will be whether collaborative activity is possible without the intentions not to be the first to defect that lie at the center of promises. Second, this question receives a doctrinal expression in the debate over whether only a complete promise may underwrite a section 90 claim, or whether a simple offer may, in the right circumstances, do so as well-a debate that resonates with the cases, including most notably with the dispute between Learned Hand and Roger Traynor. Compare James Baird Co. v. Gimbel Bros., 64 F.2d 344 (2d Cir. 1933) (Hand, J.), with Drennan v. Star Paving Co., 333 P.2d 757 (Cal. 1958) (Traynor, J.).

169. See Wood v. Lucy, Lady Duff-Gordon, 118 N.E. 214,214 (N.Y. 1917). As then-Judge Cardozo observed, although the formal requirements of consideration were not satisfied, the whole arrangement was "instinct with an obligation." Id. (internal quotation marks omitted); see also U.C.C. $\$ 2-306(2)$ (1997) ("A lawful agreement by either the seller or the buyer for 
into a requirements contract that the seller seeks to avoid for lack of consideration by claiming that her buyer, even though he has been placing and paying for orders, never undertook an express obligation to purchase any quantity at all. ${ }^{170}$ Courts in these cases observe collaboration among the parties to agreements whose express terms do not quite satisfy the bargain requirement, and they supplement the terms to manufacture consideration and enforce the agreements, just as the collaborative view recommends.

Second, and relatedly, the law no longer attends to technical defects in consideration in connection with modifications of already collaborative contractual arrangements. Thus, the UCC abandons and the Restatement retreats from the preexisting duty rule, and the law no longer insists upon independent consideration to support contractual modifications. ${ }^{171}$ This is also as the collaborative view recommends. It should be sufficient for enforceabililty that postmodification contracts retain their bargain form-that is, that these contracts would involve good consideration had they been the initial arrangement between the parties-because this ensures that the parties continue to collaborate. There is no reason to insist that the process of contract modification be itself independently collaborative.

And third, an approach to consideration that supplements the basic doctrinal emphasis on bargains with additional corrective rules, tailored to circumstances in which the connection between the bargain form and collaboration breaks down, supports an appealing reconstruction of the legal treatment of gratuitous, or donative, promises. ${ }^{172}$ The law of contract, applying the consideration doctrine, is famously suspicious of donative promises. This suspicion is justified, on the collaborative view, because donative promises are unusually likely to involve passive promisees and so to fail to engender collaborative relations: The paradigm case of the donative promise, after all, involves a promisee who simply waits for the

exclusive dealing in the kind of goods concerned imposes unless otherwise agreed an obligation by the seller to use best efforts to supply the goods and by the buyer to use best efforts to promote their sale.").

170. See E. Air Lines v. Gulf Oil, 415 F. Supp. 429, 435 (S.D. Fla. 1975); see also U.C.C. $\$ 2-306(1)$ ("A term which measures the quantity by the output of the seller or the requirements of the buyer means such actual output or requirements as may occur in good faith, except that no quantity unreasonably disproportionate to any stated estimate or in the absence of a stated estimate to any normal or otherwise comparable prior output or requirements may be tendered or demanded.").

171. See U.C.C. § 2-209; RESTATEMENT, supra note 97, §89. For a canonical statement of the old rule, see, for example, Alaska Packers' Ass' $n$ v. Domenico, 117 F. 99, 102 (9th Cir. 1902). The court there held that "[c]onsent to [the contract modification] ... was, in our opinion, without consideration, for the reason that it was based solely upon the libelants' agreement to render the exact services, and none other, that they were already under contract to render." Id.

172. The argument is admittedly more tenuous in this instance, and the decisions are perhaps more uncertain. 
promisor unilaterally to make her gift, and therefore presents no target for the promisor to engage as collaboration requires. ${ }^{173}$

At the same time, not all gratuitous promises involve promisees who are passive in this way. A promise is gratuitous insofar as it is not motivated by the return performance that a promisor expects to receive from her promisee. But as the Restatement's own indifference to motive reveals, a return performance need not motivate a promise in order for a promisor to intend to induce it and be induced by it. ${ }^{174}$ Donative promises, in other words, do not conceptually require passive promisees. Moreover, donative promisees may be active in this way even though the reciprocal inducement does not appear on the face of the donative promise, which does not expressly take on the bargain form. The collaborative view counsels respecting such promises in spite of their literal lack of a bargain, and courts have in fact intervened to recognize the claims of such active donative promisees, by recasting the active engagement with their promisors in a form that satisfies the consideration requirement. For example, where a benefactor and a college had been collaborating to improve the college's financial health and educational status, a court read a practice of commemorating large donors by attaching their names to college buildings or projects into the terms of a gift, in order to find consideration for the gift promise and render it enforceable. ${ }^{175}$ Once again, where

173. Donative promises made with benevolent motives may, as the earlier discussion of benevolent personal promises revealed, possibly underwrite collaboration even when promisees remain passive. See supra note 166 and accompanying text. Because the law declines to inquire into a promisor's motives, this possibility will not generally support the enforcement of donative promises. The two exceptions to this rule involve donative promises made to charitable organizations and those made as part of marriage settlements, which are, at least under the Restatement, held enforceable even without consideration. See RESTATEMENT, supra note 97, $\S 90(2)$ ("A charitable subscription or a marriage settlement is binding under Subsection (1) without proof that the promise induced action or forbearance."). This exceptional doctrinerendered more exceptional still by the fact that although it appears under the heading of section 90 reliance it expressly requires no reliance itself-may, under the collaborative view, be brought within the law's broader structure by reading into the rule a presumption (ideological and absurd, perhaps, but not surprising) that promises to charities and promises in marriage settlements are benevolently motivated, so that they can sustain collaborative relations even apart from the bargain form.

174. See supra note 158 and accompanying text.

175. See Allegheny Coll. v. Nat'l Chautauqua County Bank, 159 N.E. 173 (N.Y. 1927). The subtlety of the distinction between active and passive donative promises is illustrated by the famous case of Williston's tramp, who is told by a benevolent passerby that if he walks to the clothing shop around the corner he may select an overcoat on his benefactor's credit. See 1 JAEGER, supra note $143, \S 112$.

Is the tramp an active or a passive promisee? The answer depends upon the parties' intentional stances toward the tramp's walk to the clothing store. If the promisor intends the promise to induce the walk and intends for the walk to induce him to provide the coat, and if the tramp intends the walk to induce the provision of the coat and intends the promise of the coat to induce his walking to the store, then the arrangement is collaborative even though, because the tramp has not expressly promised to walk to the store, it does not display the bargain form. If, on the other hand, the promisor is merely offering to buy the tramp a coat but not to get it for him, and the tramp is merely deciding whether or not to collect on the offer, then the tramp is a passive 
collaboration arises apart from the bargain form, the consideration doctrine may be flexibly applied to vindicate the collaborative relation.

The collaborative theory of contract therefore explains both the consideration doctrine's central bargain-based rule and the law's several tendencies to manipulate and depart from this rule. Bargains-simply in virtue of their form and quite apart from their substantive fairness or adequacy-present an excellent proxy for collaboration, and the law of contract, which finds its roots in the moral value of the collaborative relation, is therefore justified in adopting the consideration doctrine and emphasizing the bargain form. But bargains are not a perfect proxy for collaboration, and the law therefore justifiably departs from the letter of consideration doctrine in order to support collaborative arrangements that, for one reason or another, do not quite fit the bargain form.

\section{B. Expectation Damages}

When a promisor breaches a contract, expectation damages present the principal remedy that the law offers to the disappointed promisee. ${ }^{176} \mathrm{He}$ is to be put in a position just as good as the one he would have occupied had the promisor performed as the contract required-no worse, but also no better. ${ }^{177}$ Explaining this legal regime has been one of the preoccupations of contract theory for nearly a century. ${ }^{178}$ The collaborative view of contract provides a new defense of the expectation remedy, which improves upon existing arguments in several important ways. ${ }^{179}$

promisee and the arrangement involves no collaboration. Both possibilities are, incidentally, quite realistic. In the first, the passerby and the tramp intend to clothe the tramp together; in the second, the passerby intends to enable the tramp to clothe himself. A court adjudicating the tramp's contractual claim to the coat may find consideration or not, depending on its view of the facts.

Williston himself did not of course think or write in terms of collaboration, and his own view of the case was simply that it involved no consideration because "the walk was not requested as the price of the promise, but was merely a condition of a gratuitous promise." Id. This approach seems to me to elide the central distinction in the case, namely whether the tramp's walk to the store was a condition of the promisor's intent to provide the coat or a condition of possessing a coat that the promisor unconditionally intended to make available-whether, as it were, the walk functioned as a condition outside or inside the promisor's donative intention. This subtle difference is critical to contract law, because it is the difference between an intention to collaborate with the tramp and an intention merely to benefit him.

176. See generally RESTATEMENT, supra note $97, \S \S 344,347$.

177. See generally id. $\S 344$ (defining the expectation interest of a promisee as "having the benefit of his bargain by being put in as good a position as he would have been in had the contract been performed").

178. This question was first raised to prominence by Lon Fuller and William Perdue in their classic multipart article The Reliance Interest in Contract Damages. Fuller \& Perdue, supra note 56

179. It is worth observing at the outset, if only to forestall misunderstanding, that the legal enforcement of contracts does not undermine the collaborative value of the contract relation. The thinness of the collaborative conception of respect-the fact that collaboration may arise among persons motivated exclusively by their own interests--renders collaboration consistent with enforcing contractual agreements at law. Collaboration is perhaps different, in this respect, from 


\section{The Conventional Wisdom}

One common approach to these matters defends the law's conspicuous attachment to expectation damages in economic terms. Although working out the details of the economic analysis of contract damages has proved both intricate and challenging, the essential idea behind this analysis is straightforward enough. Expectation damages induce both promisors and promisees to make a wide range of choices more efficiently than they would under alternative damage rules. ${ }^{180}$ Accordingly, expectation damages tend to increase the joint value that the bargain offers to the promisor and the promisee combined. This is thought to be a strong argument in favor of expectation damages, both because of the intrinsic attraction of maximizing total value and, relatedly, because the promisor and promisee, approaching their bargain from the ex ante point of view, have reason to want regulatory rules that maximize the total surplus available for them to divide.

The connection between expectation damages and efficiency is not, however, quite perfect. For example, expectation damages, even in conjunction with a mitigation principle, can induce inefficient overreliance. ${ }^{181}$ In addition, in markets in which a promisee's expectation and her reliance costs (including the costs of her foregone opportunities) come apart, expectation damages may induce promisors to take inefficient levels of care in deciding whether or not to contract. ${ }^{182}$ These examples may be multiplied, ${ }^{183}$ and this should come as no surprise. Contract remedies

richer, more cooperative forms of community-for example, the forms of community that arise in connection with personal promises among benevolently motivated intimates-which may be destroyed when their terms are enforced.

180. The first systematic statement of the efficiency of expectation damages to appear in the legal literature was Robert L. Birmingham, Breach of Contract, Damage Measures, and Economic Efficiency, 24 RUTGERS L. REV. 273 (1970). Two excellent and quite broad economic analyses of the expectation remedy appear in Richard Craswell, Contract Remedies, Renegotiation, and the Theory of Efficient Breach, 61 S. CAL. L. REV. 629 (1988); and Lewis A. Komhauser, An Introduction to the Economic Analysis of Contract Remedies, 57 U. COLO. L. REV. 683 (1986).

181. See Steven Shavell, Damage Measures for Breach of Contract, 11 BELL J. ECON. 466, 472 (1980). Aaron Edlin and Alan Schwartz observe that efficient investment can be secured by a price structure that combines the investment and breach decisions in the same party, and that such pricing can lead to overcompensatory remedies. See Aaron S. Edlin, Cadillac Contracts and Up-Front Payments: Efficient Investment Under Expectation Damages, 12 J.L. ECON. \& ORG. 98, 104-11 (1996); Aaron S. Edlin \& Alan Schwartz, Optimal Penalties in Contracts, 78 CHI.-KENT L. REV. 33, 44-52 (2003).

182. See Richard Craswell, Precontractual Investigation as an Optimal Precaution Problem, 17 J. LEGAL STUD. 401 (1988).

183. See, e.g., A. Mitchell Polinsky, Risk Sharing Through Breach of Contract Remedies, 12 J. LEGAL STUD. 427 (1983) (arguing that when both parties to contracts are risk-averse, efficiency requires a remedy somewhat below expectation damages); A. Mitchell Polinsky \& Steven Shavell, Punitive Damages: An Economic Analysis, 111 HARV. L. REV. 869, 936-38 (1998) (claiming that when meritorious plaintiffs are less than certain to recover, the efficient remedy may exceed expectation damages). This expanded list remains, needless to say, far from exhaustive. 
influence contractual behavior in so many intricate and often countervailing ways that no perfect connection between efficiency and expectation damages may reasonably be expected. Moreover, the functional character of the economic approach to law denies the formal category expectation damages any independent role in the analysis of contract remedies. This means, as Richard Craswell has observed, that even if, on some particular set of facts, efficiency analysis happens to recommend the expectation remedy, this will be a coincidence only, and the formal category "will not have played any role in the analysis leading up to that conclusion." 184 Economic argument therefore does not present a complete defense of the expectation remedy.

Furthermore, economic efficiency is not the only consideration relevant to evaluating the expectation remedy, so that even a more perfect connection between efficiency and expectation damages would not conclusively justify the remedy. The reason, simply, is that in addition to influencing the total value of a bargain, damage measures determine the distribution of this value as between the parties in the event of a breach. It is not difficult to imagine circumstances in which the distribution imposed by the expectation remedy appears, at least at first blush, unduly to favor either promisors or promisees.

To illustrate the first, promisor-favoring circumstance, imagine that a promisor-seller and promisee-buyer contract for the sale of some good and that, a moment later, an alternative buyer who values the good more highly than the initial buyer appears and presents the possibility of a further gain. Under the expectation damages regime, this gain goes to the seller, who may satisfy the first buyer's original expectations and resell the good to the second buyer at a price that includes as much of the second buyer's additional valuation as the seller's bargaining power allows her to capture. The seller may proceed in this way, moreover, in spite of the fact that she has contracted to deliver the good to the first buyer. This reveals, as is commonly observed, ${ }^{185}$ that the expectation remedy renders contract law less solicitous of promisees than tort law is of owners - there is no general tort doctrine of efficient conversion analogous to the contract doctrine of efficient breach. ${ }^{186}$ Together, these observations suggest that, at least in

184. Richard Craswell, Against Fuller and Perdue, 67 U. CHI. L. REV. 99, 107 (2000).

185. See, e.g., DOUGLAS LAYCOCK, THE DEATH OF THE IRREPARABLE INJURY RULE 245-64 (1991); Daniel Friedmann, The Efficient Breach Fallacy, 18 J. LEGAL STUD. 1 (1989).

186. This broad statement masks significant doctrinal complexities in the law of restitution as it arises in connection with torts. The usual cases involve defendants who interfere with plaintiffs' property rights under circumstances in which the benefit to the defendant exceeds the cost to the plaintiff. The general rule is that if a defendant's interference is justified or merely negligent, the plaintiff's recovery is capped by her loss, but that if the defendant's conduct is consciously or intentionally tortious, the plaintiff may recover the defendant's larger gain. Compare, e.g., Vincent v. Lake Erie Transp. Co., 124 N.W. 221 (Minn. 1910) (holding that where the defendant damaged the plaintiff's dock while trespassing to save his boat in a storm, the plaintiff should 
some cases, expectation damages are inadequate to the demands of fairness in the contract setting: Fairness, it may seem, requires the promisor to restore to her promisee the benefit that she has extracted from a performance to which the promisee was entitled. Fairness requires restitution. ${ }^{187}$

To illustrate the second, promisee-friendly circumstance, imagine that a promisor-seller and promisee-buyer agree on terms-say, a below-market purchase price-that are exceptionally favorable to the buyer, and that the seller breaches almost at once, or at least before the buyer has incurred any costs in reliance on the contract. ${ }^{188}$ Expectation damages give buyers in

recover the cost of repairs to the dock and not the larger value of the defendant's saved boat), with Olwell v. Nye \& Nissen Co., 173 P.2d 652 (Wash. 1946) (holding that where the defendant knowingly used the plaintiff's egg-washing machine without permission, the plaintiff should recover the labor costs the defendant saved by using the machine). The efficient breaches whose benefits the expectation remedy allows defendants to retain are, of course, typically intentional.

187. This reference to "restitution" involves something of a nonstandard usage-or, more precisely, picks out a nonstandard case of restitution. Restitution is most commonly claimed in cases in which a promisee seeks to recover something he has transferred to a promisor in connection with a contract that the promisor then breached. In a typical example, a promisee who has rendered part payment for a performance that is never provided seeks to recover his payment in restitution.

In such typical cases, the promisee's restitution damages will be smaller than his expectation and indeed even than his reliance damages-as the Restatement observes, "Although it may be equal to the expectation or reliance interest, [the restitution interest] is ordinarily smaller because it includes neither the injured party's lost profit nor that part of his expenditures in reliance that resulted in no benefit to the other party." RESTATEMENT, supra note $97, \S 344 \mathrm{cmt}$. a. A promisee will typically seek restitution, therefore, only when there is some special reason to do so, for example in order to recover some unique good that the promisee has transferred to the breaching promisor or in the unusual case in which a promisor breaches a contract that has a negative expectation for the promisee. Restitution displays this humble character in ordinary cases because the restitution remedy does not focus directly on the injured promisee but rather seeks "to put the party in breach back in the position that party would have been in if the contract had not been made." FARNSWORTH, supra note $103, \S 12.19$.

But the humility of restitution (and the survival of the expectation regime and its doctrine of efficient breach) depends critically on the assumption that the promisor who commits an efficient breach cannot be said to have taken something - the promised performance-from the promisee and benefited from it in a manner that makes disgorgement necessary. As Farnsworth observes, courts have refused to allow recovery in restitution in such cases, that is,

when the injured party seeks to require the party in breach to disgorge gain that has resulted not from the injured party's performance but rather from the other party's breach. ... as where a seller breaks a contract and sells the goods to a third person for more than the contract price.

Id. $\S 12.20$ (emphasis omitted).

The intuition in the main text asks how this limit on restitution, which Farnsworth identifies as an "exception" to the general structure of restitution, $i d$., can be justified. A defense of the expectation remedy must address this intuition. The defense that I offer does so by explaining that the cases in which restitution for the gains produced by an efficient breach should be allowed are precisely those in which these gains can also be recharacterized as falling within the promisee's expectation.

188. Here it is crucial that the buyer has not incurred even opportunity costs, most likely in the form of passing over offers by other sellers. This condition, which is reflected in the main text's reference to a below-market price, will rarely be satisfied in commercial settings, especially where there are competitive markets (because buyers in such markets face many sellers, the second-best of which will be only marginally less attractive than the best). Such thoughts led 
such cases the full benefits of their bargains, and it may seem that such purely executory promises, unconnected to any detrimental reliance, are simply too insubstantial to support this result ${ }^{189}$ - that buyers in such cases are getting more than they deserve. ${ }^{190}$ Whereas the first set of cases casts expectation damages as allowing promisors to profit unfairly from something that is no longer theirs, the second set casts expectation damages as unreasonably giving promisees something for nothing. ${ }^{191}$ Each of these two observations connects intuitively to arguments for abandoning

Fuller and Perdue, who thought expectation damages too solicitous of promisees, to be least skeptical of expectation damages in commercial contexts, roughly because the pervasiveness of opportunity costs in such contexts allows expectation to be recharacterized as reliance. Fuller \& Perdue, supra note 56, at 62 . Anthony Kronman presents a similar argument. See Anthony T. Kronman, A New Champion for the Will Theory, 91 YALE L.J. 404, 409 (1981).

Nevertheless, commercial instances of the case imagined in the main text do arise. A particularly dramatic example supplied the backdrop to the famous lawsuit between Texaco and Pennzoil. See Texaco, Inc. v. Pennzoil, Co., 729 S.W.2d 768 (Tex. Ct. App. 1987). The stylized facts were these: Getty Oil sold itself to Pennzoil for $\$ 3.5$ billion in spite of holding net assets (in the form of proven oil reserves) worth $\$ 11$ billion. Forty-eight hours later, it breached the contract and resold itself to Texaco for a much higher price. Pennzoil sued claiming its expectation under the contract (technically, Pennzoil sued Texaco on a theory of tortious interference with the contract). A jury found for Pennzoil and, in spite of the fact that Pennzoil had suffered no losses whatsoever as a result of the breach, awarded $\$ 7.53$ billion in expectation damages.

Plaintiffs who sue on exaggerated warranties present more commonplace examples of efforts to enforce contractual relations unbacked by reliance. These cases typically arise when sellers make commercially unrealistic claims for their products and disappointed buyers sue to enforce promissory expectations based on these claims. Such expectations are unbacked by any reliance (including by any lost opportunities) because the exaggerated character of the sellers' promises render them much more valuable to the buyers than any alternatives that were available. Buyers sometimes win such cases, as in Chatlos Systems, Inc. v. National Cash Register Corp., 670 F.2d 1304 (3d Cir. 1982), in which a seller incorrectly warranted that a $\$ 50,000$ computer system would perform tasks that no commercially available system priced below $\$ 250,000$ could perform, and the disappointed buyer recovered $\$ 200,000$ in expectation damages unbacked by reliance. Buyers also sometimes lose such cases, as in Overstreet v. Norden Laboratories, Inc., 669 F.2d 1286 (6th Cir. 1982), in which a seller incorrectly warranted that a vaccine would protect horses from a disease and the disappointed buyer was (over vigorous dissent) denied recovery for horses lost to the disease on the ground that because no other vaccine existed, the buyer's horses were not lost in reliance on the warranty.

The argument to come proposes that Texaco and Chatlos were rightly decided and that Overstreet was not.

189. As Fuller and Perdue put it, in enforcing the expectation remedy apart from reliance losses, "[t]he law no longer seeks merely to heal a disturbed status quo, but to bring into being a new situation. It ceases to act defensively or restoratively, and assumes a more active role. With the transition, the justification for legal relief loses its self-evident quality." Fuller \& Perdue, supra note 56 , at 56-57.

190. This last formulation reveals that the point does not necessarily depend on the buyer's having incurred absolutely no reliance costs, but may perhaps extend naturally to every case in which expectation damages exceed reliance-in which the expectation remedy places a buyer in a better position than she occupied in the status quo ante. One might say that, in all such cases, expectation damages give buyers more than they deserve, precisely to the extent that they exceed reliance damages.

191. The second set of cases, incidentally, also presents facts on which the expectation remedy induces inefficient promisor care in contracting. See supra text accompanying note 182. 
expectation damages in favor of some greater or smaller remedyrestitution damages in the first case, reliance damages in the second. ${ }^{192}$

The economic argument for expectation damages is therefore inadequate twice over, and the overall case for the expectation doctrine would be stronger if the economic argument stood in the company of a moral argument that displayed a more perfect connection to the formal category expectation damages and also defeated or at least defused these noneconomic intuitions. I seek to provide such an argument-to forge a definite connection between the collaborative ideal that I have articulated and the expectation remedy. This effort proceeds in two stages, which address the two intuitions against the expectation remedy that I have just identified. In the first stage, I argue that, in the narrow circumstances at issue, ${ }^{193}$ expectation and restitution do not establish morally distinct remedial regimes and that there is therefore nothing morally interesting about restitution as a remedy for breach of contract. The fundamental moral choice in contract remedies is the choice between the expectation remedy (with restitution assimilated into it) and the reliance remedy, and my principal purpose is to take aim at this choice. In the second stage of the argument, I argue in favor of the expectation remedy by connecting the formal category expectation damages to the value of collaboration.

192. I have consciously left specific performance out of the discussion in the main text in order to avoid a confusion between the amount or size of a contract remedy and its form. On the one hand, with respect to amount, specific performance has many of the same features of the restitution remedy, in that it allows promisees to force breaching promisors to disgorge the gains made possible by their breaches. Indeed, it may be that in some cases the most effective way to enable promisees to secure these gains in cash form is to allow them to claim specific performance. On the other hand, specific performance adopts a very different form from the restitution remedy, in that it involves an injunction and hence creates a property rule rather than a liability rule. This is of course critical to some of the classic doctrinal justifications for specific performance, which turn on the idea that, in cases involving unique or irreplaceable performance, compensation for breach is impossible and only specific performance can secure a promisee's expectation. Specific performance is relevant to my argument here only in connection with the first, instrumental account of its purpose. Questions of the commensurability of in-cash remedies and in-kind performance, and more practically of the difficulties of measuring the cash value even of performance that can in principle be priced, present interesting and important problems but do not impinge on my main argument. See generally Anthony T. Kronman, Specific Performance, 45 U. CHI. L. REV. 351 (1978).

The mention of specific performance here raises one further point, which is worth noticing expressly. Neither the restitution remedy nor the specific performance remedy will provide promisees with the entire gains to be had from efficient breaches in all cases. Instead, when the transaction that an efficient breach involves is available to the promisor but not the promisee, then both restitution and specific performance will result in bargaining. Under restitution, the promisor will agree to enter into the transaction only if the promisee waives some portion of her restitutionary claim; under specific performance, the promisor will agree to reveal the transaction (or engage in the transaction on the promisee's behalf) only if the promisee offers to pay the promisor some portion of the gains that it involves.

193. That is, when restitution is understood in the narrow sense I am giving it. See supra note 187. 


\section{The Collaborative View}

The collaborative argument for expectation damages begins by clarifying the conceptual relation between restitution and expectation. I claim that the intuition in favor of restitution rests on a conceptual mistake involving the conflation of two different levels of abstraction. Once this conflation is eliminated, the restitutionary remedy appears as simply a special case of the expectation remedy, as necessary for securing promisees' expectations in connection with contracts that have certain content.

The remedies that I have been calling "expectation" and "restitution" can of course yield different results when they are applied in particular cases. This, after all, is what drives the intuition that the expectation remedy is too friendly to breaching promisors, whom it allows to retain gains from breach that restitution would require them to disgorge. But even though it is entirely reasonable to ask whether a promisor or her promisee ought to possess the gains made possible by an efficient breach, one must be careful, in addressing this issue, to distinguish the question who should possess these gains from the very different question how the gains should be characterized. To say that the gains from efficient breaches should go to promisees because restitution rather than expectation is the right remedy for breach of contract conflates these two questions. The claim that gains from an efficient breach should be returned to promisees as "restitution" is not an independent argument for this remedy but just a way of expressing a conclusion about the content of the promisees' expectations.

The expectation remedy, as it is commonly said, provides a promisee with the "benefit of the bargain."194 This is a formal principle only; any substantive conclusion concerning the actual remedial entitlements of a disappointed promisee of course depends on a separate understanding of the content of the bargain whose benefit he is to receive. One of the benefits that the bargain encompasses involves the possibility that, between the time of contracting and the time of performance, the value of the promised performance in the hands of the promisor might grow and indeed come to exceed the value that the specific performance in question confers on the promisee. In a simple contract for the sale of a widget, say, a third party offering an above-market price for the widget, or (more likely) proposing a more profitable use of the productive resources needed to manufacture the widget, may appear to the promisor but remain unavailable to the promisee. Efficient breaches occur precisely in such circumstances.

The prospect that an opportunity for efficient breach might arise, and the value associated with this prospect, therefore count among the benefits 
generated by the contract. And the parties may allocate this benefit, by means of the contract, just as they allocate any other. For example, the contract may cap the promisee's entitlements at the value she herself can extract from the promised performance, in which case promisors would be permitted to profit from efficient breaches. Alternatively, the contract might specify that the promisee's entitlements include even value that the promisor could extract from the performance through dealings with third parties who remain unavailable to the promisee, in which case promisors who breached efficiently could not keep any gains for themselves. In this latter case, one might say, adopting a shorthand manner of speech, that the promisor must disgorge the gains from efficient breach to the promisee, who is entitled to "restitution" of these gains. But that conclusion depends on the earlier conclusion that the parties, by means of the contract, allocated these gains to the promisee. And in this case, the gains in question belong to the promisee's benefit of the bargain; they belong to the promisee's expectation, properly understood. ${ }^{195}$ Restitution is not a competitor to the expectation remedy but rather a component of the expectations that accompany certain contractual arrangements, and claims that restitution should be paid following a particular breach merely state conclusions about the expectations established by the breached contract.

This treatment of the relationship between restitution and expectation damages in contract-the claim that restitution for the gains from efficient breach just presents a special case of expectation-does not represent any substantial insight or doctrinal innovation. It merely gives a clear expression to an idea that is commonly, if inarticulately, understood in practice. ${ }^{196}$ The law's generally encouraging stance toward efficient

195. This is perhaps obscured somewhat by a common way of speaking, adopted for example in the Restatement, that characterizes a promisee's expectations in terms of "attempting to put him in as good a position as he would have been in had the contract been performed, that is, had there been no breach." Id. This formulation encourages the thought that the restitution remedy must be conceptually distinct from expectation because it seems to leave the promisee better off than he would have been "had the contract been performed."

But this characterization of restitution-as leaving promisees better off than performancereflects a confusion, and, indeed, the same confusion that lies behind the view that restitution and expectation are distinct. When a contract allocates the gains from efficient breach to a promisee, then a breaching promisor's failure to transfer these gains to the promisee itself represents a breach. And the promisee will receive the benefit of his bargain only if he is put in as good a position as if this breach had not occurred-as if the contract had been performed in this respect-which requires, once again, that the promisor disgorge her gains from the efficient breach.

196. The relationship that I have asserted between restitution and expectation is not, however, universally acknowledged. It is rejected, for example, in the familiar moral argument that principles of fidelity or faithfulness require promisors to do what they say they will do and therefore support making specific performance (a cognate of restitution) the remedy for breach of contract. See, e.g., LAYCOCK, supra note 185, at 255-60; Friedmann, supra note 185, at 2. It is also rejected, at least implicitly, in a small but perhaps growing number of judicial opinions suggesting that breaching promisors should be required to disgorge their gains from efficient breaches under the "'principle of the law of restitution that one should not gain by one's 


\section{breaches should be read, therefore, not as enshrining expectation damages} in preference over restitution on a conceptual level, but rather as establishing a principle of contract interpretation under which contracts that are silent are interpreted to exclude from a promisee's expectation the gains from possible efficient breaches (and in this way also rendering restitution for such gains unjustified on its own terms). ${ }^{197}$

own wrong."' Earthinfo, Inc. v. Hydrosphere Res. Consultants, Inc., 900 P.2d 113, 117-21 (Colo. 1995) (quoting E. Allan Farnsworth, Your Loss or My Gain? The Dilemma of the Disgorgement Principle in Breach of Contract, 94 YALE L.J. 1339, 1341 (1985)).

The trouble with these arguments is that the idea that promisors should be true to their words (and do wrong to break them) does not yet say what the content of their promises consists of principles of fidelity are plainly not principles of interpretation. Moreover, it is possible to understand promisors as committing themselves not to perform in every event but rather to give their promisees the performance or its equivalent value - as Holmes would say, to perform or to pay damages. On this interpretation, promisors who breached efficiently and kept the gains involved would not thereby betray their promises. Instead, at least in a formal sense, such promisors would do precisely as they had promised-under the promise to perform or pay damages. These arguments simply reprise the discussion in the main text. There, I observe that a claim for restitution is nothing more than an application of the expectation remedy to contracts with a particular content; here, I apply this insight to the question of what fidelity to such contractual promises demands. The observation that the principle of fidelity does not select for the resitutionary remedy has, of course, been made before. See HANOCH DAGAN, THE LAW AND ETHICS OF RESTITUTION (forthcoming 2004) (manuscript at 288-93, on file with author) [hereinafter DAGAN, THE LAW AND ETHICS OF RESTITUTION]; Craswell, supra note 3, at 490; Hanoch Dagan, Restitutionary Damages for Breach of Contract: An Exercise in Private Law Theory, 1 THEORETICAL INQUIRIES L. 115, 121 (2000) [hereinafter Dagan, Restitutionary Damages]. The doctrinal point that restitution can be recast as a special case of expectation perhaps represents a modest advance in clarity.

The real doctrinal advance made possible by the collaborative view of contract-and the place at which my view departs from Richard Craswell's and Hanoch Dagan's-involves the reliance remedy. Craswell and Dagan both believe that the principle of fidelity is consistent with any remedy rule, including, presumably, the reliance rule. Craswell says that the fidelity principle "merely fill[s] out the details of what it is a person has to remain faithful to," Craswell, supra note 3, at 490, and Dagan adds that, in light of this, fidelity is "content neutral[]," Dagan, Restitutionary Damages, supra, at 121 . I deny this, and use the collaborative account of contract that I have developed to reject reliance damages for breach of contract. That argument is presented fully in a moment, but the intuition behind it can be recast in terms of the principle of fidelity and articulated in a rough manner here. The reliance remedy reduces a promisor's duties under her promises to the tort-like duties not to harm that she would incur in making any representations. It thereby deprives her promise of its distinctive character and leaves her with nothing to display fidelity to.

Finally, one other difference between my view and Dagan's is worth noting. Although Dagan accepts that the principle of fidelity does not require promisors to disgorge the gains that they make from efficient breaches, he also proposes that the "cooperative" element of contract-its creation of a "zone of mutual cooperation and confidence, dependence and vulnerability"-supports a rule under which promisors and promisees share the gains from efficient breach. DAGAN, THE LAW AND ETHICS OF RESTITUTION, supra (manuscript at 299-300). My collaborative view, by contrast, develops an account of contractual solidarity that does not require any such sharing.

197. Alan Schwartz has shown that, under fairly general conditions, promisees will be better off under a remedy regime that allows promisors to retain the gains created by efficient breaches. See Alan Schwartz, The Myth That Promisees Prefer Supracompensatory Remedies: An Analysis of Contracting for Damage Measures, 100 YALE L.J. 369 (1990). Accordingly, the principle of contract interpretation that reads silent contracts as establishing this regime will match the actual preferences of sophisticated promisees. 
Finally, this account of the conceptual relationship between expectation and restitution (the idea that expectation is the fundamental idea and restitution is just a special case) is reconfirmed in connection with exceptions to the principle that contracts are read to allow promisors to retain the gains from efficient breach. When the law, for some independent reason, establishes a regime under which promisees may expect specific performance--and therefore includes the gains from efficient breach within promisees' expectations - then it also grants restitutionary damages (now understood as a component of expectation damages) in connection with breaches that render actual performance somehow impossible. This circumstance arises, for example, in connection with breaches of contracts for the sale of real property in which the seller conveys the land not to her buyer but rather to a third party who has made a higher offer. If the rights of the third party rule out ordering specific performance, courts treat the seller as a trustee for the initial buyer and award the proceeds from the second sale to this buyer as restitution. ${ }^{198}$ Just as restitutionary damages are not

Unsophisticated promisees present a morally more complex problem. Unsophisticated promisees will either take no view of their remedies or, worse yet, carry their own personal views about promising with them into legal contracts, including, plausibly, views connected to intuitive arguments that reject expectation damages in favor of the restitutionary regime discussed earlier. Of course, the fact that unsophisticated parties do not actually choose to allow promisors to retain the gains from efficient breaches does not prevent them from enjoying the benefits of this rule. The consumer in a competitive market, for example, who mistakenly believes herself to be entitled to specific performance of her purchase agreements, and mistakenly prefers this remedy, may nevertheless face prices that her sellers can afford to offer only because (as they know but she does not) the expected gains from efficient breaches will accrue to them. Moreover, if the transaction costs of correcting the consumer's mistakes-both positive and normative-about remedies are high enough (as they likely are in many cases), she will never be disabused of her erroneous preferences and views of her legal rights. In such cases, the rule imposing the expectation remedy remains in some rough sense substantively fair to the consumer, even though it also overrides her choices. Finally, consumers who were made to understand the content of their legal rights and the reasons for them might well come to approve of the expectation remedy but also to resent those who had imposed on them the costs of understanding it. These facts present an interesting case of paternalism, in which the victims of paternalism have an interest not only in the paternalistic policy but also-because of the high costs of enabling them to choose for themselves-in the paternalism itself.

198. Gassner v. Lockett, which was pointed out to me by Alan Rau, presents a typical fact pattern. 101 So. 2d 33 (Fla. 1958). The defendant conveyed a parcel of real property to the plaintiff (who did not record the sale) and later reconveyed the same parcel to a third party (who did record the sale) for a higher price, the land having appreciated in the interim. The plaintiff sued, seeking specific performance of the original conveyance, which was unavailable in light of the third party's good title to the land. Nevertheless, the court treated the defendant as a trustee for the plaintiff with respect to the land and awarded the plaintiff damages that included any profit that might have accrued to the defendant by virtue of the resale. See id. at 34 .

The court reached this conclusion in spite of an express recognition that the defendant (an old man) had displayed no bad faith in making the second sale but was merely forgetful of the first, which introduces an interesting asymmetry into the law. Restitution is generally available to tort victims in analogous cases only when the torts are intentional, see supra note 186, but the plaintiff in Gassner received restitution in spite of the court's recognition that the breach was not intentional. It seems, counterintuitively, that the law is in this respect friendlier to contract-based than to tort-based restitutionary claims. This result is, however, the right one. It is right doctrinally because of the conceptual point made in the main text, namely that the Gassner plaintiff's 
awarded when they are excluded from a promisee's expectation, so they are awarded when they are included. Once again, expectation is the conceptually fundamental remedy. Restitution is awarded only as a particular case of expectation.

The intuition that expectation damages unfairly favor efficiently breaching promisors, and that fairness requires restitution, thus does not present a moral challenge to the expectation remedy: Once certain conceptual confusions are cleared away, all plausible claims to restitution, understood in this narrow sense, ${ }^{199}$ are revealed merely to present special cases of the expectation remedy. By contrast, the second challenge to expectation damages that I reported earlier, based on the intuition that promisees who receive their full expectations in the absence of any reliance are getting something for nothing, raises a fundamental moral question about the expectation damages regime that cannot be dismissed by such purely conceptual argument. Instead, a defense of expectation damages must address this question by means of a substantive moral argument that connects the basic ideals that underlie contractual obligation specifically and precisely to the expectation remedy. Developing such an argument turns out to be a tricky business indeed.

For example, Fried's well-known effort to defend the expectation remedy by reference to the value of autonomy (which he says lies at the root of his account of contract as promise ${ }^{200}$ ) fails to render the connection between autonomy and expectation damages sufficiently precise. Fried tries to connect autonomy to the expectation remedy in two ways. First, he observes that a person can exercise the full power of her autonomy only if she can, when she chooses, commit herself so as "to make nonoptional a course of conduct that would otherwise be optional" for her. ${ }^{201}$ Moreover, Fried adds, just as the making of such commitments is necessary to the exercise of a person's autonomy, so the enforcement of such commitments is necessary to the recognition, by others, of the person's autonomy: He claims that "respect for others as free and rational requires taking seriously their capacity to determine their own values" and that this requires "holding people to their obligations," which themselves reflect these values. ${ }^{202}$ To treat a person otherwise, Fried says, is to "infantilize him, as we do quite

restitutionary claim wins because it is also, and more fundamentally, a claim for expectation damages, and this claim proceeds under a theory of strict liability. The result is morally right for a structurally related reason. I argue in a moment that strict liability for expectation damages is required to vindicate the value of the collaborative relation that contract (distinctively) involves. Expectation damages in Gassner required restitution.

199. Once again, see supra note 187.

200. Fried's view is ultimately as much concerned with harm as with autonomy, although I do not take up this interpretive complexity here. I prefer, in the present context, to focus on Fried's views as advertised rather than to develop my own reconstruction of them.

201. FRIED, supra note 1 , at 13.

202. Id. at 20. 
properly when we release the very young from the consequences of their choices." 203 For Fried, the value of autonomy requires the expectation remedy because a failure to enforce promissory expectations against a promisor at once diminishes and disrespects his autonomy.

The trouble with Fried's account is that although it constitutes a plausible argument in favor of imposing some measure of damages for breach of contract, it does not display sufficient precision to support a preference for enforcement by means of the expectation remedy in particular. As Richard Craswell observes, "[A]lmost any remedy-reliance damages, punitive damages, specific performance, etc.--makes the promised course of conduct non-optional to some degree, depending on the severity of the threatened penalty." 204 Accordingly, "[t]here is surely nothing in the idea of individual autonomy that requires the exact degree of non-optionality provided by the expectation measure."205 Moreover, the relationship between the expectation remedy and respect is similarly tenuous. Although it is natural to say that we disrespect a person if we treat his promises as incapable of generating any obligations at all, it is far from clear what affirmative treatment of promises respecting a person requires. Perhaps it is enough, for respect, to treat promises as giving rise to moral but not to legal obligations; and perhaps it is enough to limit enforcement to the reliance remedy. There is therefore no immediate reason to believe (and Fried has proposed none) that respect requires the precise extent of enforcement imposed by the expectation remedy. Fried's argument fails in each case to establish a sufficiently precise connection between the moral ideals from which it begins and the expectation remedy that it purports to

203. Id. at 21.

204. Craswell, supra note 3 , at 518 .

205. Id. Although my treatment of Fried here closely follows Craswell's, a slight difference in emphasis is worth noting. Craswell's larger aim is to argue that Fried's philosophical view of promising cannot account for contract law's default rules quite generally. He thus adds:

The idea of individual autonomy does suggest that individuals should be allowed to make their conduct nonoptional to any extent they choose, by specifying one of these remedies in their contract. But the law must still select one of these remedies as the default rule, and nothing in the notion of individual autonomy gives any reason for favoring the expectation measure over any of the others.

Id. I am less concerned than Craswell with default rules in general, and the law's preference for the expectation remedy establishes more than simply a default rule-recall the restrictions that the law imposes on specific performance and penalty clauses. Moreover, whereas the ideal of autonomy is orthogonal to contract law's preference for expectation damages cast as a default rule, it is, at least if Craswell is right to suppose that autonomy requires leaving the extent of enforcement up to the parties, opposed to the mandatory elements in the law's preference for expectation damages. I include the conditional remark because it is not clear to me that Craswell is right to suppose that the ideal of autonomy requires the remedial rules that the law adopts to be default rules only. Perhaps autonomy is in fact best promoted by a particular remedial regime (or, more likely, undermined by certain regimes), so that certain remedies conflict with autonomy even if they are chosen by the parties. My only point is that Fried has not presented any reason to believe that the law's preference for expectation damages constitutes an ideal remedial regime with respect to autonomy. 
defend. It certainly provides no grounds specifically for preferring expectation over reliance as the measure of contract damages.

Craswell presents his argument against Fried as part of an important broader attack on philosophical efforts to connect contract law to the morality of promising, in which Craswell claims that, in contrast to economic theory, moral philosophy cannot account for many of the familiar doctrines of contract law, including in particular the expectation remedy. ${ }^{206}$ But although I agree with Craswell's view of Fried, I reject his broader claims about philosophical argument more generally. The collaborative ideal that I developed in the previous Part determinately favors a remedial regime that protects promisees' expectations. Indeed, the connection between the collaborative ideal and the expectation remedy extends even into some of the details of that remedy's administration. The account of contractual obligation that I have developed consequently makes it possible for me not just to argue for the expectation remedy in general but also to take sides in certain doctrinal disputes that arise within the expectationbased regime of contract damages. I take up each of these claims in turn, moving from the more general to the more particular. At the general level, the fundamental moral choice concerning contract remedies is, as I have said, the choice between the expectation remedy (with restitution assimilated into it) and the reliance remedy. ${ }^{207} \mathrm{I}$ therefore begin by taking up this choice and arguing that reliance damages fail to vindicate the collaborative ideal, which demands the greater measure of damages contemplated by the expectation remedy.

A promisor has a duty to protect her promisee's reasonable reliance, to be sure. I do not deny that a person who relies on the words or actions of another and is harmed when her trust is betrayed may, in appropriate circumstances, recover her losses; nor do I deny that such claims can arise in and around contracts. Persons have a general duty not to treat others merely as means, and a promisor who encourages her promisee to rely when this serves her own purposes and then abandons him to bear the costs of his reliance violates this duty. But the contractual setting is in such cases not the ground but merely the background of the promisor's duty. And the reliance remedy casts the promisor's wrong in such cases as of a piece with the wrongs she might commit by harming and using another person in any number of ways, for example by simple, nonpromissory deception or coercion.

Just as persons must refrain from treating even strangers merely as means, so they must of course refrain from treating their contract partners

206. See Craswell, supra note 3.

207. As I explained earlier, expectation and restitution (as I am understanding it) do not establish morally distinct remedial regimes, and there is therefore nothing morally interesting about restitution as a remedy for breach of contract. 
merely as means. But persons may satisfy the requirement that they not treat each other merely as means and yet remain strangers or indeed become estranged. And contract is not just an application of the morality of interactions among strangers. Contract involves patterns of interlocking intentions, in which each party's intentions are end-providing for the other and in which each party intends to give the other authority over her future actions. These patterns of intentions cause contract to generate a morally valuable relation-a relation of collaboration-among the parties. And the parties are able, through this relation, to move beyond refraining (negatively) from using each other merely as means, and instead (affirmatively) to recognize each other as ends in themselves. Contract is a mechanism through which persons may cease to be strangers and enter into a community.

The reliance remedy fails to recognize this central feature of contract. When it measures the parties' remedial claims by comparing their postbreach positions to the positions that they occupied, as strangers, in the status quo ante, the reliance remedy, looking backwards, treats the parties as if they had remained strangers. The reliance remedy cannot, therefore, underwrite the central moral innovation that contract represents-the collaborative relation of mutual respect that contract involves. To support this communal relation, a contract remedy must not just reflect the parties' duties (carried over from their prior relation as strangers) to refrain from using each other merely as means but must, additionally, reflect the parties' further forward-looking commitment affirmatively to treat each other as ends in themselves, which lies at the core of the collaborative relation established through the contract.

This commitment is expressed through the interlocking pattern of intentions and ends that constitutes contract's substance. Promisors treat their promisees as ends in themselves by sharing the ends of contracts with their promisees. These ends are, in the first instance, that the contracts be performed - that the promisees be put in the position that they would have occupied save for a breach. But even where there is a breach, the relation between promisor and promisee can be salvaged as long as the promisor presents her promisee with a replacement that has the same value to the promisee as the promised performance, which is to say that it satisfies the promisee's expectations in the contract. A promisor who pays expectation damages continues to collaborate with her promisee, in spite of her breach. Indeed, the payment of expectation damages may be understood as presenting an extension of the meshing subplans and interlocking intentions that characterized the collaborative community of contract in the first place. A promisor and promisee share ends (and the promisor treats the promisee as an end) by intending to adjust their actions to bring about the shared ends of the promise, and by giving each other authority to require such 
adjustments. The payment of expectation damages is just the consummation of these intentions - the final adjustment (by the breaching promisor) of her actions to make a substitute for the promised performance come about and the final recognition of the promisee's authority to demand this performance. Expectation damages encompass the exact ends whose sharing enables the parties to contracts to treat each other as ends in themselves. And, in this way, expectation damages precisely track the contracting parties' transformation from strangers to collaborators and vindicate the distinctive value of the collaborative community that this transformation engenders.

This argument explains why promisors' contractual duties extend beyond protecting their promisees' reliance and, moreover, forges a precise connection between the morality of contract and the expectation remedy. The connection arises, however, at a formal level only. The collaborative theory of contract supports the expectation remedy but offers no insight into determining the content of promisees' expectations in particular cases. As I argued earlier, remedies that allow promisors to retain the gains from efficient breaches, remedies that require promisors to disgorge these gains to their promisees, and even remedies that require promisors specifically to perform contracts may all be cast, formally, as protecting promisees' expectations interpreted in the relevant ways. The collaborative view of contract does not join the debate among these substantive alternatives, which it leaves to familiar arguments concerning efficiency, administrability, and individual liberty. The collaborative view will sanction all three outcomes in the right circumstances, provided of course that they can be cast in the form of the expectation remedy.

The collaborative view does not leave the expectation remedy completely devoid of content, however, because not every substantive remedy can be cast, formally, as the expected outcome of a collaborative relationship. Some substantive remedies are ruled out because casting contractual expectations in terms of these remedies would undermine any collaboration that a contract might involve. Moreover, these limiting cases of collaboration are no mere theoretical constructions, but instead place practically important lower and upper bounds on the remedies to which disappointed promisees are entitled. And finally, these limits turn out to be reflected in the positive law.

First, the collaborative ideal imposes a substantive lower bound on remedies for breach of contract. The practical effect of this lower bound is to restrict contracting parties' freedom to limit the damages that promisees may recover in case of breach. Many limitations on damages can, of course, straightforwardly be recast as altering promisee expectations and are therefore perfectly consistent with the collaborative ideal and with the morality of contract. Efforts to exclude consequential damages from a 
promisee's remedies present a typical and prominent example. Just as a contract clause that requires a promisor to transfer the gains from efficient breaches to her promisee can be understood as increasing the promisee's expectations under the contract, so a clause that protects a promisor from liability for consequential damages can be understood as decreasing the promisee's expectations. But not every limitation of damages can be understood as consistent with the expectation remedy and the collaborative ideal in this way. In particular, the morality of contract is inconsistent with the parties' agreeing that a disappointed promisee's damages shall be limited to his reliance.

The reliance remedy that my earlier argument excluded from contract cannot reenter the arena by being recast in the form of the parties' expectations. The collaborative ideal upon which the earlier argument depended is more robust than this suggestion allows. A contract term that limits a promisee's remedy to reliance damages specifically undermines any contractual expectations that the promisee might otherwise entertain. Such a term expressly rejects any forward-looking commitments that the contract containing it might otherwise encompass and expressly denies the promisee authority to require the promisor to provide the promised performance, and it therefore nullifies whatever sharing of ends the rest of the contract proposes and undoes whatever collaboration the contract might otherwise involve. Simply put, a term limiting a promisee's remedies to reliance damages returns the parties to their original state as strangers. This observation just repeats and enforces the conclusion of the earlier argument that rejected reliance damages as the general remedy for breach of contract: Reliance damages are characteristic of relations among strangers who may not treat each other merely as means and yet do not treat each other as ends in themselves. But contractual obligation, and the expectation remedy that it involves, are distinctive precisely for enabling persons to cease to be strangers and to come to treat each other as ends.

This is not to say that persons who exchange assurances but limit their liability to reliance enter into no relation at all. They may have joint intentions of the forms that Bratman describes, and they may owe obligations to each other that they do not owe persons generally. In particular, such persons have given notice that their representations may be relied upon, so that if one of them abandons her intentions without making good the other's reliance, she will have bypassed his will and treated him, impermissibly, as a mere means. But although such persons may owe each other obligations that they do not owe persons generally (because they have, in effect, expanded the tort of misrepresentation beyond its usual 
bounds), they remain strangers. ${ }^{208}$ The reason is that the intentions and obligations associated with such representations do not come together: The obligations do not secure the intentions, as the collaborative relation, and the form of respect that this relation involves, require. ${ }^{209}$ Critically, the obligations are not obligations to secure the success of the intentions, so that even if the assurances allow persons to share ends, they do not allow persons to treat each other as ends. ${ }^{210}$

Moreover, the legal regime that governs efforts to limit promisees' remedies resonates with these ideas. The most articulate treatment of the issue appears in section 2-719 of the Uniform Commercial Code. The UCC specifies, in subsection 1 , that the parties to a contract may limit damages for breach as they choose (subject, of course, to general considerations concerning unconscionability ${ }^{21}$ ) and establishes some basic interpretive presumptions to govern such efforts. ${ }^{212}$ This matches my theoretical observation that most limitations of remedies may be recast as special cases of the expectation remedy and should be enforced under this heading. But then the UCC adds, in subsection two, that "[w]here circumstances cause an exclusive or limited remedy to fail of its essential purpose, remedy may be had as provided in this Act." ${ }^{213}$ Moreover, as the comments to the UCC make plain, subsection 2 applies even apart from general concerns about substantive fairness and unconscionability: "[W] here an apparently fair and reasonable clause because of circumstances fails in its purpose or operates to deprive either party of the substantial value of the bargain, it must give way to the general remedy provisions of this Article."214 Section 2-719(2) requires, in other words, that promisees retain some distinctively promissory remedy, some remnant of the value of the bargain, something that may be cast as a contractual expectation. ${ }^{215}$ The law thus supports the

208. There is no contradiction in this. Someone may owe one person an obligation that she does not owe another and yet be, in my sense, equally a stranger to both, which is to say that she may be in community with neither. Just think of a person who has rendered another vulnerable to her and owes that person a special duty of care.

209. When persons exchange assurances backed only by a reliance remedy, their intentions in favor of each other are limited to intentions not to harm each other-intentions that may exist even among strangers-and do not compass whatever shared ends they adopt.

210. I would like to thank Richard Craswell for persuading me of the need to emphasize this point.

211. See U.C.C. $\$ 2-719 \mathrm{cmt} .1$ (1997).

212. See id. § 2-719(1).

213. Id. $\S 2-719(2)$.

214. Id. § $2-719 \mathrm{cmt} .1$ (emphasis added).

215. Courts have not always applied section 2-719(2) in a manner that is entirely consistent with my interpretation of the Code or with the official comment. The clause most commonly arises in connection with cases in which a contract expressly limits a buyer's remedies to repair or replacement of the goods, and "[ $t$ ]here is now broad consensus among the courts that a seller's failure to effect a timely and satisfactory cure indicates that an exclusive repair or replacement limitation has failed of its essential purpose." John A. Sebert, Jr., Rejection, Revocation, and Cure Under Article 2 of the Uniform Commercial Code: Some Modest Proposals, 84 NW. U. L. REV. 375,396 (1990). This is as my view of the matter recommends, but even where courts in such 
collaborative ideal by ensuring that when the parties to a contract have been collaborating, but their initial arrangement comes, as events develop, to lose its distinctively contractual, collaborative character, then the terms of the arrangement will be reformed to reinstate a contractual remedy and restore the collaborative relation. ${ }^{216}$

Furthermore, the collaborative ideal also imposes a substantive upper bound on contract remedies. The practical effect of this upper bound is to reject punitive damages as a general remedy for breach of contract. Punitive damages require breaching promisors to make additional payments to promisees, over and above any compensation for the lost benefits of performance and even over and above restitutionary disgorgement. They do not serve to secure or complete the collaboration or to protect the promisee's interest or expectation in the collaborative venture, but instead look to burden the breaching promisor with a punishment or reprimand. The collaborative ideal rejects punitive damages for breach of contract because

cases strike down limitations of remedy clauses under section 2-719(2), they remain reluctant to allow buyers to take advantage of the full range of remedies "as provided in this Act" to which the Code refers. See, e.g., Kearney \& Trecker Corp. v. Master Engraving Co., 527 A.2d 429, 438 (N.J. 1987) (limiting the application of section 2-719(2) to allow buyers to recover full consequential damages only in cases in which "circumstances of the transaction, including the seller's breach, cause the consequential damage exclusion to be inconsistent with the intent and reasonable commercial expectations of the parties"). Moreover, courts sometimes limit a buyer's remedy in such cases to some form of returning the goods and receiving a refund of his purchase price. See Sebert, supra, at 396 (noting that when exclusive remedies fail to fulfill their essential purposes, a "buyer at least would be entitled to reject or to revoke her acceptance"); see also U.C.C. $\$ 2-719(1)$ (a) (expressly authorizing limitations of damages to a repayment of the price of defective goods purchased). This is in effect the reliance remedy that my philosophical argument finds insufficient to underwrite a contractual relationship. I am tempted to say that courts in such cases do not proceed in contract at all but instead treat the parties as strangers and approach the plaintiff's claim as sounding in the tort of misrepresentation. Insofar as the law sanctions this approach, it weakens contractual collaboration.

216. It is worth observing that section 2-719(2) precisely replicates the formal structure of the consideration doctrine: The Code allows the parties to limit remedies and displays no special concern (beyond the general application of the unconscionability doctrine) for the substantive adequacy or fairness of such remedies as remain. But at the same time, the Code insists on the fact of some remedy that does not fail of its essential purpose, and that thus remains distinctively contractual. Moreover, the subject matter of section 2-719(2) is of a piece with the subject matter of the consideration doctrine: A promise in which the promisee relinquishes every remedy is in effect a gratuitous promise rather than a bargain. It certainly does not participate in the collaborative ideal, because the promisee in such a case disavows, through the limitation-ofremedy clause, the authority to demand performance upon which that ideal depends. This makes it natural to ask why the law enforces such promises at all-why it does not just find contracts whose exclusive remedies fail of their essential purposes void for lack of consideration. I suspect that the best answer to this question is that the cases in which section 2-719(2) is invoked present parties who have, in spite of the limitation-of-remedy clause, clearly been collaborating but fall afoul of the technical requirements of the consideration doctrine. The law imposes a default remedy to complete the collaboration that has so obviously been ongoing. This approach, moreover, closely tracks the law's treatment of consideration in exclusive dealings or requirements contracts which, as I observed previously, see supra text accompanying notes 169-170, also creates consideration when none otherwise exists in order to support ongoing, evidently collaborative relations. In both cases, the law steps in to repair technical inadequacies in relations, the main lines of which are clearly collaborative. 
it rejects the suggestion that a promisor who breaches a contract-but does nothing more-acts wrongfully in any sense that might justify punishing her.

To understand why the collaborative view rejects punitive damages as a general remedy for breach of contract, it is helpful to return to the Kantian ideas from which this approach to the morality of contract set out, and in particular to the Formula of Humanity. This principle, as I have repeatedly observed, identifies two ways in which one person may wrong another and therefore identifies two classes of conduct for which punishment might be appropriate: First, one person might use another merely as a means; and second, she might fail to treat him as an end. A simple breach of contract involves neither wrong. First, it has been clear since early in the argument that a promisor who breaches a contract does not generally manipulate her promisee or use him merely as a means. As long as she approached the contract honestly-that is, with the intention of performing-her subsequent breach does not manipulate her promisee at all. ${ }^{217}$ And second, the recent discussion of expectation damages reveals that a breaching promisor need not even estrange herself from her promisee, but may, in spite of the breach, continue to treat her promisee as an end in himself. She does so by paying compensatory damages that secure her promisee's expectations in the shared ends that the contractual collaboration involved.

A simple breach of contract, without more, therefore does not constitute a wrong that the collaborative theory of contract recognizes. Moreover, insofar as punitive damages cause a promisee to prefer his promisor's breach over her performance, they give him an incentive to induce her to breach and in this way encourage him to adopt ends in which she cannot possibly share. Accordingly, quite apart from being unnecessary for vindicating collaboration, punitive damages in fact actively corrode collaboration. This cements the collaborative view's opposition to punitive damages in connection with simple breaches of contract, because such damages are now cast as affirmatively hostile to collaboration. In reaching this conclusion, the collaborative view once again matches the positive law, which also denies punitive damages in ordinary cases of breach of contract. $^{218}$

Of course, the fact that punitive damages should not generally be awarded for simple breach of contract does not entail that punitive damages should never be awarded for any breach of contract, and both the collaborative view and legal doctrine contemplate punitive damages in certain special cases. Two special cases in particular deserve mention, both because they return (once again) to the two components of the Formula of

217. But recall, once again, the cautionary note struck above. See supra note 26 .

218. See, e.g., U.C.C. $\S 1-106(1)$. 
Humanity and because they resonate with the positive law. First, and uncontroversially, a breaching promisor, even though she does not treat her promisee merely as a means simply by breaching, may yet treat him as a means by some other actions that accompany her breach. Her breach may involve fraud (perhaps in connection with a lying promise) or force (perhaps in connection with duress). In each of these cases, the promisor's actions would, quite apart from the contract, wrong even a stranger, and this wrong may deserve punishment, including punishment imposed through punitive damages. The law recognizes this possibility by allowing punitive damages in cases in which a breach of contract also constitutes an independent tort. ${ }^{219}$

Second, and more controversially, a breaching promisor may fail to treat her promisee as an end insofar as she does not just breach her promise but also refuses to pay the compensatory expectation damages that vindicating contractual collaboration requires. In this case, even though the breaching promisor does not use her promisee as a means, she does render sharing ends with him impossible and in this sense, as I have said before, estranges herself from him. Such estrangement constitutes a wrong, although whether this wrong justifies punishment seems to me uncertain (after all, it does not inflict harm in any straightforward sense). The law quite possibly also recognizes both this wrong and its uncertain status, in the form of the controversial doctrine of bad faith breach of contract, ${ }^{220}$ although the uncertain and uneven development of this doctrine makes it difficult to say whether the doctrinal category of bad faith in fact tracks the idea of estrangement that the collaborative view proposes. ${ }^{221}$

219. See, e.g., Excel Handbag Co. v. Edison Bros. Stores Inc., 630 F.2d 379, 384 (5th Cir. 1980).

220. See, e.g., Chung v. Kaonohi Ctr. Co., 618 P.2d 283 (Haw. 1980); Dold v. Outrigger Hotel, 501 P.2d 368 (Haw. 1972). Both cases were abrogated by Francis v. Lee Enterprises Inc., 971 P.2d 707 (Haw. 1999).

221. The collaborative theory of contract and the positive law of remedies perhaps converge on another point also. The collaborative view's conclusion that punitive damages corrode collaboration is perhaps matched in the law's reluctance to enforce liquidated damages clauses that impose penalties on breaching parties. See RESTATEMENT, supra note 97, § 356; U.C.C. $\S 2-718(1)$. Note that civil law seems less hostile to penalty clauses. For example, Article 1152 of the French Civil Code enforces liquidated damages provisions quite generally, including penalty clauses, although a 1985 amendment allows judges to reduce penalties that are plainly too large or too small. See MÉGA CODE CIVIL 1302 (Xavier Henry et al. eds., 5th ed. 2003).

My uncertainty here reflects the fact that although some penalty clauses likely would constitute party-chosen punitive remedy regimes, it is far from clear that all would do so, and it is not at all clear how to distinguish punitive penalty clauses from those that serve some other purpose. Part of the difficulty involved in understanding the relationship between penalty clauses and punitive damages arises out of the fact that the economics of penalty clauses is itself a difficult subject. For many years, lawyer-economists believed penalty clauses quite generally to be inefficient. This led some to abandon the standard inference from a term's appearance in a contract to the fact that it was chosen by the parties, and to replace this with an inference that penalty clauses involved mistake or fraud, thereby justifying the law's refusal to enforce them. See, e.g., Samuel A. Rea, Jr., Efficiency Implications of Penalties and Liquidated Damages, 
The collaborative theory of contract confines the expectation remedy between reliance damages as a lower bound and punitive damages as an upper bound. In doing so, it forges a precise connection, of a kind that has eluded alternative approaches to contract, between the morality of contract and expectation damages (including some details of the law's administration of expectation damages). The first-order analysis of the connection between collaboration and contract remedies is therefore complete, but a second-order question still deserves attention. This concerns the character of the collaborative ideal upon which the first-order argument in favor of the expectation remedy depends and, in particular, the question whether a liberal state may properly deploy its coercive power to impose contract remedies on the basis of this ideal.

This question arises because it is one of the basic tenets of liberalism that a society's laws may not enforce controversial moral ideals, ${ }^{222}$ and one of the consequences of this basic principle is to impose limits on the reasons for which the law may enforce contracts. Even an argument that manages to establish a precise connection between a moral principle and a remedial regime will nevertheless fail to justify providing this remedy at law if the principle is itself inappropriately controversial, and this entails that the law may not enforce contracts simply for the reason that, according to some substantive moral view, it is wrong to breach them. "[E]nforcing voluntary obligations," observes Raz (referring to promissory and contractual obligations), "is not itself a proper goal for contract law." 223 The reason for this, Raz continues, is that "[ $t]$ o enforce voluntary obligations [for their own sakes] is to enforce morality through the legal imposition of duties on individuals." 224 Indeed, as Raz says, "[i]n this respect, it does not differ from the legal proscription of pornography." ${ }^{225}$ At the same time,

13 J. LEGAL STUD. 147 (1984). Others took the inefficiency of penalty clauses to entail that sophisticated parties, at least, would never adopt them and therefore disapproved of the law's refusal to enforce penalty clauses on the ground that it invited courts incorrectly to identify valid liquidated damages clauses as unenforceable penalties. See, e.g., Schwartz, supra note 197, at 383-87. Both approaches make most sense against the backdrop of the clear inefficiency of penalty remedies; they disagree only about evidence and inference. Aaron Edlin and Alan Schwartz, however, now challenge this conventional wisdom and argue that certain liquidated damages clauses imposing supracompensatory remedies are efficient because they are necessary to induce efficient investment. See Edlin, supra note 181; Edlin \& Schwartz, supra note 181.

The moral analysis of penalty clauses (at least, the moral analysis proposed by the collaborative theory of contract) is sensitive to the outcome of these economic investigations. Although I am not prepared to say that inefficient penalty clauses are necessarily punitive, I am tempted by the view that efficient penalties are not punitive. Such efficient penalties do not corrode the parties' collaboration but rather increase its value.

222. The precise content of this principle is, of course, itself the subject of a vigorous debate, which I discuss briefly below. See infra note 228 .

223. Joseph Raz, Promises in Morality and Law, 95 HARV. L. REV. 916, 937 (1982) (reviewing ATIYAH, supra note 56).

224. Id.

225. Id. 
contracts may be enforced in the service of ends that do not involve controversial moral ideals. Raz identifies the prevention of harm to promisees as the principal example of an acceptable end, ${ }^{226}$ and the promotion of economic efficiency perhaps represents another such end.

Moreover, familiar moral interventions in the law of contracts-for example, efforts to bring moral ideals of fidelity or faithfulness to bear on the choice of contract remedies-violate these principles of liberal restraint. Even if a moral argument connecting ideals of fidelity and faithfulness to some contract remedy or other could be established, ${ }^{227}$ this argument could not possibly support imposing the remedy at law. The principle of fidelity to one's word, understood in this way, is without question a controversial moral ideal. It is connected to controversial moral conceptions of integrity and honor and perhaps even to religious principles concerning oaths. (The principle of fidelity is in this respect perhaps not much different from the moral principles of sexual purity that underlie a certain form of the condemnation of pornography.) It is at odds with more prosaic, more secular conceptions of morality, according to which placing a special emphasis on promissory obligations, as distinct from more general sentiments of kindness and regard for others, involves at best rule-worship and at worst self-indulgent conceit. Even if the principle of fidelity favored a particular remedy for breach of contract, a liberal state whose contract law established this remedy on this ground would impermissibly legislate morality. ${ }^{228}$

226. "Compensating individuals for harm resulting from reliance on voluntary obligation is . . . a proper goal for the law." Id. Raz concludes that, as an initial matter, reliance damages are more easily defensible than expectation damages. He adds, however, that expectation damages may nevertheless be defensible by an indirect root that connects expectation damages to the prevention of harm under the theory that the expectation remedy is necessary to protect the practice of contract and the demise of this practice would cause harm. See id.

227. The principal efforts in this direction attempt to argue that fidelity requires promisors specifically to perform their promises or at least to deliver any proceeds from efficient breaches to their promisees. See, e.g., LAYCOCK, supra note 185, at 245-64; Friedmann, supra note 185 . I have argued that these efforts fall into a conceptual confusion concerning restitution and expectation. See supra note 196. Now it appears that even if this judgment is mistaken, moral arguments from fidelity cannot support legal doctrines concerning remedies.

228. Fried's proposal that the value of autonomy can underwrite expectation damages stands in a significantly more complex relation to liberal principles of restraint. And although I doubt that autonomy is in fact connected to expectation damages as Fried proposes, see supra notes 200205 and accompanying text, it remains instructive to ask whether this connection, if real, would justify expectation damages on terms that the liberal state could accept. Fried clearly recognizes that liberalism rejects using state power in the service of controversial moral ideals: He asks whether enforcing promises (in the service of autonomy) is consistent with, as he puts it, the basic liberal distinction between the good and the right, see FRIED, supra note 1, at 7-8, by which he means to refer to the liberal principle that the state may not engage its power in the service of controversial conceptions of the good. But Fried's question about his view is not easy to answer, because it engages in the dispute about the fundamental character of liberal restraint.

Some liberals, including most famously Mill, see JOHN STUART MILL, ON LIBERTY (David Spitz ed., Norton \& Co. 1975) (1859), and Raz, see JOSEPH RAZ, THE MORALITY OF FREEDOM (1986), conceive of autonomy as a special kind of value and hold that the liberal refusal to enforce 
The collaborative ideal, by contrast, may underwrite a liberal state's exercise of coercive power. Collaboration does not present a substantive moral value in any ordinary sense but rather articulates a highly flexible form of relation among persons. The pattern of interlocking intentions upon which collaboration depends can arise (and can underwrite a community in which persons cease to be strangers and come to treat each other as ends in themselves) no matter what substantive content the patterned intentions take on. Moreover, this feature of collaboration is carried forward into the more particular legal doctrines that the collaborative ideal supports, as is illustrated by each of the doctrinal discussions presented a moment ago: The consideration doctrine insists on the form but remains indifferent to the substance of collaboration, and the expectation remedy similarly focuses the law on the forward-looking form of contractual expectations but allows the parties to adopt any substantive expectations that may be expressed in this form. Collaboration is, therefore, a mode of interaction that remains equally available to persons regardless of the sectarian content with which they seek to fill it. And finally, the moral underpinnings of the collaborative relation reinforce collaboration's nonsectarian character. The collaborative ideal of community does not impose any requirements of mutual support or intimacy on those who engage it (recall the distinction between

morality does not extend to autonomy. Rather, such "comprehensive liberals" insist, autonomy represents the condition under which liberal restraint is justified, because it presents the condition under which individuals may choose freely among the several more ordinary moral values that liberal restraint requires the state to refrain from enforcing. Fried's autonomy-based view of enforcing contract clearly falls into this camp; indeed, Fried presents the connection between autonomy and the expectation remedy in precisely this light, by casting expectation damages as necessary for according appropriate respect to persons' powers autonomously to choose their values. See FRIED, supra note 1, at 20-21. If comprehensive liberalism provides the right account of liberal restraint, then a liberal state might enforce the expectation remedy on Fried's grounds (provided, of course, that the connection Fried draws between autonomy and expectation damages were correct).

Other liberals, however, including most notably Rawls, take a different view of liberal restraint, according to which even autonomy (at least in the rich version that Mill, Raz, and Fried champion) itself represents a controversial moral ideal that liberal states may not enforce. See JOHN RAWLS, POLITICAL LIBERALISM (1993); RAWLS, supra note 56. Such "neutralist liberals" emphasize that the ideal of autonomy is at odds with the host of moral views that reject the comprehensive liberal's focus on individual choice among ends, and instead see the good life as involving a connection between a person's ends and her broader culture, including perhaps even structures of authority. Thus, in the present context, neutralist liberals observe that many perfectly respectable moral views - many religiously based conceptions of charity and forgiveness, for example--reject Fried's idea that we respect persons by enforcing their autonomously chosen commitments against them. On the neutralist view, then, liberal states may not enforce expectation damages on the basis of the value of autonomy, and Fried's argument for the expectation remedy ultimately fails (even if it could succeed at connecting autonomy to expectation damages in the first place).

I do not argue in favor of one or the other conception of liberalism here. I have introduced the distinction only to show that Fried's autonomy-based defense of expectation damages depends on resolving it in a particular way. The collaboration-based argument for expectation damages that $I$ introduce in the main text, by contrast, does not present these difficulties. It is compatible with both comprehensive and neutralist principles of liberal restraint. 
collaboration and cooperation), and collaboration may arise among persons whose association is motivated purely by self-interest on all sides. Collaboration is not, of course, devoid of all normative content-no guide to action possibly could be-but its normative commitments are all thin and formal in precisely the ways that the liberal vision of politics requires.

\section{CONCLUSION}

These pages have presented a new philosophical account of promise and contract that attempts to reclaim these practices as independent, distinctive, and central elements of our moral and political experience. The account does not focus on promisors or promisees considered severally, as traditional views have done, but instead focuses on the relation that promises and contracts establish among those who engage them. When persons make promises and contracts, they cease to be strangers and come to treat each other, affirmatively, as ends in themselves. When persons break promises and contracts, by contrast, they render the sharing of ends impossible, at least in respect of the promised performance, and in this way become not merely strangers, but actively estranged. The morality of promise and contract therefore engages one of the most basic values in our practical lives, and this value underwrites every element of promissory and contractual obligation.

The approach that I have developed produces insights at several, increasingly concrete, levels of analysis. Most abstractly, it explains the relationship between the moral experience of making promises and contracts on the one hand, and of keeping them on the other; it explains the formal role that the obligation to keep promises and contracts plays in our all-things-considered practical reasoning, the way in which this obligation appears to us as a constraint upon our actions; and it resolves an old and familiar puzzle about the distinctive place of the will among the grounds of promissory and contractual obligation. Intermediately, the theory explains how the legal practice of contract, in which parties may be motivated by their narrow self-interests and may interact in discrete transactions only, might nevertheless participate in the broader ideal of treating persons as ends in themselves and in the broader relation of respectful community that this ideal invokes. To this end, the theory articulates an ideal of collaboration that, even as it falls short of full-blooded cooperation, nevertheless invokes the forms of respectful recognition upon which the morality of promising quite generally depends. And most concretely, the structure of contractual collaboration suggests resolutions to familiar puzzles of legal doctrine, involving consideration and expectation damages, that have eluded alternative views. 
My argument has therefore worked its way steadily inward, which is natural and proper in an effort to explain particular legal practices in terms of general moral principles. The task of the theory going forward, by contrast, will be to work its way back outward-to connect the specific collaborative ideal that I have identified as the foundation of contract in particular to broader ideals of respect and community that figure prominently in the overall scheme of liberal moral and political justification, within which the legal practice of contract appears. This is, as I have repeatedly suggested, properly a task for the next stage in a larger movement of thought to which the argument of these pages contributes, but which it does not exhaust. Nevertheless, it is possible, in concluding the present phase of the argument, to look ahead a little and to see, in rough outline, how the next phase will go. This will have the effect of shoring up the approach to contract developed here by revealing that the collaborative ideal that I have found at the center of contract is not just attractive in itself, but also plays an essential part in the broader ambitions of liberal political thought. ${ }^{229}$

The next phase of the argument will begin from the familiar observation that public order and social stability are fragile achievements. Persons face constant incentives to defect from the coordinated schemes on which these goods depend and to pursue their own ends more vigorously than coordination allows. Too frequent defections undermine coordination entirely, render public order and social stability unsustainable, and introduce a state of affairs that is worse, for every person, than the coordinated state that it replaces. The first end of politics, including liberal politics, is therefore to sustain coordination in the face of the incentives to defect.

These incentives to defect fall into two categories. To begin with, defection may serve persons' narrow self-interest more effectively than coordination: Coordinated schemes allocate property rights, for example, and one person may appropriate another's holdings to serve her own interests. The stability of coordination depends, therefore, on overcoming egoism, that is, persons' tendency to care only about their own interests.

229. In this way, looking ahead will help allay concerns that the collaborative approach to contract that $I$ have developed in these pages presents nothing more than a moral curiosity, or alternatively, that it presents only the minimum moral content of the contract relation-a sort of baseline below which contract becomes impossible (or at least morally empty). The first concern is that the collaborative account of contract represents a mere sideshow to more important arguments that seek to justify contract on alternative grounds (including, perhaps, the more traditional grounds of serving autonomy, preventing harm, and promoting well-being). The second concern is that the collaborative account of contract represents a mere beginning to an argument that asks what more intensive forms of sharing contract should incorporate, as under Anthony Kronman's well-known argument. See Anthony T. Kronman, Contract Law and Distributive Justice, 89 YALE L.J. 472 (1980). 
But even where egoism has been overcome, coordination remains insecure. Even persons who display an impartial concern for the interests of others, and who never pursue their own interests more vigorously than this impartial concern for the general interest allows, will nevertheless disagree about what the general interest is. And defection may, once again, enable persons to promote their impartial but nevertheless sectarian conceptions of the general interest more effectively than coordination allows: Coordinated schemes also allocate influence over collective decisionmaking, and one person may seek to usurp another's influence in order to serve not her own private interest but her sectarian view of the general interest. The stability of coordination therefore depends on overcoming not only egoism but also egocentrism, that is, persons' tendency, even if they display an impartial concern for the general interest, to care only about their own points of view of what the general interest is. ${ }^{230}$

Political theories may be separated into three classes, according to their attitudes toward social coordination and the problems of overcoming egoism and egocentrism. The political theories in the first class conclude that not even egoism can be overcome and, therefore, that sustaining social stability and public order depends upon establishing a government so powerful that each person's narrow self-interest is always best served by cooperating with its commands. These absolutist theories insist, with Hobbes, that the minimal solution to the problem of sustaining public order is also the maximal solution. The political theories in the second class conclude that egoism can be overcome but that egocentrism cannot be and, therefore, that sustaining social stability and public order depends upon establishing a government that imposes a universally accepted conception of the general interest. These totalitarian theories insist that public order depends upon uniform, all-encompassing devotion to one vision of the general good. Finally, the political theories in the third class conclude that both egoism and egocentrism may be overcome and, therefore, that social stability and public order may be sustained even in an open, pluralist society. These liberal theories insist that public order may be sustained by political justifications that address each person, separately, from her own point of view.

Liberal political theories therefore adopt the most ambitious approach to the problem of sustaining public order that is conceptually available and, consequently, bear the heavy persuasive burdens of explaining how the principles and institutions that they propose can overcome both egoism and egocentrism. In future work, I will argue that contract contributes to liberalism's efforts to meet the second of these burdens. More specifically, I

230. An impartial concern for the interests of ail will not, of course, help to overcome egocentrism because it is itself a source of egocentrism. 
will seek to display the practice of contract, understood along the collaborative lines that I have developed here, as a proving ground for overcoming egocentrism. In light of the intimate connection that exists between contract as a legal institution and the market as an economic institution, this argument will contribute to the venerable, if episodic, tradition of scholarly debate about whether the market exercises a civilizing or destructive influence on the individual persons who come under it and on political and social relations among these persons. ${ }^{231}$ The argument's distinctive contribution will be to address this question in a philosophical and normative mode rather than (as is more common) in a sociological and positive mode. I will argue that contract-and through contract the market-has an effect on the reasons persons have, and not just the characters that they display, that supports a particularly ambitious, liberal solution to the problem of social unity.

The basic associations in which this argument will traffic are straightforward enough. The parties to contracts, in forming a collaborative community, commit themselves to a mutually responsive, interlocking pattern of intentions in which each takes certain of the other's intentions as end-producing for herself and each gives the other authority over her intentions. A party to a contract engages, therefore, not with the other party's interests as she understands them, but directly with the other party's point of view, as expressed through his contractual intentions, to which she must accommodate herself. Contractual collaboration therefore depends precisely upon a commitment to overcoming egocentrism, at least in the context of the contract. Moreover, insofar as the practice of forming interlocking contractual intentions efficiently serves the (often conflicting) ends that the several parties bring to their contractual relations, ${ }^{232}$ contract enlists persons' narrow self-interest in the service of overcoming egocentrism. And finally, in light of my earlier argument that promises and contracts enable persons to cease to be strangers and to attend to their basic needs for community - as expressed in Arendt's idea of "the will to live together with others in the mode of acting and speaking" 233 — contract also enlists persons' broader ethical interests in the service of overcoming egocentrism.

Going forward, I will seek to develop these ideas and to display the characteristically liberal forms of social solidarity that contract encourages-forms of solidarity that do without intimacy and so avoid the

231. The most prominent recent contribution to this literature is Albert $\mathrm{O}$. Hirschmann, Rival Interpretations of Market Society: Civilizing, Destructive, or Feeble?, 20 J. ECON. LIT. 1463 (1982).

232. The economic theory of contract is, after all, right as far as it goes: Contracts are often efficient mechanisms for generating beneficial reliance.

233. ARENDT, supra note 34, at 246. 
taint of the clan. I shall try, in effect, to trace the progress of sentiments that defuse egocentrism by analogy to the way in which Hume traced the progress of sentiments that defuse egoism. I shall claim that the practice of contract-through the collaborative ideals that it involves-plays an essential role in this progress. I shall therefore seek to reject the common view that, regardless of their efficiency or other instrumental attractions, contract and other market-based practices present an intrinsically debased form of human interaction, in which persons are motivated by the uglier forms of self-interest, including most notably fear and greed. ${ }^{234}$ This view underestimates, to my mind, the deeply and intrinsically communal character of contractual and market relations, and ignores these relations' contributions to addressing the threats to social solidarity that egoism and egocentrism pose. In an earlier article, I observed that market relations, whatever their other connections to self-interest, also provide the measure of what overcoming egoism requires. ${ }^{235}$ In the future, I shall argue that the market-in connection with the practice of contract-presents the vehicle through which egocentrism may be overcome as well.

234. A typical example of this view appears in G.A. Cohen, Back to Socialist Basics, I/207 NEW LEFT REV. 3, 9 (1994).

235. See Daniel Markovits, How Much Redistribution Should There Be?, 112 YALE L.J. 2291 (2003). In taking this approach, I followed Ronald Dworkin, What Is Equality? Part 2: Equality of Resources, 10 PHIL. \& PUB. AFF. 283 (1981). 


\title{
Book Review
}

\section{Corporate Anatomy Lessons}

\author{
David A. Skeel, Jr. ${ }^{\dagger}$
}

The Anatomy of Corporate Law: A Comparative and Functional Approach. By Reinier Kraakman" et al. New York: Oxford University Press, 2004. Pp. 260. \$85.00.

\section{INTRODUCTION}

Every ten years or so, a book is published that sets the terms of discussion in corporate law scholarship for the years that follow. In 1976, Melvin Eisenberg published The Structure of the Corporation, ${ }^{1}$ a work that redefined how scholars and policymakers thought about the role of the board of directors. Eisenberg's model of the "monitoring board"-a board that oversees the managers of a company instead of attempting to

$\dagger$ Professor of Law, University of Pennsylvania Law School. I am grateful to Henry Hansmann, Gérard Hertig, Hideki Kanda, Reinier Kraakman, Stephen Lubben, Katharina Pistor, and Harry Rajak for helpful comments; to Brian Nelson and the editors of The Yale Law Journal for numerous insightful suggestions for improving the Review; and to the University of Pennsylvania Law School for generous summer funding. This Review is dedicated to the memory of Michael Whincop, who was a great friend, a rising star, and an important contributor to the literature discussed in the Review.

* Ezra Ripley Thayer Professor of Law, Harvard Law School.

1. MElvin A. Eisenberg, The Structure of THE Corporation (1976). The first in a line of classic corporate law books, and still by far the most influential book ever written on American corporate law, was ADOLF A. BERLE, JR. \& GARDINER C. MEANS, THE MODERN CORPORATION AND PRIVATE PROPERTY (1932), which identified the growing separation between ownership and control in America's largest corporations. The most influential book in the intervening years was a collection of essays, THE CORPORATION IN MODERN SOCIETY (Edward S. Mason ed., 1959). 